Peter Oestmann

\title{
Gemeines Recht und Rechtseinheit
}

\section{Zum Umgang mit Rechtszersplitterung und Rechtsvielfalt in Mittelalter und Neuzeit}

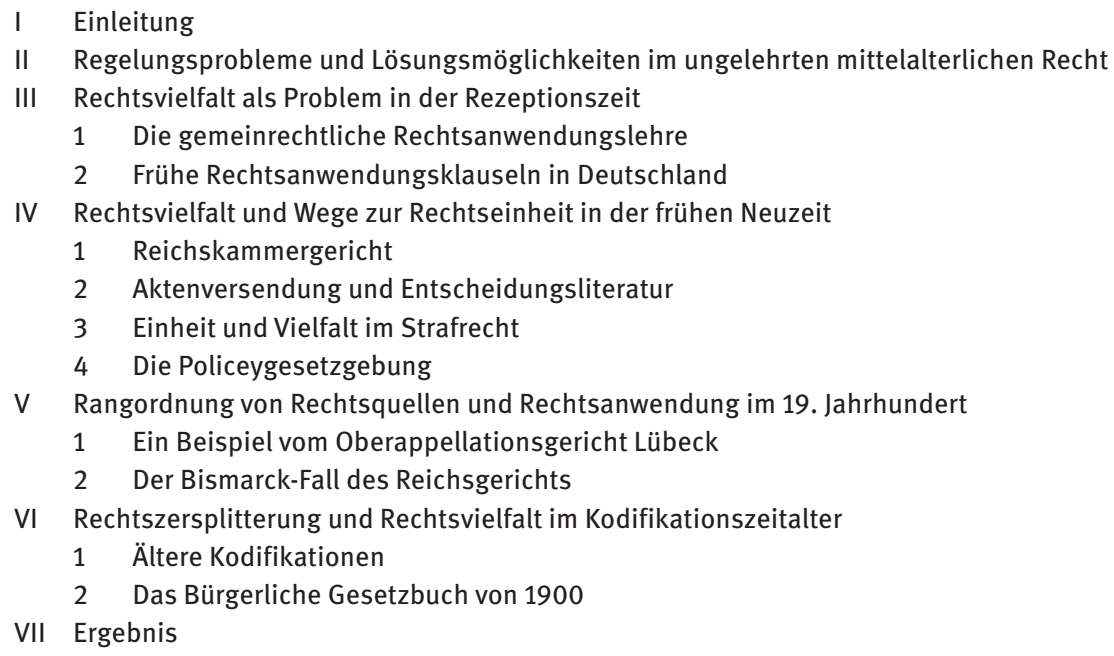

\section{Einleitung}

Auf einem Symposion, das sich mit Hierarchie, Kooperation und Integration im heutigen europäischen Rechtsraum beschäftigt, mag ein Blick in die Vergangenheit durchaus hilfreich sein. Zahlreiche Fragen, die sich im Zusammenhang mit der Rechtsangleichung zwischen verschiedenen Staaten, mit überstaatlicher Gerichtsvielfalt oder mit dem Transfer von der einen in die andere Rechtsordnung ergeben, sind gar nicht so modern, wie sie erscheinen mögen. Vor allem das Rangverhältnis zwischen Rechtsquellen ganz unterschiedlicher Herkunft war über lange Zeiten der europäischen Geschichte ein allzu vertrautes Problem. Selbst der Brückenschlag von der Rechtsgeschichte in die aktuelle europäische Vielschichtigkeit ist alles andere als neu. Helmut Coing betonte schon 1985, dass gerade der heutige Jurist seine Erfahrungen mit dem Nebeneinander von Staatsverfassungen, einfachen Gesetzen, Tarifverträgen und allgemeinen Geschäftsbedingungen sammle und dazu das europäische Recht und internationale Verträge berücksichtigen müsse. ${ }^{1}$ Das stimmt, und

1 Helmut Coing, Europäisches Privatrecht. Bd. 1: Älteres Gemeines Recht (1500 bis 1800), 1985, S. 40 . 
genau deswegen können sich europäische Juristen in der Gegenwart die vormoderne Buntheit erheblich anschaulicher vorstellen als ihre Vorgänger vor einigen Jahrzehnten, als man noch wie selbstverständlich von einzelstaatlicher Gesetzgebung und von der landeseigenen Kodifikation ausging. ${ }^{2}$

Wenn die Geschichte Reflexionswissen bereitstellen soll, kann es im Folgenden nur darum gehen, zu zeigen, wie verschiedene historische Epochen es geschafft haben, Rechtsvielfalt, überlappende Gerichtszuständigkeiten, schriftliche und mündliche Überlieferung, private und hoheitliche Normen in den Griff zu bekommen. In einem ganz wichtigen Punkt schert mein Beitrag aber zugleich aus dem Gesamtthema der Akademiekommission „Funktion des Gesetzes in Geschichte und Gegenwart“ aus. Sowohl das Regelungsproblem, nämlich die Rechtsvielfalt als solche, als auch die historischen Lösungsmöglichkeiten zur Herstellung von Einheit knüpfen nur bedingt an Gesetze an. Die Funktion des Gesetzes darf man historisch in diesem Zusammenhang nicht überschätzen. Gesetze mit Geltungsanspruch, modern gesprochen vielleicht sogar mit kontrafaktischem Geltungsanspruch, sind eine vergleichsweise späte geschichtliche Erscheinung. ${ }^{3}$ Der Schwerpunkt dieses Überblicksbeitrages wird auf denjenigen Epochen und Rechtsbereichen liegen, in denen die Gesetzgebung eine eher bescheidene Rolle spielte.

Zunächst ist ein Wort zur Terminologie angebracht. Wenn im Folgenden von Rechtsvielfalt die Rede ist, geht es hierbei immer um das gleichzeitige Vorhandensein verschiedener Rechte innerhalb desselben Gebietes. Ausdrücklich nicht gemeint ist also das geographische Nebeneinander einzelner Rechte bis hin zur völligen Rechtszersplitterung. Eine weithin bekannte deutsche Rechts- und Gerichtskarte von 1896 hielt etwa auf einer Landkarte, aber auch in einem äußerst detaillierten Register fest, welche verschiedenen partikularen Rechte in den einzelnen Gerichtssprengeln des deutschen Kaiserreiches gebräuchlich waren. ${ }^{4}$ Durch die Kodifikation des BGB verschwanden alle diese Stadt- und Landrechte. An ihre Stelle trat ein einheitliches Gesetzbuch. Soweit verschiedene Rechte aber lediglich räumlich nebeneinander galten, stellt dies kein ernsthaftes Problem von Rechtsvielfalt dar. Wenn in Preußen das Allgemeine Landrecht einschlägig war, im Rheinland der französische

2 Kurze Gegenüberstellung der frühneuzeitlichen Vormoderne mit dem 19. Jahrhundert bei PETER Oestmann, Rechtsvielfalt vor Gericht. Rechtsanwendung und Partikularrecht im Alten Reich (Rechtsprechung. Materialien und Studien 18), 2002, S. 682.

3 Zur Formalisierung und kontrafaktischen Stabilität NikLas Luhmann, Das Recht der Gesellschaft (Suhrkamp Taschenbuch Wissenschaft 1183), 1. Aufl. 1995, S. 133-134; zur Rezeption in der Geschichtswissenschaft BARBARA STOLlberg-RILINGER, Die Frühe Neuzeit - Eine Epoche der Formalisierung?, in: Andreas Höfele/Jan-Dirk Müller/Wulf Oesterreicher (Hrsg.), Die Frühe Neuzeit. Revisionen einer Epoche (Pluralisierung und Autorität 40), 2013, S. 3-27 (6).

4 Diethelm KlipPel (Hrsg.), Deutsche Rechts- und Gerichtskarte. Mit einem Orientierungsheft neu herausgegeben und mit einer Einleitung versehen, erweiterter Nachdruck 1996 der Ausgabe 1896; dazu Peter Oestmann, Rechtsvielfalt, in: Nils Jansen/Peter Oestmann (Hrsg.), Gewohnheit. Gebot. Gesetz. Normativität in Geschichte und Gegenwart: eine Einführung, 2011, S. 99-123 (100-101). 
Code Civil, in Bayern der Codex Maximilianeus, dann gab es zwar unterschiedliche Rechte. Aber innerhalb eines fest umrissenen Gebietes stand jederzeit fest, welche Normen anwendbar waren, wenn es um die Lösung rechtlicher Streitigkeiten ging. Viel komplizierter als solche Rechtszersplitterung stellt sich demgegenüber die Situation dar, wenn innerhalb desselben Gebietes mehrere verschiedene Rechte praktische Bedeutung hatten. Bei solchen Überlagerungen stellt sich die Frage, welche Quellen vorrangig vor anderen zu berücksichtigen sind. Wie verschiedene Zeiten derartige Überlappungen bewältigt haben, steht im Mittelpunkt dieses Aufsatzes.

Die Unterscheidung von Rechtsvielfalt und Rechtszersplitterung ist hierbei bewusst überzeichnet. Die räumliche Erstreckung vieler Rechte ist historisch nämlich alles andere als klar, und auch die jeweiligen Gerichtssprengel waren nicht geographisch fest beschrieben. Die gelehrte Statutentheorie, die seit dem Mittelalter die Rechtsvielfalt in den Griff zu bekommen versuchte, schuf zugleich Regeln, die wir heute dem internationalen Privatrecht bzw. dem Kollisionsrecht zuordnen würden. ${ }^{5}$ Die Problemkreise gingen also ineinander über, waren aber nicht deckungsgleich.

\section{Regelungsprobleme und Lösungsmöglichkeiten im ungelehrten mittelalterlichen Recht}

Das ungelehrte Recht löste Fragen der Rechtsvielfalt zumeist durch den Rückgriff auf die persönliche Zugehörigkeit $\mathrm{zu}$ einer bestimmten rechtsgewohnheitlichen Ordnung. Diese Tradition weist weit zurück und ist seit den Rechtsaufzeichnungen germanischer Stämme im Frühmittelalter vielfach belegt. Die jeweiligen Rechtsgewohnheiten bezogen sich vor allem auf den eigenen Stamm. Manchmal hatten auch einzelne Teilstämme ihre eigenen Rechtsgewohnheiten. ${ }^{6}$ Diese Gewohnheiten sind in den lateinischen Stammesrechten, den Leges Barbarorum, überliefert. Mit Gesetzen hat man es hierbei nicht zu tun. ${ }^{7}$ Auch ist weithin unklar, ob und inwieweit die

5 GÜNTER HERRMANN, Johann Nikolaus Hert und die deutsche Statutenlehre (Neue Kölner rechtswissenschaftliche Abhandlungen 25), 1963, S. 159-162 (mit der Zusammenfassung zum wichtigsten kollisionsrechtlichen Werk); GÜNTER MERzyn, Der Beitrag Benedikt Carpzovs zur Entwicklung des Kollisionsrechts (Göttinger rechtswissenschaftliche Studien 49), 1963.

6 Zum Konzept der Rechtsgewohnheiten Gerhard Dilcher/HeINER LÜCK/REINER SCHUlze/ELMar WAdLE/JÜRgEn WeITZEL/Udo WolteR, Gewohnheitsrecht und Rechtsgewohnheiten im Mittelalter (Schriften zur Europäischen Rechts- und Verfassungsgeschichte 6), 1992; MARTIN PILCH, Der Rahmen der Rechtsgewohnheiten. Kritik des Normensystemdenkens entwickelt am Rechtsbegriff der mittelalterlichen Rechtsgeschichte, 2009; GERD ALthofF, Rechtsgewohnheiten und Spielregeln der Politik im Mittelalter, in: Nils Jansen/Peter Oestmann (Hrsg.), Gewohnheit. Gebot. Gesetz. Normativität in Geschichte und Gegenwart: eine Einführung, 2011, S. 27-52.

7 Die ältere Typologie (Gesetz und Gesetzbuch im Spannungsfeld von Weistum und Rechtsbesserung) noch bei WiLHELM EBEL, Geschichte der Gesetzgebung in Deutschland (Göttinger rechtswissenschaftliche Studien 24), 1988 (von Friedrich EBEL erweiterter Nachdruck der 2. Aufl. 1958), S. 30-36. 
schriftlichen Quellen in der Rechtspraxis Bedeutung erlangt haben. ${ }^{8}$ Das Selbstverständnis der Aufzeichnungen ist in einem wichtigen Punkt aber eindeutig. Das Stammesrecht betraf jeweils die Stammesangehörigen. Die fränkische Lex Ribuaria war das Recht der ribuarischen Franken, die Lex Salica das Recht der salischen Franken. Mit dem Herrschaftsgebiet eines Königs oder irgendwelchen geographischen Grenzen oder Gerichtssprengeln hat das wenig zu tun. Etwas anders stellte sich die Lage im friesischen Recht dar. Dort bildete der Fluss Laubach (Lauwers) eine klare Grenze zwischen verschiedenen friesischen Teilrechten. Allerdings handelt es sich eher um eine scheinbare Ausnahme. Denn diesseits und jenseits der Laubach lebten verschiedene Teile des friesischen Stammes, die möglicherweise zu unterschiedlichen Zeiten in das Karolingerreich integriert wurden. ${ }^{9}$ Modern gesprochen folgte das frühmittelalterliche Recht also dem Personalitätsprinzip. ${ }^{10}$ Damit war zugleich eine wesentliche Vorentscheidung getroffen: Die romanische Bevölkerung in West- und Mitteleuropa lebte nicht nach den germanischen Stammesrechten, sondern nach ihren eigenen Gewohnheiten, nämlich nach römischem Recht. ${ }^{11}$ Die Überlieferung ist hier eindeutig. In mehreren germanischen Reichen gab es verschiedene Rechtsaufzeichnungen für die germanische und die romanische Bevölkerung. Neben einer Lex Visigothorum stand die Lex Romana Visigothorum. ${ }^{12}$ Wenn also klar war, wer zu welcher Bevölkerungsgruppe gehörte, ergaben sich aus dem Personalitätsprinzip nur wenige Probleme. Daneben gab es nach der Christianisierung in allen germanischen Reichen kirchliche Strukturen, die dem sich bildenden Kirchenrecht unterstanden. Die weltlichen Rechtsgewohnheiten und das kirchliche Recht bezogen sich aber zunächst wohl

8 Hermann Nehlsen, Aktualität und Effektivität germanischer Rechtsaufzeichnungen, in: Peter Classen (Hrsg.), Recht und Schrift im Mittelalter (Vorträge und Forschungen 23), 1977, S. 449-502 (im Inhaltsverzeichnis leicht abweichender Aufsatztitel angegeben).

9 HaRAld Siems, Studien zur Lex Frisionum (Münchener Universitätsschriften. Juristische Fakultät. Abhandlungen zur rechtswissenschaftlichen Grundlagenforschung 42), 1980, S. 9, 173-207; DERS., Art. Lex Frisionum, in: Adalbert Erler/Ekkehard Kaufmann (Hrsg.), Handwörterbuch zur deutschen Rechtsgeschichte (= HRG), Bd. 2, 1. Aufl. 1978, Sp. 1916-1922 (1918); GERHARD KöBLER, Art. Friesisches Recht, in: Albrecht Cordes/Heiner Lück/Dieter Werkmüller (Hrsg.), HRG, Bd. 1, 2. Aufl. 2008, Sp. 18501854 (1851-1852); NikolaAs EgBERT ALGRA, Grundzüge des friesischen Rechts im Mittelalter, in: Horst Haider Munske u.a. (Hrsg.), Handbuch des Friesischen/Handbook of Frisian Studies, 2001, S. 555-570 (555-556).

10 Karol ModzelewsKi, Das barbarische Europa. Zur sozialen Ordnung von Germanen und Slawen im frühen Mittelalter (Klio in Polen 13), 2011, S. 82-86; klassisch HEINRICH BRUNNER, Deutsche Rechtsgeschichte, Bd. 1, 2. Aufl. 1906, S. 382-399.

11 ModZELEWSKi (Anm. 10), S. 86.

12 HeRmann NeHLSEn, Art. Lex Romana Burgundionum, in: Adalbert Erler/Ekkehard Kaufmann (Hrsg.), HRG, Bd. 2, 1. Aufl. 1978, Sp. 1927-1934; HARALd SiEms, Art. Lex Romana Visigothorum, ebd., Sp. 1940-1949; DetLEF LiebS, Art. Lex Romana Visigothorum, in: Johannes Hoops (Begr.), Reallexikon der Germanischen Altertumskunde, Bd. 18, 2. Aufl. 2001, S. 323-326; Edition von Gustav HÄNEL, Lex Romana Visigothorum [...]. Editio post Sichardum prima, 1849 (Nachdruck 1962). 
auf verschiedene Regelungsgegenstände und bestanden auf diese Weise nebeneinander, ohne dass Probleme der Rechtsvielfalt daraus erwuchsen. ${ }^{13}$

Mögliche Konflikte scheint die Praxis sehr pragmatisch gelöst zu haben. Berühmt ist der Bericht des Bischofs GrEgor VON Tours über die Fehde des SICHAR. ${ }^{14}$ In dieser Episode aus dem 6. Jahrhundert ist ein Mörder aufgrund einer Gerichtsverhandlung verpflichtet, ein Wergeld für die Tötung seiner Feinde zu bezahlen. Der Gegner nimmt die Buße aber nicht an und setzt die Gewalttaten seinerseits fort. Daraufhin kommt es zu einer zweiten Verhandlung. Die eigentlich fällige Buße wird auf die Hälfte reduziert, weil der ursprünglich Geschädigte sich geweigert hat, sie anzunehmen. Damit es zur Ausgleichszahlung kommt, stellt die Kirche dem Mörder das Geld als Darlehen zur Verfügung, ein im Frühmittelalter mehrfach belegter Ausweg. ${ }^{15}$ GREGoR VON Tours fügt an seine Erzählung den Kommentar an, dies sei eigentlich gegen die „Gesetze“ gewesen (,et hoc contra legis actum“) und nur geschehen, um Frieden zu stiften. ${ }^{16}$ Die Bindungswirkung des Stammesrechts war schwach, die Überlagerung durch andere, vor allem kirchliche Vorstellungen von Frieden stellte kein ernsthaftes Hindernis dar.

Viel problematischer scheint in diesen frühmittelalterlichen Reichen der Rechtsstatus stammesfremder germanischer Bevölkerung gewesen zu sein. Diese Personen unterstanden jedenfalls nicht dem Stammesrecht der ansässigen Bevölkerung, sondern folgten dem Recht ihres eigenen Stammes, auch wenn sie außerhalb des hauptsächlichen Siedlungsgebietes lebten. Die ältere rechtshistorische Literatur hat vermutet, Stammesfremde seien nach ursprünglicher Rechtsauffassung völlig rechtund schutzlos gewesen. ${ }^{17}$ Das Problem der Rechtsvielfalt hätte man auf diese Weise sehr einfach gelöst, indem man das Recht der Stammesfremden schlichtweg nicht beachtete. Doch diese radikale Sichtweise geben die Quellen nicht her. In den zuhauf erhaltenen Bußenkatalogen besitzen vielmehr auch Stammesfremde durchaus ein eigenes Wergeld. Dieses Wergeld fällt zwar regelmäßig niedriger aus als dasjenige

13 Beispiel Bischofswahl: ANDREAS THIER, Hierarchie und Autonomie. Regelungstraditionen der Bischofsbestellung in der Geschichte des kirchlichen Wahlrechts bis 1140 (Recht im ersten Jahrtausend 1), 2011; Herausbildung eines kanonischen Prozessrechts: Mathias SchmoEcKeL, Die Jugend der Justitia. Archäologie der Gerechtigkeit im Prozessrecht der Patristik, 2013.

14 GrEgor von Tours, Zehn Bücher Geschichten, übersetzt und bearbeitet von WiLHELm GieSEBRECHT und Rudolf BuchneR, Bd. 2, 8. Aufl. 1990, Buch VII Kap. 47, Buch IX Kap. 19, S. 152-157, 256-259; umfassend zur Sichar-Fehde, wenn auch stark wirkungsgeschichtlich, CARSTEN BERNOTH, Die Fehde des Sichar. Die Geschichte einer Erzählung in der deutschsprachigen und frankophonen rechtshistorischen und historischen Literatur unter besonderer Berücksichtigung der Auseinandersetzungen des 19. Jahrhunderts (Rheinische Schriften zur Rechtsgeschichte 10), 2008.

15 Weiteres Beispiel bei Karl Kroeschell, Deutsche Rechtsgeschichte. Bd. 1: Bis 1250, 13. Aufl. 2008, S. 102 (Urkunde aus St. Gallen um 813).

16 Gregor von Tours (Anm. 14), S. 156 Zeile 13-14, S. 157 Zeile 16-17.

17 BrunNer (Anm. 10), S. 399-405; RichARd SCHRÖDER/EbeRHARD FrH. v. KÜNSSBERG, Lehrbuch der deutschen Rechtsgeschichte, 7. Aufl. 1932, S. 56, einschränkend für die fränkische Zeit ebd., S. 244 für Reichsfremde (angeblich unter Königsschutz). 
der stammeseigenen Bevölkerung. ${ }^{18}$ Doch passt diese Differenzierung ins Bild einer Gesellschaft, die den Rechtsstatus ohnehin nach dem Grad der persönlichen Freiheit, nach Alter und Geschlecht mehrfach abstufte. Schwierigkeiten im Umgang mit Rechtsvielfalt zeigen sich an solchen Vorstellungen nicht.

Ausdrücklich belegt sind Diskussionen über verschiedene Rechte dagegen aus dem Reich der Westgoten in Spanien. Die etwa um 654 entstandene Lex Visigothorum enthält folgende Regelung:

II 1. 11. Ne excepto talem librum, qualis hic, qui nuper est editus, alterum quisque presumat habere.

Nullus prorsus ex omnibus regni nostri preter hunc librum, qui nuper est editus, adque secundum seriem huius amodo translatum, librum legum pro quocumque negotium iudici offerre pertemtet. Quod si presumserit, XXX libros auri fisco persolvat. Iudex quoque, si vetitum librum sibi postea oblatum disrumpere fortasse distulerit, predicte damnationis dispendio subiacebit. Absolut niemand von allen in unserem Reich soll außer diesem Gesetzbuch, das neulich ausgegeben wurde, und genau so wie sein Inhalt übertragen wurde, irgendein Gesetzbuch in irgendeiner Sache dem Richter anzubieten versuchen. Wer sich dies anmaßt, zahle dreißig Goldstücke an den Fiskus. Der Richter aber, wenn er ein solches verbotenes Buch, das ihm zum Zerreißen angeboten wurde, womöglich beiseite schafft, soll der vorbezeichneten Strafe verfallen sein. ${ }^{19}$

Die Lex Visigothorum stammt aus einem germanischen Reich mit einer vergleichsweise straffen Herrschaft und einem recht hohen Grad an Schriftlichkeit. Das Stammesrecht befiehlt den Richtern, bei ihren Entscheidungen die schriftliche Rechtsaufzeichnung zu beachten und streng dem Inhalt des Stammesrechts $\mathrm{zu}$ folgen. Anscheinend kursierten im Westgotenreich aber verschiedene Rechtsaufzeichnungen, die sich deutlich voneinander unterschieden. Aber lediglich auf den ersten Blick ist damit das Problem von Rechtsvielfalt berührt. Offenbar gab es nämlich nicht mehrere konkurrierende Rechte oder unterschiedliche Rechtsmassen, die sich gegenseitig überlagerten und verdrängten. Vielmehr dürften die vom Stammesrecht bekämpften Aufzeichnungen aus undurchsichtigen und unlauteren Quellen gestammt haben. ${ }^{20}$

18 Überblick bei WolfGang Schild, Art. Wergeld, in: Adalbert Erler/Ekkehard Kaufmann/Dieter Werkmüller (Hrsg.), HRG, Bd. 5, 1998, Sp. 1268-1271 (1269-1270).

19 Lex Visigothorum 2, 1, 11, bei Karl ZeUmer (Hrsg.), Leges Visigothorum (Monumenta Germaniae Historica. Leges Nationum Germanicarum 1) 1902, S. 58-59. Die Übersetzung lehnt sich an einen Vorschlag von JoACHIM RÜCKERT an. EUGEN WOHLHAUPTER, Gesetze der Westgoten (Germanenrechte. Texte und Übersetzungen 11), 1936, S. 36-37, bietet unter 2, 1, 11 eine andere Vorschrift, die bei Zeumer unter 2, 1, 13 verzeichnet ist; aktuellste Literaturübersicht wohl bei ANDREAS KimmELMANN, Die Folter im Beweisverfahren der Leges Visigothorum: Chindasvinths Gesetzgebung im Spiegel der westgotischen Rechtsentwicklung (Rechtshistorische Reihe 409), 2010; CARLOS PETIT, Art. Leges Visigothorum, in: Albrecht Cordes/Hans-Peter Haferkamp/Heiner Lück/Dieter Werkmüller (Hrsg.), HRG, 2. Aufl., 19. Lieferung 2014, Sp. 697-704, und in der Bibliotheca Legum: http://www.leges.uni-koeln. de/lex/leges-visigothorum/ (besucht am 07.04.2014).

20 Hermann Nehlsen, Der Schutz von Rechtsaufzeichnungen gegen Fälscher in den Germanenreichen, in: Fälschungen im Mittelalter. Internationaler Kongreß der Monumenta Germaniae Historica 
Entweder kursierten Handschriften des Stammesrechts mit gravierenden Schreibfehlern, oder aber bestimmte Personen hatten auf eigene Faust den Text des Stammesrechts verändert, um sich gegenüber einem Richter damit Rechtsvorteile zu sichern. Die Vielfalt voneinander abweichender Rechtsaufzeichnungen kennzeichnete damit keineswegs die Vielfalt von Rechten, sondern lediglich die geringe Zuverlässigkeit der nicht autorisierten schriftlichen Überlieferung. Wenn die Richter solche abweichenden Rechtshandschriften bei Androhung von Bußen zerreißen sollten, ging es also nicht darum, Vielfalt zu beseitigen und Rechtseinheit durchzusetzen. Vielmehr sollte lediglich die von Anfang an gewollte Eindeutigkeit des Stammesrechts gewahrt und nicht verdunkelt werden.

Möglicherweise wurde das Personalitätsprinzip zunächst in mittelalterlichen Städten überwunden. ${ }^{21}$ Die Städte besaßen ihren vergleichsweise klar abgegrenzten Rechtsraum, der durch königliche oder stadtherrliche Privilegien umschrieben war und danach durch selbstgesetztes Recht näher ausgestaltet wurde. Unabhängig davon, ob jemand das Bürgerrecht besaß oder lediglich sog. Einwohner war, erfasste das Stadtrecht jeden, der dauerhaft in der Stadt lebte. ${ }^{22}$ Die Rechtsgewohnheiten der umliegenden Gegend spielten innerhalb der Stadtgrenzen kaum eine Rolle. Deutlich erkennbar ist das etwa an der Stadt Lübeck. Mit der Stadtgründung erhielt Lübeck im späten 12. Jahrhundert das Recht der westfälischen Stadt Soest. ${ }^{23}$ Im umliegenden Holstein lebte die Bevölkerung dagegen nach sächsischen Rechtsgewohnheiten

München, 16.-19. September 1986. Teil II: Gefälschte Rechtstexte. Der bestrafte Fälscher (Monumenta Germaniae Historica. Schriften 33/II), 1988, S. 545-576 (S. 556 zur Quellenstelle und allgemein S. 546-547, 555-563 zum westgotischen Recht); ebenfalls zur Quellenstelle VICTOR CRESCENZI, Per una semantica del lavoro giuridicamente rilevante in Isidoro da Siviglia, nella Lex Romana Visigothorum, nell'Edictum Theoderici, e nella Lex Visigothorum, in: Ravenna capitale. Uno sguardo ad occidente. Romani e Goti, Isidoro di Siviglia, 2012, S. 217-275 (230-231).

21 Typologisch sehr klar MAX WEBER, Wirtschaft und Gesellschaft. Grundriß der verstehenden Soziologie, 5. Aufl. (von Johannes WincKelmanN) 1980, S. 752; GerHARD Dilcher, Die Entstehung der lombardischen Stadtkommune. Eine rechtsgeschichtliche Untersuchung (Untersuchungen zur deutschen Staats- und Rechtsgeschichte N.F. 7), 1967, S. 158-160: „örtlich bestimmter Rechtsbereich“.

22 EBERHARD IsENMANn, Die deutsche Stadt im Mittelalter 1150-1550. Stadtgestalt, Recht, Verfassung, Stadtregiment, Kirche, Gesellschaft, Wirtschaft, 2012, S. 171; KARL S. BADER/GERHARd Dilcher, Deutsche Rechtsgeschichte. Land und Stadt - Bürger und Bauer im Alten Europa, 1999, S. 456-458; Zweifel am einheitlichen Rechtsraum bei VALENTIN Groebner, Zu einigen Parametern der Sichtbarmachung städtischer Ordnungen im späteren Mittelalter, in: Pierre Monnet/Otto Gerhard Oexle (Hrsg.), Stadt und Recht im Mittelalter/La ville et le droit au Moyen Âge (Veröffentlichungen des Max-Planck-Instituts für Geschichte 174), 2003, S. 133-151 (134-135); zum Personalitätsprinzip im Landrecht DiETMAR WiLloweit, Zur Frage des Personalitätsprinzips im Sachsenspiegel und in schlesischen Lokationsurkunden des 13. Jahrhunderts, in: Dietmar Willoweit/Winfried Schich (Hrsg.), Studien zur Geschichte des sächsisch-magdeburgischen Rechts in Deutschland und Polen (Rechtshistorische Reihe 10), 1980, S. 94-115; zur Diskussion im gelehrten Recht HERRMANN (Anm. 5), S. 3-6.

23 Wilhelm EBEL, Lübisches Recht. Bd. 1: Entfaltung und Blüte, 1971, S. 128-135, ERICH HoffmanN, Lübeck im Hoch- und Spätmittelalter: Die große Zeit Lübecks, in: Antjekathrin Graßmann (Hrsg.), Lübeckische Geschichte, 4. Aufl. 2008, S. 81-339 (242). 
bzw. nach dem Holstenrecht. Mit eigenen Willküren entwickelte der Rat der Stadt das jeweilige Stadtrecht weiter. ${ }^{24}$ Die Stadt war damit ein eigener Rechtsraum, der sich deutlich vom Umland unterschied. Die Bevölkerung musste in zahlreichen Städten sogar einmal jährlich einen Eid auf das Stadtrecht ablegen. An diesen sog. Schwörtagen oder Burspraken stellte man damit für jedermann sichtbar klar, dass alle Einwohner nach demselben Recht lebten. ${ }^{25}$ Rechtsvielfalt als Problem entstand dann ebenfalls nicht, weil ein erster Schritt auf dem Weg zum Territorialitätsprinzip der Rechtsgeltung erfolgt war.

Lediglich für Fremde, die sich nur zeitweise in der Stadt aufhielten, gab es Ausnahmen. Für sie bestanden vielerorts eigene Gastgerichte, wenn es sich um Messestädte handelte auch Messegerichte. Doch wie diese Gerichte arbeiteten und wie man die Fremden dort behandeln sollte, legte die Stadt selbst fest. ${ }^{26}$ Widersprüche oder Anwendungsschwierigkeiten zwischen dem Stadtrecht für die eigene Bevölkerung und dem Fremdenrecht konnte es auf diese Weise nie geben.

Auch mit einem weiteren Problem ging das ungelehrte mittelalterliche Recht sehr pragmatisch um. Die Vielfalt verschiedener Rechtsgewohnheiten oder lokaler Rechte konnte sich leicht als Schwierigkeit herausstellen, wenn streitige Rechtsfälle an einen überregional angesehenen Oberhof oder Schöffenstuhl gelangten. Hierbei handelt es sich um eine typische Erscheinung der spätmittelalterlichen Gerichtsverfassung. Wenn in einer gerichtlichen Streitigkeit die Schöffen vor Ort nicht in der Lage waren, das Recht zu finden bzw. zu erkennen, wandten sie sich regelmäßig hilfesuchend an einen Oberhof. Solche Anfragen waren keine Rechtsmittel im modernen Sinne, denn es gab noch gar keine untergerichtliche Entscheidung, gegen die eine Seite hätte vorgehen können. Vielmehr erhofften sich Richter und Urteiler des Ausgangsgerichts besseres Recht vom Oberhof. ${ }^{27}$ Nach einem schönen Spruch MAX WEBERs hat man es

24 BAder/Dilcher (Anm. 22), S. 613-617; klassisch Wilhelm Ebel, Die Willkür. Eine Studie zu den Denkformen des älteren deutschen Rechts (Göttinger rechtswissenschaftliche Studien 6), 1953, S. 4667.

25 Ebel (Anm. 23), S. 307-317; THEOdor BüHLER, Rechtsschöpfung und Rechtswahrung an der Schnittstelle zwischen Mündlichkeit und Schriftlichkeit aufgrund von mittelalterlichen Rechtsquellen insbesondere aus Mitteleuropa (Europäische Rechts- und Regionalgeschichte 18), 2012, S. 39, 152-156.

26 BAder/Dilcher (Anm. 22), S. 461-464; Isenmann (Anm. 22), S. 158-159; Claudia Seiring, Fremde in der Stadt (1300-1800). Die Rechtsstellung Auswärtiger in mittelalterlichen und neuzeitlichen Quellen der deutschsprachigen Schweiz, 1999 (= Diss. jur. Fribourg 1998), S. 66-75; nur knappe Hinweise bei Anne Dünzelmann, Vom Gaste, den Joden und den Fremden. Zur Ethnographie von Immigration, Rezeption und Exkludierung Fremder am Beispiel der Stadt Bremen vom Mittelalter bis 1848 (Geschichte 37), 2001, S. 84 (Gastrecht), 122-124 (Schutzbürgerschaft); kein Hinweis auf Gastgerichte bei Frank MeYer, Gefürchtet und bestaunt. Vom Umgang mit Fremden im Mittelalter, 2007, S. 143-157 (dort nur allgemein zu Fremdheit in Städten).

27 Guter allgemeiner Überblick bei JüRGEN WEITZEL, Über Oberhöfe, Recht und Rechtszug. Eine Skizze (Göttinger Studien zur Rechtsgeschichte 15), 1981; Dieter WERKMÜLLER, Art. Oberhof, in: Adalbert Erler/Ekkehard Kaufmann (Hrsg.), HRG, Bd. 3, 1984, Sp. 1134-1146. 
hier mit Rechtshonoratioren ${ }^{28} \mathrm{zu}$ tun, die aufgrund ihrer langjährigen Erfahrung das notwendige Ansehen besaßen und deren Entscheidung genau deshalb von den Beteiligten des Ausgangsgerichts akzeptiert wurde. Die Oberhofsprengel erstreckten sich teilweise über große Entfernungen. Der Ingelheimer Oberhof in der Nähe von Bingen am Rhein urteilte über die Anfragen aus etwa 70 anderen Orten. ${ }^{29}$ Der Lübecker Oberhof entschied Fälle aus dem Bereich des lübischen Rechts bis hin nach Reval im heutigen Estland. ${ }^{30}$ Und der Magdeburger Schöffenstuhl galt als Autorität im Bereich des sächsisch-magdeburgischen Stadtrechts bis weit nach Osteuropa hinein. ${ }^{31}$

Daraus konnten leicht Schwierigkeiten mit Rechtspluralismus entstehen. Denn das Ortsrecht des anfragenden Gerichts konnte sich durchaus vom Recht des Oberhofs unterscheiden. Möglicherweise bestanden dort besondere örtliche Gewohnheiten für einzelne Fragen. Und genau jetzt ergaben sich Probleme. Das Ansehen der Oberhofschöffen als rechtspraktisch erfahrene Urteiler beruhte auf ihrem gesammelten Wissen, nicht auf einer universitären Ausbildung. Und ihr Erfahrungswissen fußte selbstverständlich nur auf denjenigen Rechtsgewohnheiten, nach denen sie selbst lebten und an denen sie regelmäßig ihre Entscheidungen ausrichteten. Die Autorität der Schöffen setzte es nahezu zwingend voraus, dass sie Auskunft erteilten über ihr eigenes Recht und nicht über fremde Rechte. Deswegen urteilten die meisten Oberhöfe und Schöffenstühle auf der Grundlage ihres eigenen ius fori und beachteten abweichende Gewohnheiten nicht. Falls die anfragenden Gerichte auf ihre Ortsbräuche verwiesen, lehnten es die Oberhofschöffen ab, diese Grundlagen auch nur zu prüfen. Die einschlägigen Wendungen der Magdeburger Schöffen hat JÜRGEN WEITZEL zusammengestellt:

noch der stat Breslaw gewonheyt und wilkor sprechen wir keyn recht nicht; aber was ihr in der gewonheit habt [...], darüber gebührt uns nicht ein recht zu sprechen; uff ewer stat gnode, wilkor und gewonheyt behort uns nicht zu erkennen; uff soliche gewonheyt uns in recht nicht

28 WeBER (Anm. 21), S. 456-467, besonders 461-462.

29 ADALBERT ERLER (Hrsg.), Die älteren Urteile des Ingelheimer Oberhofes, Bd. 4, 1963, S. 55-56 (Auflistung und Landkarte).

30 TовіAs KäMPF, Das Revaler Ratsurteilsbuch. Grundsätze und Regeln des Prozessverfahrens in der frühneuzeitlichen Hansestadt (Quellen und Darstellungen zur hansischen Geschichte N.F. 66), 2013, S. 212-230.

31 Dazu die Schriftenreihe Ius saxonico-maideburgense in Oriente. Das sächsisch-magdeburgische Recht als kulturelles Bindeglied zwischen den Rechtsordnungen Ost- und Mitteleuropas: Bd. 1: ERNST EICHLER/HEINER LÜCK (Hrsg.), Rechts- und Sprachtransfer in Mittel- und Osteuropa. Sachsenspiegel und Magdeburger Recht, 2012; Bd. 2: Inge Bily/Wieland CARLs/Katalin GönCZI, Sächsisch-magdeburgisches Recht in Polen. Untersuchungen zur Geschichte des Rechts und seiner Sprache, 2011; außerdem Heiner LÜck/Matthias Puhle/AndReas Ranft (Hrsg.), Grundlagen für ein neues Europa. Das Magdeburger und Lübecker Recht in Spätmittelalter und Früher Neuzeit (Quellen und Forschungen zur Geschichte Sachsen-Anhalts 6), 2009. 
geboret zcu erkennen; uns gehoret nicht, uff der stete, der lande und furstenthumer gewonheit in rechten nicht zu erkenne, sunder uff die sache sprechen wir vor recht. ${ }^{32}$

Wenn es innerhalb des Oberhofsprengels verschiedene Ortsgewohnheiten gab, nahmen die Magdeburger Schöffen solche Besonderheiten also ausdrücklich gar nicht zur Kenntnis. ${ }^{33}$ Sie wussten um die rechtlichen Unterschiede, beachteten sie aber nicht. Für die hier verfolgte Fragestellung nach dem Verhältnis von Rechtsvielfalt und Rechtseinheit ergibt sich daraus ein wichtiger Befund: Die Oberhöfe betrieben der Sache nach Rechtsvereinheitlichung innerhalb ihres Jurisdiktionsgebietes, indem sie auch für Anfragen aus entfernten Gegenden immer ihr eigenes Recht zugrundelegten. Gerade dann also, wenn es zu Streitigkeiten um abweichende Gewohnheiten und rechtliche Gebräuche kam, standen die Chancen schlecht, dass ein Oberhof sie berücksichtigte. Die Oberhofschöffen kannten diese Rechtsgewohnheiten nicht, und eine gelehrte Doktrin, wie man vor Gericht mit fremdem Recht umgehen sollte, war nicht vorhanden.

Es verwundert nicht, dass sich diese konsequente Haltung erst im späten 15. Jahrhundert zu ändern begann. Vom Lübecker Oberhof sind seit 1486 Entscheidungen bekannt, in denen die Ratsherren auch fremde Gewohnheiten ihren Sprüchen zugrunde legten. Zunächst betonten sie jedoch immer, dass die vorgetragenen fremden Rechte auch „na wonheit unde der stadt Lubecke rechte“ bestehen könnten. ${ }^{34}$ Aus der Perspektive des ungelehrten mittelalterlichen Rechts stellt die Berücksichtigung örtlicher Gewohnheiten also eine besonders späte Erscheinung dar. Höchstwahrscheinlich zeigen sich hier bereits Anlehnungen an die Grundsätze des gelehrten römisch-kanonischen Rechts. ${ }^{35}$ Als Zwischenergebnis bleibt festzuhalten: Die bewusste Anerkennung von Rechtsvielfalt innerhalb desselben Gebietes und die daraus folgenden Hierarchie- und Anwendungsprobleme waren im ungelehrten einheimischen Recht im Mittelalter kaum vorhanden. Rechtseinheit folgte innerhalb der Oberhofkreise aus dem ius fori des Oberhofs selbst.

32 JÜRGEN WeITZEL, Gewohnheiten im lübischen und im sächsisch-magdeburgischen Rechtskreis, in: La Coutume - Custom. Bd. 2: Europe occidentale médiévale et moderne (Recueils de la Société Jean Bodin 52), 1990, S. 325-358 (338).

$33 \mathrm{Zu}$ diesem Problemkreis außerdem GeRHARD BuchDA, „Gewohnheiten“ in der Pößnecker Schöffenspruchsammlung, ZRG GA 78 (1961), S. 64-92; FRIEDRICH EBEL, Statutum und ius fori im deutschen Spätmittelalter, ZRG GA 93 (1976), S. 100-153.

34 Weitzel (Anm. 32), S. 335; speziell zu Lübeck auch Albrecht CoRdes, Acceptance and Rejection of 'Foreign' Legal Doctrine by the Council of Lubeck Around 1500, in: Serge Dauchy/W. Hamilton Bryson/Matthew C. Mirow (Hrsg.), Ratio decidendi. Guiding Principles of Judicial Decisions. Volume 2: 'Foreign' Law (Comparative Studies in Continental and Anglo-American Legal History 25/2), 2010, S. $17-35$.

35 Im Ergebnis ähnlich EBEL (Anm. 33), ZRG GA 93 (1976), S. 143-148, mit dem Hinweis, in der frühesten Zeit sei die Berücksichtigung fremder Statuten wohl noch nicht auf den Einfluss der gelehrten Doktrin zurückzuführen. Die immer stärkere Anlehnung an die rechtsgelehrten Modelle erfolgte aber schon im 15. Jahrhundert. 


\section{Rechtsvielfalt als Problem in der Rezeptionszeit}

Unter dem Einfluss des römisch-kanonischen Rechts vollzog sich ein entscheidender Wandel bei der Beurteilung von Rechtsvielfalt und Rechtseinheit. ${ }^{36}$ Ihrem Anspruch nach waren die beiden großen Corpora, also das Corpus Iuris Civilis und das Corpus Iuris Canonici, Autoritäten, die keine räumlichen Begrenzungen kannten. Sowohl die Inhalte des gelehrten Rechts als auch die damit verbundene Arbeitsweise von Juristen hatten etwas Universales. Ein förmlicher Geltungsanspruch war damit nicht verbunden. ${ }^{37}$ Aber die inhaltliche Kraft der ratio scripta war so groß, dass die gelehrten Juristen in ihrer Arbeit auf diese Quellen zurückgriffen. Vor allem seit dem 12. Jahrhundert gerieten das römische und das kanonische Recht in den Blick von Studenten, die später in ihrer politischen, diplomatischen oder rechtspraktischen Tätigkeit auf dieses Wissen zurückgreifen konnten. ${ }^{38}$ Neben diesem universalen römisch-kanonischen Recht gab es aber sehr früh in den italienischen Städten schon schriftliche Aufzeichnungen eigener Stadtrechte, zumeist Statuten genannt. ${ }^{39}$ Wenn jetzt ein universitär ausgebildeter Jurist als Richter in eine italienische Stadt berufen wurde, stellte sich die Frage, nach welchem Recht er auftretende Streitigkeiten entscheiden sollte, nach dem Statutarrecht der jeweiligen Stadt oder nach den Lehren, die er an der Universität kennengelernt hatte. Zwei Punkte verschärften diese Frage. Die Richter hatten üblicherweise befristete Verträge und zogen nach spätestens einem oder zwei

36 Der Begriff „Rezeption“ wird hier aus Zweckmäßigkeitsgründen beibehalten, ohne damit ein Urteil über die Art der Rechtsveränderungen abzugeben. Zur Diskussion um Rezeption, Transfer, Transplant etc. u.a. Thomas Duve, Von der Europäischen Rechtsgeschichte zu einer Rechtsgeschichte Europas in globalhistorischer Perspektive, Rg 20 (2012), S. 18-71 (52-55); EvA ScHumanN, Rechts- und Sprachtransfer am Beispiel der volkssprachigen Praktikerliteratur, in: Andreas Deutsch (Hrsg.), Historische Rechtssprache des Deutschen, 2013, S. 123-174 (158-161).

37 Nils JAnsEn, The Making of Legal Authority. Non-legislative Codifications in Historical and Comparative Perspective, 2010, S. 21-23, 28-34.

38 Zur mittelalterlichen italienischen Universität HERMANN LANGE, Römisches Recht im Mittelalter. Bd. 1: Die Glossatoren, 1997, S. 35-53; CoING (Anm. 1), S. 10-13; zum deutschen Spätmittelalter RAINER C. Schwinges, Zur Professionalisierung gelehrter Tätigkeit im deutschen Spätmittelalter, in: Hartmut Boockmann/Ludger Grenzmann/Bernd Moeller/Martin Staehelin (Hrsg.), Recht und Verfassung im Übergang vom Mittelalter zur Neuzeit, II. Teil (Abhandlungen der Akademie der Wissenschaften zu Göttingen, phil.-hist. Klasse III/239), 2001, S. 473-493.

39 HAGEN KELlER, Die Kodifizierung des Mailänder Gewohnheitsrechts von 1216 in ihrem gesellschaftlich-institutionellen Kontext, in: Atti dell' $11^{\circ}$ congresso internazionale di studi sull'alto medioevo Milano, 26-30 ottobre 1987, 1989, Bd. 1, S. 145-171 (149); DERS./REINHOLD SCHNEIDER, Rechtsgewohnheit, Satzungsrecht und Kodifikation in der Kommune Mailand vor der Errichtung der Signorie, in: Hagen Keller/Jörg W. Busch (Hrsg.), Statutencodices des 13. Jahrhunderts als Zeugen pragmatischer Schriftlichkeit (Münstersche Mittelalter-Schriften 64), 1991, S. 167-191; Dilcher (Anm. 21), S. 157 (älteste Gesetzgebung 1135); MARIO AsCHERI, Satutory Law of Italian Cities from Middle Ages to Early Modern, in: Gisela Drossbach (Hrsg.), Von der Ordnung zur Norm: Statuten in Mittelalter und Früher Neuzeit, 2010, S. 201-216; Überblick über die Statutarrechte bei ARMIN WoLF, Gesetzgebung in Europa 1100-1500. Zur Entstehung der Territorialstaaten, 2. Aufl. 1996, S. 76-85. 
Jahren gleich weiter in eine andere Stadt. ${ }^{40}$ Wie sollten sie sich innerhalb so kurzer Zeit also Kenntnis über die Einzelheiten des Stadtrechts verschaffen? Zum anderen beschränkte sich das universitäre Lehrprogramm auf römisches und kanonisches Recht, auf die beiden iura. Das Partikularrecht nahm man an der mittelalterlichen Universität nicht zur Kenntnis. Aber die gelehrten Juristen entwickelten eine Doktrin, wie man vor Ort mit den Fragen von Rechtsvielfalt umgehen sollte.

\section{Die gemeinrechtliche Rechtsanwendungslehre}

Das Ergebnis war die weithin bekannte Statutentheorie. ${ }^{41}$ Auf der Grenzlinie von materiellem Recht und Prozessrecht formulierten die gelehrten Juristen drei Grundsätze, mit denen sie den Rechtspluralismus in den Griff bekommen wollten. ${ }^{42}$ Zunächst sollte das Recht des engeren Rechtskreises dem Recht des weiteren Rechtskreises vorgehen. In der Hierarchie der Rechtsquellen verdrängte also das speziellere Recht das allgemeinere. Das bezog sich nicht auf einzelne Vorschriften innerhalb derselben Rechtsquelle, sondern auf das Rangverhältnis der Quellenmassen als solcher. Immer dann also, wenn es für ein spezielles Problem eine Lösung im Statutarrecht gab, sollte man das Problem nach dem Statutarrecht lösen. Nur bei Lücken im partikularen Recht durfte man auf das allgemeine Recht zurückgreifen. Das römisch-kanonische Recht erschien auf diese Weise als subsidiäre Rechtsquelle und stand in der Normenhierarchie an letzter Stelle. Das genaue Verhältnis zwischen kanonischem und römischem Recht befand sich lange in der Diskussion, besonders in Einzelfragen, die beide Rechte unterschiedlich beantworteten. Da das kanonische Recht einerseits in seiner Entstehung jünger als das römische Recht war, seine praktische mittelalterliche Anwendung zugleich aber der Berücksichtigung des römischen Rechts zeitlich vorausging, gab es verschiedene Spielarten von Bereichslehren und zeitlich gestuften Vorrangverhältnissen. ${ }^{43}$

40 Woldemar Engelmann, Die Wiedergeburt der Rechtskultur in Italien durch die wissenschaftliche Lehre, 1938, S. 66-67, 485.

41 Überblick über verschiedene Spielarten der Statutentheorie bei CoING (Anm. 1), S. 137-146; epochenüberspannender Überblick bei KNUT WolFGANG NöRR, Iura novit curia: aber auch fremdes Recht? Eine rechtsgeschichtliche Skizze, in: Serge Dauchy/W. Hamilton Bryson/Matthew C. Mirow (Hrsg.), Ratio decidendi. Guiding Principles of Judicial Decisions. Volume 2: 'Foreign' Law, 2010, S. 9-16.

42 Zur Auslegungs- und Rechtsanwendungslehre im späten Mittelalter EngELMANN (Anm. 40), S. 128-171; WolfGang WiEgand, Studien zur Rechtsanwendungslehre der Rezeptionszeit (Münchener Universitätsschriften - Juristische Fakultät. Abhandlungen zur rechtswissenschaftlichen Grundlagenforschung 27), 1977.

43 Genauere moderne Forschung zu den Rechtsanwendungsklauseln und zur Gerichtspraxis in diesem Punkt fehlt weithin; in der Sache sehr pointiert Willem J. Zwalve/Boudewijn Sirks, Grundzüge der europäischen Privatrechtsgeschichte. Einführung und Sachenrecht, 2012, S. 68: römisches Recht als subsidiäres Recht innerhalb des kanonischen Rechts, eigenständige Bedeutung oft erst nach der Reformation. Zur beschwerlichen mittelalterlichen Diskussion RichaRd H. HELMHOLz, Ka- 
Die materielle Nachrangigkeit des römisch-kanonischen Rechts wurde freilich durch die zweite und dritte Stufe der Rechtsanwendungslehre deutlich abgeschwächt. Der zweite Lehrsatz lautete nämlich, bei der Auslegung des Statutarrechts müsse man versuchen, ein Ergebnis zu erzielen, das möglichst wenig vom römisch-kanonischen Recht abwich: „Statuta sunt stricte interpretanda, ut minime laedant ius commune“. Die sogenannte strikte Interpretation ${ }^{44}$ forderte also ausdrücklich, das partikulare Recht mit den Methoden des universitären gelehrten Rechts auszulegen. Das ging bis hin zu Inhaltskontrollen. Nach den Lehren der gemeinrechtlichen Juristen durften böse und ungerechte Gewohnheiten und Statutarrechte nicht angewandt werden. Ein frühneuzeitlicher Paradefall stammte aus Erfurt. Angeblich durfte dort niemand in den Rat aufgenommen werden, der Peter hieß. ${ }^{45}$ Rationabilität, Vernünftigkeit - so nannte man die Eigenschaft, die das Statutarrecht erfüllen musste, um überhaupt beachtlich zu sein. ${ }^{46}$ Dann erst begann die Auslegung. Nach dem theoretischen Ausgangspunkt war das Statutarrecht eine Ausnahme zum allgemeinen römisch-kanonischen Recht. Als Ausnahmeregelungen sollten statutarrechtliche Normen eng verstanden werden, um den Geltungsbereich des universalen Rechts möglichst wenig einzuschränken. Typische Diskussionen bezogen sich auf das Familien- und Erbrecht. Im Ehegüterrecht sowie im Intestaterbrecht unterschieden sich die örtlichen Rechte stark voneinander. Aber, so die gelehrten Juristen, über ihren unmissverständlichen Wortlaut hinaus sollten die partikularen Quellen nicht ausgedehnt werden. Die strikte Interpretation schränkte auf diese Weise die Rechtsvielfalt ein, weil sie den Anwendungsbereich des römisch-kanonischen Rechts ausweitete.

Die dritte Stufe der Statutentheorie bezog sich auf die Situation vor Gericht. Hier nahmen die gelehrten Juristen Rücksicht auf die Ausbildung der universitär geschul-

nonisches Recht und europäische Rechtskultur (dt. Übersetzung von JöRG MÜLLER), 2013, S. 212-219; für die Sichtweise des weltlichen Rechts und vor allem die spätere Zeit einschlägig ist UDo WoLTER, Ius canonicum in iure civili. Studien zur Rechtsquellenlehre in der neueren Privatrechtsgeschichte (Forschungen zur Neueren Privatrechtsgeschichte 23), 1975, S. 51-52, 123-128, 163-165 (zu Böhmer), 172; unklar CHRISTOPH LINK, Kirchliche Rechtsgeschichte. Kirche, Staat und Recht in der europäischen Geschichte von den Anfängen bis ins 21. Jahrhundert, 2. Aufl. 2010, § 6 Rn. 13 (S. 42): im Mittelalter ebenbürtig neben dem römischen Recht, § 13 Rn. 9 (S. 89): nach der Reformation in evangelischen Territorien subsidiär hinter dem römischen Recht.

44 MARIo SBRICCOLI, L'interpretazione dello statuto. Contributo alla studio della funzione dei giuristi nell'età comunale (Università di Macerata. Pubblicazioni della facoltà di giurisprudenza. Seconda serie 1), 1969; ReInHARD ZimmermanN, Statuta sunt stricte interpretanda? Statutes and the Common Law: A Continental Perspective, The Cambridge Law Journal 56 Nr. 2 (Juli 1997), S. 315-328; HeLMHOLZ (Anm. 43), S. 22; weitere Nachweise bei OEstmann, Rechtsvielfalt vor Gericht (Anm. 2), S. 7.

45 WolfGANG WiEgAND, Die privatrechtlichen Rechtsquellen des Usus modernus, in: Dieter Simon (Hrsg.), Akten des 26. Deutschen Rechtshistorikertages (Ius Commune. Sonderheft 30), 1987, S. $237-252$ (241).

46 Am Beispiel der Consuetudines Winfried Trusen, Römisches und partikuläres Recht in der Rezeptionszeit, in: ders., Gelehrtes Recht im Mittelalter und in der frühen Neuzeit (Bibliotheca Eruditorum 23), 1997, S. $97-120(116)=737^{\star}-760^{\star}\left(756^{\star}\right)$. 
ten Richter. Diese konnten den genauen Inhalt des Partikularrechts zwar zufällig wissen, besaßen zumeist aber keine genaueren Kenntnisse darüber. Und deshalb sagte man, es gehöre zu den Aufgaben der Parteien, das Gericht über die Existenz und den Inhalt des Statutarrechts zu informieren. Dogmatisch begründete man dies mit dem Hinweis, sowohl das Vorhandensein als auch der jeweilige Gehalt des Statutarrechts seien tatsächliche Fragen, und für die Beibringung von Tatsachen im Zivilprozess seien die Parteien verantwortlich. „Statuta sunt facti“ und „consuetudo est facti“ wurden zu den Merksätzen der gelehrten Doktrin. Diese Beibringungsobliegenheit, zeitgenössisch oft als Allegation bezeichnet, verknüpfte man mit einer Beweisregel. Danach sollte das Gericht grundsätzlich das universale römisch-kanonische Recht seinen Entscheidungen zugrundelegen, soweit nicht eine Partei ein abweichendes Statutarrecht vorgetragen und bewiesen hatte. Diese Anwendungsvermutung nannte man seit dem 17. Jahrhundert fundata intentio, doch der Sache nach gab es diese Auffassung bereits seit mindestens dem 13./14. Jahrhundert. ${ }^{47}$ Die Vermutungsregel zugunsten des römisch-kanonischen Rechts besagte also, dass der Richter von Amts wegen nur das gelehrte Recht kennen musste. Wer sich auf abweichende Quellen berief, ging ein Beweisrisiko ein. Es gab in partikularrechtlichen Fragen damit ein onus probandi, eine Beweislast zum Nachteil desjenigen, der abweichende regionale Rechtsquellen anführen wollte. Falls es nämlich um Existenz und Inhalt dieser Normen Streit gab und er seine Ansicht nicht erhärten konnte, griff das Gericht ohne weiteres auf das römisch-kanonische Recht zurück.

Gerade diese dritte Stufe der Statutentheorie dürfte in der Sache erheblich dazu beigetragen haben, dass trotz der zahlreichen verschiedenen Stadtrechte zunächst in Italien ein auch praktisch wirksames überregionales gemeines Recht entstand. In den Feinheiten gab es stets Diskussionen. Falls das spezielle Recht beispielsweise allgemein bekannt war, ${ }^{48}$ falls es im Stadtbuch überliefert war oder sonstwie leicht zugänglich erschien, galt es als ius commune in loco und unterlag dann nicht den Allegations- und Beweisanforderungen des übrigen Statutarrechts. ${ }^{49}$ Der genaue Inhalt des gemeinen Rechts unterschied sich auf diese Weise von Ort zu Ort, von Region zu Region. Trotzdem scheinen die gemeinrechtliche Rechtsquellenhierarchie sowie die Rechtsanwendungslehre stark dazu beigetragen zu haben, die vergleichsweise kleinräumigen mittelalterlichen Rechtskreise aufzubrechen und einen europäischen Rechtsraum zu schaffen. Wesentliche Einzelentscheidungen des Rechts waren weithin gleich, die Prozessmaximen folgten überwiegend den gelehrten Vorbildern

47 Wolfgang Wiegand, Zur Herkunft und Ausbreitung der Formel „habere fundatam intentionem“, in: Sten Gagnér/Hans Schlosser/Wolfgang Wiegand (Hrsg.), Festschrift für Hermann Krause, 1975, S. $126-170$.

48 Einzelheiten zur sog. Notorietät bei Mathias SCHMOECKEL, „Excessus notorius examinatione non indiget“. Die Entstehung der Lehre von der Notorietät, Rivista Internazionale di Diritto Comune 14 (2003), S. 155-188.

49 Wiegand (Anm. 42), S. 151, 153; Oestmann, Rechtsvielfalt vor Gericht (Anm. 2), S. 9, 15. 
des gemeinrechtlichen Prozesses, ${ }^{50}$ und vor allem konnten die Werke der lateinischen, auch der praktisch ausgerichteten Literatur einen europäischen Diskussionsraum eröffnen, der durch partikulare Zersplitterung kaum beeinträchtigt war. Gesetzgebung war für all dies nicht erforderlich.

\section{Frühe Rechtsanwendungsklauseln in Deutschland}

Wendet man von hier aus den Blick auf das Heilige Römische Reich Deutscher Nation, hat man es mit zeitlichen Verschiebungen zu tun, steht aber weithin vor ähnlichen oder denselben Befunden. Schon die Glosse zum Sachsenspiegel von JoHANN voN BucH aus der ersten Hälfte des 14. Jahrhunderts stellte das besondere Recht der Sachsen dem Kaiserrecht gegenüber. ${ }^{51}$ Mit diesem Titel bezeichnete man damals das römisch-kanonische Recht. ${ }^{52}$ In einer Zeit, in der die Magdeburger Schöffen sich noch weigerten, abweichende Gewohnheiten aus dem magdeburgisch-sächsischen Rechtskreis bei ihren Entscheidungen überhaupt zur Kenntnis zu nehmen, war sich JoHANN vON Buch über das gleichzeitige Nebeneinander des sächsischen und des römischkanonischen Rechts durchaus im Klaren.

Ganz wie in den italienischen Vorbildern entstanden jetzt nördlich der Alpen ebenfalls Rechtsaufzeichnungen in Städten und später in Territorien, die sich an die gelehrte Statutentheorie anlehnten. Eines der frühesten Beispiele stammt aus Lüneburg von 1401:

Dat me tovorn sik holden scal an dit ieghenwardighe buk und an de Stad priuilegia. Dar de to schedinge welker sake wes drepet wol, dat der utscrifte hir nicht in geschreuen weren, und wes me in dessem boke edder in den priuilegien nicht en vind, dar willet de Rat vnd borghere in allen saken vnd schelingen na desser tyd sik mer richten an mene sassech lantrecht. Vnde wes me dar nicht ane vind, dar schal me sik denne in den stucken richten vnd holden an dat keyserrecht. Vnd wes me dar uort nicht ane vind, dar scal me sik holden an dat gheistlike recht. Welke sake ok uor desser tyd wanner to luneborgh gherichtet sint, der me sik enkede uordenket, vnd de me

50 Umfassend zu den mittelalterlichen gelehrten Wurzeln WiESŁAW LITEWSKI, Der römisch-kanonische Zivilprozeß nach den älteren ordines iudiciarii, 2 Bände, 1999; KNUT WolfGANG NöRR, Romanisch-kanonisches Prozessrecht. Erkenntnisverfahren erster Instanz in civilibus, 2012.

51 Frank Michael Kaufmann (Hrsg.), Glossen zum Sachsenspiegel-Landrecht. Buch'sche Glosse (Monumenta Germaniae Historica. Fontes iuris Germanici antiqui nova series VII), 2002, 3 Bände; Buch 1 cap. 61 [= I 62 § 7], S. 448, Buch 3 cap. 62 [= III 69 § 3], S. 1390-1391; auch bei Julius WilHeLM PLANCK, Das Deutsche Gerichtsverfahren im Mittelalter. Nach dem Sachsenspiegel und den verwandten Rechtsquellen, Bd. 1, 1879, S. 88.

52 Hermann Krause, Kaiserrecht und Rezeption (Abhandlungen der Heidelberger Akademie der Wissenschaften, phil.-hist. Klasse 1952/1), 1952, S. 94-95; BERnD KANNOwSKI, Die Umgestaltung des Sachsenspiegelrechts durch die Buch'sche Glosse (Monumenta Germaniae Historica. Schriften 56), 2007, S. 197-201; HIRAM KüMPER, Sachsenrecht. Studien zur Geschichte des sächsischen Landrechts in Mittelalter und früher Neuzeit (Schriften zur Rechtsgeschichte 142), 2009, S. 216, 267 (Nikolaus Wurm). 
bewisen magh, dat de mit rechte scheden sint, wanner denne na desser tyd der saken ghelyk mer vallen, so scal me sodane saken na dem rechte vordan scheden. ${ }^{53}$

Dieser oft erwähnte Ratsbeschluss leitete das Lüneburger Stadtrecht ein. ${ }^{54}$ Die Rechtsvielfalt, also das gleichzeitige Nebeneinander ganz verschiedener Rechte, war dem Rat der Stadt Lüneburg vollkommen präsent. Deswegen gab diese Präambel eine Normenhierarchie vor, nach der das Gericht in der Praxis mit den unterschiedlichen Quellenmassen umgehen sollte. An erster Stelle stand das Stadtbuch, also das 1401 aufgezeichnete Stadtrecht. Danach folgte das Privilegienrecht, also das vom Stadtherren verliehene Stadtrecht. ${ }^{55}$ Bei Lücken sollte man auf das sächsische Landrecht zurückgreifen, also auf den Sachsenspiegel. Obwohl der Sachsenspiegel ursprünglich ländliche Gewohnheiten wiedergeben wollte und gerade kein spezifisches Stadtrecht enthielt, erlangte er schnell auch in den sächsischen Städten gesetzesgleiche Geltung. In Lüneburg gab es schon bald eine Prachthandschrift für den Rat, die ausdrücklich subsidiär herangezogen werden sollte. ${ }^{56}$ Bei Lücken im Sachsenrecht griff

53 Bei Wilhelm Theodor Kraut (Hrsg.), Das alte Stadtrecht von Lüneburg, 1846, S. 2 Zeilen 6-22. Übertragung: Dass man zuvor sich halten soll an dieses gegenwärtige Buch und an die Stadtprivilegien. Falls es bei der Entscheidung einer Sache vorkommt, dass die Vorschrift hierin nicht geschrieben ist und man sie in diesem Buch oder in den Privilegien nicht findet, da wollen Rat und Bürger, dass man sich in allen Sachen und Streitigkeiten ab dieser Zeit richtet nach dem sächsischen Landrecht. Wenn man darin nichts findet, dann soll man sich in diesen Sachen richten und halten an das Kaiserrecht. Und wenn man weiterhin da nichts findet, dann soll man sich halten an das geistliche Recht. Welche Sachen auch vor dieser Zeit irgendwann zu Lüneburg gerichtet sind, soweit man sich irgendwie daran erinnert und man die beweisen mag, dass sie mit Recht entschieden sind, wenn dann ab dieser Zeit gleichartige Sachen nochmals vorfallen, so soll man solche Sachen nach dem früheren Recht entscheiden.

54 Erwähnt bei Отто Sтовве, Geschichte der deutschen Rechtsquellen, 2 Bände, 1860/64, Bd. 1, S. 652, Bd. 2, S. 326; TRUSEN (Anm. 46), S. $102=742^{\star}$; KLAUS LuIG, Universales Recht und partikulares Recht in den „Meditationes ad pandectas“ von Augustin Leyser, in: ders., Römisches Recht. Natur-

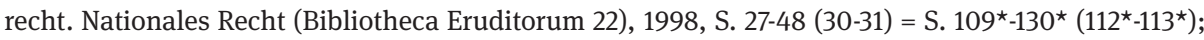
FRIEDRICH EBEL, Wirkungen des Lüneburger Stadtrechts von 1401, in: ders., Unseren fruntlichen grus zuvor. Deutsches Recht des Mittelalters im mittel und osteuropäischen Raum. Kleine Schriften, hrsg. von Andreas Fijal, Hans-Jörg Leuchte und Hans-Jochen Schiewer, 2004, S. 351-358 (351 mit weiteren Belegen in Fn. 3); KARL KroescheLl, recht unde unrecht der sassen. Rechtsgeschichte Niedersachsens, 2005, S. 174-175; KeRSTIN SEIDEL, Vorzeigen und nachschlagen. Zur Medialität und Materialität mittelalterlicher Rechtsbücher, Frühmittelalterliche Studien 42 (2009), S. $307-328$ (307 mit weiteren Belegen in Fn. 2).

55 Hinweis auf lüneburgische Privilegien bei BeRnHARd DiestelKaMP, Die Städteprivilegien Herzog Ottos des Kindes, ersten Herzogs von Braunschweig-Lüneburg (1204-1252) (Quellen und Darstellungen zur Geschichte Niedersachsens 59), 1961, S. 138-161.

56 ECKHARD FREISE, Sachsenspiegel des Lüneburger Rates, in: Egbert Koolman/Ewald Gäßler/Friedrich Scheele (Hrsg.), der sassen speyghel. Sachsenspiegel - Recht - Alltag. Beiträge und Katalog zu den Ausstellungen „Bilderhandschrifen des Sachsenspiegels - Niederdeutsche Sachsenspiegel“ und „Nun vernehmet in Land und Stadt - Oldenburg. Sachsenspiegel. Stadtrecht“ (Veröffentlichungen des Stadtmuseums Oldenburg 21), 2 Bände, 1995, Bd. 1, S. 447-449 (mit Abbildung und Literatur); 
sodann das Kaiserrecht ein, abweichend von der üblichen gelehrten Doktrin sogar noch vor dem kanonischen Recht. ${ }^{57}$ Aber das gemeinrechtliche Prinzip war hier sehr klar erkennbar. Das jeweils speziellere Recht verdrängte das nachrangige allgemeinere Recht. Stadtrecht vor Landrecht, Landrecht vor römisch-kanonischem Recht. ${ }^{58}$ Auf diese Weise versuchte der Lüneburger Rat die mindestens fünf Quellenschichten zu ordnen. Am Ende des wiedergegebenen Ratsbeschlusses tauchten darüber hinaus ältere Gewohnheiten oder frühere Entscheidungen auf, die bei zukünftigen Fällen ebenfalls die Richtschnur bilden sollten. ${ }^{59}$ In welchem Verhältnis sie zu den übrigen Rechtsmassen stehen sollten, sagte der Lüneburger Rat nicht. Dafür geht es an dieser Stelle ausdrücklich um das aus dem gemeinen Recht bekannte Beweiserfordernis. ${ }^{60}$

\section{Rechtsvielfalt und Wege zur Rechtseinheit in der frühen Neuzeit}

Rechtsanwendungsklauseln wie diejenige aus Lüneburg von 1401 setzten sich nach und nach in den wichtigsten Gerichts- und Prozessordnungen durch und bestimmten das normative Bild bis weit ins 19. Jahrhundert hinein. Die Regelungen waren hierbei keineswegs einheitlich. In den Feinheiten gab es bemerkenswerte Unterschiede. Sie betrafen hauptsächlich die Frage, ob die Auslegungs- und Beweisregeln zugunsten des römisch-kanonischen Rechts das einheimische bzw. partikulare Recht schwächten und zurückdrängten oder ob es nicht auch in einem gelehrtrechtlichen Umfeld möglich war, den Eigenwert regionaler Rechtsordnungen zu bewahren. Die normativen Quellen zeigen diese Unterschiede durchaus, wenn man sie genau liest und miteinander vergleicht. ${ }^{61}$

ERIKA SinAUER, Eine Lüneburger Sachsenspiegelhandschrift, ZRG GA 45 (1925), S. 408-413. Die erste Anwendung des Sachsenspiegels in Lüneburg ist aber wohl erst für 1411 belegt, dazu SEIDEL (Anm. 54), Frühmittelalterliche Studien 42 (2009), S. 319.

$57 \mathrm{Zu}$ diesem Befund schweigt Sтовве, Bd. 2 (Anm. 54), S. 326. Trusen (Anm. 46), S. $102=742^{\star}$ erwähnt kurz die Reihenfolge, geht aber nicht genauer darauf ein. KRoESCHELL (Anm. 54), S. 174 meint, die Reihenfolge entspreche „genau der gemeinrechtlichen Lehre“, aber genau das ist ungewiss.

58 Das neuzeitliche Lüneburger Stadtrecht verwies dann nur noch pauschal auf die gemeinen beschriebenen Rechte: Christian Gottlieb Riccius, Zuverläßiger Entwurff von Stadt-Gesezen oder Statutis vornehmlich der Land-Städte, 1740, S. 157; SтоввE, Bd. 2 (Anm. 54), S. 328.

59 Darauf weist ausdrücklich EBEL (Anm. 54), S. 352 hin.

60 Etwas ungenau Luig (Anm. 54), S. $31=113^{\star}$, der lediglich betont, für das Stadtrechtsbuch selbst habe die ex-officio-Anwendung gegolten.

61 Beispiele bei Frank L. SchäFER, Juristische Germanistik. Eine Geschichte der Wissenschaft vom einheimischen Privatrecht (Juristische Abhandlungen 51), 2008, S. 241-248. 


\title{
1 Reichskammergericht
}

Sowohl in der zeitgenössischen Diskussion als auch in der modernen rechtshistorischen Literatur spielen die Rechtsanwendungsvorschriften der Reichskammergerichtsordnungen eine besonders hervorgehobene Rolle. Schon die erste Reichskammergerichtsordnung von 1495 enthielt eine ausdrückliche Übernahme der gemeinrechtlichen Statutentheorie. ${ }^{62}$ Die umfangreichste und langlebigste Kammergerichtsordnung stammte sodann von 1555. Sie erlegte den richterlichen Mitgliedern des obersten Reichsgerichts, den Assessoren, folgende Amtspflicht auf:

\begin{abstract}
Die beisitzer des cammergerichts sollen in keiner sach, sie sey als gering als sie immer wölle, allein auf ihr gutbedüncken oder eines jeden erwegen, billigkeit oder eygen fürgenomen und nicht dem rechten gemeß informierten gewissen, sonder auf des reichß gemeine recht, abschied und den jetztbewilligten und auf diesem reychßtage aufgerichten frieden in religion- und andern sachen, auch handhabung des friedens und erbare ländische ordnungen, statuten und redliche, erbare gewonheiten der fürstenthumben, herrschaften und gericht (die für sie gebracht werden), wie sollichs von alter jederzeyt cammerrichter und beysitzern auferlegt und gehalten worden ist, nach vermög und außweisung ires eydts, wie der hieunden gesetzt, urtheil fassen und außsprechen. ${ }^{63}$
\end{abstract}

Diese Formulierung bezog sich auf das „ampt im rhat“, also auf die Tätigkeit bei der richterlichen Rechtsanwendung. Ganz ähnlich lauteten aber die Eidesformeln sowohl des Kammerrichters als auch der Beisitzer. ${ }^{64}$ In der Gerichtsordnung waren die unterschiedlichen Quellen aufgezählt, die für das Gericht maßgeblich sein sollten. Im Gegensatz zu der überkommenen Lehre vom Vorrang des kleineren Rechtskreises ordnete die Reichskammergerichtsordnung die verschiedenen Rechtsmassen in umgekehrter Reihenfolge. Die Aufzählung begann mit den gemeinen Rechten des Reiches, also mit dem römischen und kanonischen Recht. Sodann ging es um die Reichsabschiede, so hießen damals die förmlichen Reichsgesetze. Besonders erwähnt war der Augsburger Religionsfriede von 1555, der zusammen mit der Reichskammergerichtsordnung beschlossen wurde. Danach kamen die Ordnungen, Statuten und Gewohnheiten der einzelnen Territorien bis hin zu kleinen Herrschaften und einzelnen Gerichten. Im Einklang mit der gelehrten Tradition sollten diese Regeln „erbar“ sein, soweit es sich um Gewohnheiten handelte sogar redlich und ehrbar. Die Inhaltskontrolle am Maßstab des überregionalen gemeinen Rechts war also wörtlich in der Gerichtsordnung enthalten. Nachgeschoben findet sich in Klammern der Hinweis „die für sie gebracht werden“. Man hat diesen Halbsatz regelmäßig als Anspielung

62 RKGO 1495 § 3, bei: Karl Zeumer (Bearb.), Quellensammlung zur Geschichte der Deutschen Reichsverfassung in Mittelalter und Neuzeit, 2. Aufl. 1913, S. 285; dazu Wiegand (Anm. 42), S. 163; OESTMANN, Rechtsvielfalt vor Gericht (Anm. 2), S. 53.

63 RKGO 1555 Teil 1, Titel XIII § 1, bei: Adolf LAUFS (Hrsg.), Die Reichskammergerichtsordnung von 1555 (Quellen und Forschungen zur höchsten Gerichtsbarkeit im Alten Reich 3), 1976, S. 93.

64 RKGO 1555 Teil 1, Titel LVI, bei: LAUFS (Anm. 63), S. 151. 
auf die gemeinrechtliche Allegations- und Beweispflicht für Partikularrecht angesehen. ${ }^{65}$ Die Reihenfolge der Rechtsquellen, wie sie in der Reichskammergerichtsordnung von 1555 erscheint, entspräche dann dem Anwendungsverhältnis, wie es aus der fundata-intentio-Theorie folgte.

Bereits im Bereich der Normengeschichte war das Bild aber viel bunter, als es die ältere Literatur annahm. Die Reichskammergerichtsordnung von 1555 blieb zwar bis zum Ende des Alten Reiches die letzte förmliche und umfassende Gerichtsordnung. Allerdings gab es im Rahmen des Jüngsten Reichsabschiedes von 1654 zahlreiche Neuerungen. Von der scheinbaren Geschwätzigkeit der frühneuzeitlichen Kanzleisprache darf man sich nicht täuschen lassen. Die Quellen aus der Entstehungszeit belegen eindeutig, mit welcher Leidenschaft die Beteiligten im Vorfeld um einzelne Formulierungen und Regelungen stritten. ${ }^{66}$ In der Tat erhielt auch die Rechtsanwendungsklausel 1654 ein neues Aussehen. Sie lautete nun folgendermaßen:

Benebens sollen Cammer-Richter, Präsidenten und Beysitzere bei Administration der heylsamen Justitz so wohl die Statuta und Gewohnheiten als die Reichs-Abschiede und gemeine Rechten vor Augen haben und wohl beobachten und sich in den Schrancken der Cammer-Gerichts-Ordnung halten, daraus nicht schreiten $[. ..] .^{67}$

Die Rechtsanwendungsklausel des Jüngsten Reichsabschiedes enthielt zwar den ausdrücklichen Verweis auf die Kammergerichtsordnung von 1555, dennoch fallen auf den ersten Blick die erheblichen Unterschiede ins Auge. Die Reihenfolge der anzuwendenden Rechtsquellen war nunmehr in genau entgegengesetzter Weise formuliert. An erster Stelle standen jetzt die Statuten und Gewohnheiten, also die bewusst gesetzten sowie die durch praktische Übung entstandenen Rechtssätze. Dann folgten die Reichsabschiede, und erst zuletzt erwähnte die Quelle die gemeinen Rechte, abermals im Plural. Der Hinweis „die vor sie gebracht werden“ fehlte an dieser Stelle. ${ }^{68}$

Für die Frage nach dem Verhältnis von Rechtsvielfalt und Rechtsharmonisierung folgen hieraus mehrere Antworten. Das gleichzeitige Miteinander, teilweise auch Gegeneinander sich gegenseitig überlappender Rechtsmassen war für die frühneuzeitlichen Gesetzgeber, aber auch für die praktischen Juristen eine schlichte Tatsache, die man zur Kenntnis nehmen musste. Um halbwegs Rechtssicherheit zu gewährleis-

65 Wiegand (Anm. 42), S. 162-180.

66 Zeitgenössische Quellen bei Johann GotTfried von Meiern, Acta Comitialia Ratisbonensia publica de MDCLIII. et MDCLIV. Oder Regenspurgische Reichstags-Handlungen von den Jahren 1653. und 1654., 2. Teil, 1740; zur Reform allgemein: HeIDE-MARIE GöTTE, Der Jüngste Reichsabschied und die Reform des Reichskammergerichts, Diss. phil. München 1998. Sowohl bei MEIERN als auch bei GöTTE taucht die Reform von $\S 105$ JRA allerdings nicht auf.

67 JRA § 105, bei: ARNo BuschmanN (Hrsg.), Kaiser und Reich. Verfassungsgeschichte des Heiligen Römischen Reiches Deutscher Nation vom Beginn des 12. Jahrhunderts bis zum Jahre 1806 in Dokumenten. Teil II: Vom Westfälischen Frieden 1648 bis zum Ende des Reiches im Jahre 1806, 2. Aufl. 1994, S. 226. Eine befriedigende moderne Edition der Quelle gibt es leider nicht.

68 Oestmann, Rechtsvielfalt vor Gericht (Anm. 2), S. 447-450. 
ten, waren Regeln erforderlich, in welchem Verhältnis diese Rechtsschichten zueinander standen. Und genau in diesem Punkt konnte es verschiedene Lösungen geben. Der Frankfurter Partikularrechtler JoHANn PHILIPP ORTH meinte in den 1730er Jahren, also etwa 80 Jahre später, durch den Jüngsten Reichsabschied sei das Reichskammergericht verpflichtet, bei seiner Rechtsprechung vorrangig auf die Gewohnheiten und Statuten zu sehen und erst danach auf das gemeine Recht zurückzugreifen. ${ }^{69}$ Für die prinzipielle Betrachtung mögen solche Unterschiede gleichgültig sein: Die Zeit löste Fragen der Rechtsvielfalt durch richterliche Anwendungsregeln. Aber in den sachlichen Ergebnissen konnte sich je nach spezieller Rechtsanwendungsklausel das praktizierte Recht gravierend verändern. Einmal setzte sich die Schwerkraft des römischkanonischen Rechts durch und ebnete die partikularen Unterschiede weitgehend ein. Ein andermal nahm man das partikulare Recht zur Richtschnur und orientierte die Rechtsprechung an solchen kleinräumigen Rechtsquellen.

Am Reichskammergericht gab es in der Tat zahlreiche Hinweise, dass die Bedeutung des Partikularrechts höher war, als es die streng romanistische Rechtsanwendungsklausel von 1555 glauben lässt. In mehreren Regelungen für die Qualifikation der Assessoren forderte man praktische Erfahrungen in der regionalen Gerichtsbarkeit. Die Quellen betonen ausdrücklich, auf diese Weise wolle man die Kenntnis der territorialen Rechte gewährleisten. ${ }^{70}$ Andererseits bestanden Verpflichtungen der territorialen Gesetzgeber, ihre Normsetzungen bzw. verschriftlichten Rechtsgewohnheiten förmlich bei den Reichsgerichten einzureichen. Man sprach hier von der Insinuation des Partikularrechts. ${ }^{71}$ Offenbar schwächte sich das aus dem mittelalterlichen gelehrten Recht bekannte Allegations- und Beweiserfordernis immer stärker ab. Wenn die Assessoren regionale Rechtsquellen kannten, sollten sie diese ohne weiteres bei ihrer richterlichen Tätigkeit berücksichtigen. Darauf deuten auch mehrere Gemeine Bescheide hin, die das Reichskammergericht in seiner Wetzlarer Zeit erließ. Schon im 17. Jahrhundert hatte das Gericht in Speyer eine umfangreiche Sammlung partikularer Rechtsquellen besessen. Nach der Zerstörung von Speyer durch die Franzosen und der Übersiedlung nach Wetzlar war dieser Bestand vernichtet bzw. unzugänglich. Jetzt forderte das Gericht die Anwälte auf, sich bei ihren reichsständischen Auftraggebern dafür einzusetzen, gedruckte Exemplare des Partikularrechts bei Gericht einzureichen. Die erste Aufforderung erging 1692:

Es wird des Kayserlichen Cammergerichts sämbtlichen Advocaten und Procuratoren hiemit anbefohlen, daß sie von denjenigen Reichsständen wie auch Reichsritterschafften, denen sie bedienet, habenden Statuten, Land- und Stadtgerichts, auch anderen Ordnungen, Reformationen,

69 JohANN PhiLIPp ORTH, Nöthig und nützlich erachtete Anmerckungen über die so genante erneuerte Reformation der Stadt Frankfurt am Main (mit 4 Fortsetzungen und einem Zusatzband), 1731/75, IV. Fortsetzung, S. 110-111; OESTMAnN, Rechtsvielfalt vor Gericht (Anm. 2), S. 449.

70 Oestmann, Rechtsvielfalt vor Gericht (Anm. 2), S. 441-444.

71 Kurzer Hinweis auch bei Wolfgang SelleRt, Art. Insinuation, in: Albrecht Cordes/Heiner Lück/ Dieter Werkmüller (Hrsg.), HRG, Bd. 2, 2. Aufl. 2012, Sp. 1256-1259 (1257). 
Privilegien, auch hergebrachten Gewohnheiten, sofern diese in Schrifften verfast oder in Druck gegeben, als welche mehrentheils bey der jüngsten frantzösischen feindlichen Invasion abhanden kommen, ein eingebunden Exemplar förderlichst beschreiben und erfordern und darauff zu des Kayserlichen Cammergerichts Leserey einlieffern sollen. ${ }^{72}$

In der Tat musste das territoriale Recht dem Reichsgericht ausdrücklich mitgeteilt werden. Die Pflicht bezog sich aber nicht auf die Parteien, sondern auf die Landesherren und ihre Regierungen selbst. Praktisch dieselbe Regelung erging 1713 für landesherrliche Privilegierungen, und 1764 wiederholte das Gericht seine Aufforderung sogar noch einmal, weil zahlreiche Territorien ihre Verpflichtung nicht erfüllt hatten. ${ }^{73}$ Durch den Druck partikularer Stadt- und Landrechte und durch die Verschriftlichung von Gewohnheiten war die Rechtsvielfalt keineswegs beseitigt. Die universitätsgelehrten Richter bzw. Beisitzer hatten es nun aber erheblich einfacher, sich über das einschlägige Landesrecht zu informieren.

Im Ergebnis hat es den Anschein, dass sich im Laufe der Zeit partikulare Gewohnheiten und römisch-kanonische Lehren miteinander verbanden. Der starre Gegensatz von einheimischem Recht und dem universalen gelehrten Recht ebnete sich zusehends ein. Zeitgenossen wie SAMUEL STRYK sprachen ganz anschaulich vom Usus modernus pandectarum. ${ }^{74}$ Der neue Gebrauch des römischen Rechts war eine ganz praktisch ausgerichtete Art der Interpretation. Es entstand zunehmend ein Mischrecht, das sich nur schwer in seine einzelnen Bestandteile zerlegen ließ. Und genau hier zeigen sich wichtige Schritte auf dem Weg, die überkommene Rechtsvielfalt stärker in Richtung Rechtseinheit weiterzubilden. Das konnte man verschieden bezeichnen. Verbreitet waren Lehren von der sog. grünenden Observanz, der viridis observantia. ${ }^{75}$ Danach sollten nur diejenigen Rechtsquellen beachtlich sein, die in der Praxis tatsächlich gebräuchlich waren. Den Konflikt zwischen einer praktizierten Norm und einer lediglich auf dem Papier stehenden Regelung konnte es auf diese Weise kaum mehr geben.

72 Gemeiner Bescheid vom 13. April 1692, bei: Peter Oestmann (Hrsg.), Gemeine Bescheide. Teil 1: Reichskammergericht 1497-1805 (Quellen und Forschungen zur höchsten Gerichtsbarkeit im Alten Reich 63/I), 2013, Nr. 229, S. 585-586.

73 Oestmann, Gemeine Bescheide I (Anm. 72), Nr. 253, S. 632-633; Nr. 285, S. 714-715; dazu DERS., Rechtsvielfalt vor Gericht (Anm. 2), S. 60.

74 Zu ihm KLAus Luig, Samuel Stryk (1640-1710) und der „Usus modernus pandectarum“, in: ders., Römisches Recht. Naturrecht. Nationales Recht, 1998, S. 219-235 = 91*-107^.

75 Belege bei Peter Oestmann (Hrsg.), Ein Zivilprozeß am Reichskammergericht. Edition einer Gerichtsakte aus dem 18. Jahrhundert (Quellen und Forschungen zur höchsten Gerichtsbarkeit im Alten Reich 55), 2009, S. 320-322; DERS., Rechtsvielfalt vor Gericht (Anm. 2), S. 117, 160, 195 (,grünend vigor“), 282, 401, 675; PIO CARONI, „Sogar wenn Löwen sprechen könnten...“ - Überlegungen zur Einführung, in: ders. (Hrsg.), Gewohnheitsrecht und seine Vergangenheit, 2000, S. 1-11 (9); zur mittelalterlichen Verwendung GIAN MARIA VARANINI, Die Statuten der Städte der venezianischen Terraferma im 15. Jahrhundert, in: Giorgio Chittolini/Dietmar Willoweit (Hrsg.), Statuten, Städte und Territorien zwischen Mittelalter und Neuzeit in Italien und Deutschland (Schriften des Italienisch-Deutschen Historischen Instituts in Trient 3), 1992, S. 195-250 (233). 
Die neuere Literatur spricht hier vom usualen Rechtsdenken. ${ }^{76}$ Die Geltungskraft von Recht, also die Autorität von Regelungen, hing auf diese Weise zugleich immer davon ab, dass sie in der Praxis auch beachtet wurden. Tatsächliche und normative Elemente von Rechtsgeltung verflossen auf diese Weise ineinander. Deswegen ist es so schwierig, für das frühneuzeitliche Recht überhaupt von „Geltung“ zu sprechen.

Dieser Blick auf die Praxis, wie ihn die Lehre vom Usus und der Observanz vorgab, und den die Gerichte selbstreferenziell mit dem Hinweis auf ihren eigenen Stilus curiae $^{77}$ aufgriffen, war eine ganz pragmatische Möglichkeit, Rechtsvielfalt $\mathrm{zu}$ überwinden und widerstreitende Normen $\mathrm{zu}$ einer einheitlichen Handhabung aufzulösen. Ein etwas tautologisches Rechtssprichwort besagte genau dies: „Recht ist, was gilt. “78 Wenn diese Form der Geltung aber mit der praktischen Beachtung Hand in Hand einherging, verschwand die Rechtsvielfalt weitgehend. Das setzte freilich voraus, dass die praktische Beachtung bzw. die Observanz als solche unstreitig war. Doch ob bestimmte Quellen in usu waren oder nicht, beurteilten die Parteien im Streitfall nicht selten unterschiedlich. Hier gerät die Quelleninterpretation schnell an ihre Grenzen. Gerade im Konfliktfall wollten beide Parteien gewinnen. Je nachdem, welche Sichtweise erfolgversprechend erschien, mochte es daher angebracht sein, die fehlende Observanz einer Regelung anzuführen und auf diese Weise die Usualinterpretation ${ }^{79} \mathrm{zu}$ unterlaufen. Wer hierbei geschickt vorging, konnte die Statutentheorie mit ihren Allegations- und Beweisregeln ohne übergroßen Aufwand wieder aufleben lassen. Die Praxis zeigt deshalb kaum überraschend ein vielschichtiges Bild.

Zuvor sind noch einige Seitenblicke erforderlich. Die fundata intentio zugunsten des gemeinen Rechts schuf zwar Geltungs- und Anwendungsregeln, doch wie angedeutet konnten sich die Ergebnisse deutlich voneinander unterscheiden. Seit dem frühen 18. Jahrhundert gab es deutschrechtliche Autoren wie CHRISTIAN THOMAsIUS

76 Thomas Simon, Geltung. Der Weg von der Gewohnheit zur Positivität des Rechts, $\operatorname{Rg} 7$ (2005), S. 100-137, 102-120; BARBARA STOLLBERG-RILINGER, Verfassungsgeschichte als Kulturgeschichte, ZRG GA 127 (2010), S. 1-32 (30-31); DIES., Des Kaisers alte Kleider. Verfassungsgeschichte und Symbolsprache des Alten Reiches, 2008, S. 175; auch OEstmann, Rechtsvielfalt vor Gericht (Anm. 2), S. 116-118.

77 Zum Begriff SAMUEL OBERLÄNDER (Hrsg.), Lexicon Juridicum Romano-Teutonicum, hrsg. und eingeleitet von RaIner Polley, Nachdruck 2000 der 4. Aufl. 1753, S. 665: „Stylus Curiae, wird beschrieben, daß es sey seine Gerichtliche Gewohnheit, welche determiniret die Ordnung und Weise zu procediren, so man im Gericht observiren muß“ (mit Verweis auf SAMUel STRYk); WolfGang SELlERT, Prozeßgrundsätze und Stilus Curiae am Reichshofrat im Vergleich mit den gesetzlichen Grundlagen des reichskammergerichtlichen Verfahrens (Untersuchungen zur deutschen Staats- und Rechtsgeschichte N.F. 18), 1973, S. 50, dann aber eher normengeschichtlich.

78 Ruth Schmidt-Wiegand (Hrsg.), Deutsche Rechtsregeln und Rechtssprichwörter. Ein Lexikon, Neuauflage 2002, S. 268.

79 Clausdieter SchotT, Die „Interpretatio usualis“, in: Jan Schröder (Hrsg.), Entwicklung der Methodenlehre in Rechtswissenschaft und Philosophie vom 16. bis zum 18. Jahrhundert (Contubernium. Tübinger Beiträge zur Universitäts- und Wissenschaftsgeschichte 46), 1998, S. 65-83; JAN SCHRÖDER, Recht als Wissenschaft. Geschichte der juristischen Methodenlehre in der Neuzeit (1500-1933), 2. Aufl. 2012, S. 79, 168-169. 
und seine Nachfolger wie GEORG BEYER und andere, die mit großer Leidenschaft gegen das römische Recht und die angebliche Überfremdung der deutschen Rechtsgewohnheiten ankämpften. Sie forderten eine Geltungs- und Anwendungsvermutung für ein sog. gemeines deutsches Recht. ${ }^{80}$ Aus der Zusammenschau mittelalterlicher Rechtsaufzeichnungen wie dem Sachsenspiegel, Schwabenspiegel, dem oberbayerischen Landrecht von 1346 und dem Kleinen Kaiserrecht sollten sich gemeine deutschrechtliche Traditionen ergeben. ${ }^{81}$ Wer sich dagegen auf einen Satz des römischen Rechts berief, sollte nachweisen müssen, dass diese Norm tatsächlich rezipiert worden sei. Damit drehten die frühen und radikalen Deutschrechtler den Spieß kurzerhand um. Methodisch allerdings taten sie dasselbe wie sämtliche Vertreter der gemeinrechtlichen fundata-intentio-Lehre. Die Rechtsvielfalt lösten sie durch Vorrang- und Nachrangigkeitsverhältnisse sowie durch Beweisregeln.

Wendet man den Blick von den unterschiedlich formulierten Spielarten der Rechtsanwendungslehre auf die Praxis, steht man vor einem buntscheckigen Bild. Versatzstücke der Statutentheorie begegnen zuhauf und überall, aber die Stoßrichtungen und Lösungswege unterscheiden sich stark voneinander. Gut untersucht ist ein Stettiner Rechtsstreit aus der Mitte des 16. Jahrhunderts. In einem erbrechtlichen Konflikt standen sich eine römischrechtliche Lösung auf der Grundlage des Corpus Iuris sowie ein Stettiner Erbrechtsstatut von 1479 gegenüber. ${ }^{82}$ Der Appellant, der sich vor dem Reichskammergericht auf das Stettiner Stadtrecht berief, verlor dort seinen Rechtsmittelprozess. In den Schriftsätzen der Parteien und in den erhaltenen Relationen der Gerichtsmitglieder erkennt man, dass tatsächlich ein Schwerpunkt der Falllösung auf der Ermittlung des anzuwendenden Rechts lag. Zweihundert Jahre später ist aus der Hansestadt Lübeck ein langandauernder Rechtsstreit überliefert, in dem es um das sog. Erbrecht der halben Geburt ging, also um die erbrechtliche Gleichstellung oder Diskriminierung nicht vollbürtiger Geschwister. ${ }^{83}$ Auch hier erörterten die Parteien lang und breit zahlreiche Vorschriften des lübischen Rechts. Sie stritten

80 Allgemein zu den Hintergründen SCHÄFER (Anm. 61), S. $84-93$ (und passim); spezifisch prozessual Peter Oestmann, Kontinuität oder Zäsur? Zum Geltungsrang des gemeinen Rechts vor und nach Hermann Conring, in: Andreas Thier/Guido Pfeifer/Philipp Grzimek (Hrsg.), Kontinuitäten und Zäsuren in der Europäischen Rechtsgeschichte (Rechtshistorische Reihe 196), 1999, S. 191-210 (207); DERS., Rechtsvielfalt vor Gericht (Anm. 2), S. 340-341; aus der älteren Literatur HERMANn ConRAD, Deutsche Rechtsgeschichte. Bd. 2: Neuzeit bis 1806, 1966, S. 378.

81 Am Beispiel von Senckenberg SCHÄFER (Anm. 61), S. 105, 137-138.

$82 \mathrm{Zu}$ diesem Fall Filippo RANIERI, Diritto comune e diritto locale nei primi decenni della giurisprudenza del Reichskammergericht. Alcune prospettive di ricerca, in: Diritto comune e diritti locali nella storia dell'Europa (Atti del convegno di Varenna 1979), 1980, S. 71-92; DERS., Gemeines und partikulares Recht in der Rechtsprechung des Reichskammergerichts. Zugleich Analyse eines Stettiner Appellationsprozesses aus dem 16. Jahrhundert, ZRG GA 131 (2014), S. 89-127.

83 Vollständige Edition bei OestMann, Zivilprozeß (Anm. 75), passim; dazu auch MatTHIAs Doms, Rechtsanwendung im Usus modernus. Eine Fallstudie zum Erbrecht der halben Geburt, Diss. jur. Münster 2010 (auch unter: http://miami.uni-muenster.de/servlets/DerivateServlet/Derivate-5803/ diss_doms.pdf, besucht am 25.02.2014). 
über die Bedeutung des revidierten Stadtrechts von 1586 und grenzten diese Regeln von den Novellen des Corpus Iuris Civilis ab, die ihrerseits ebenfalls einschlägige Antworten bereithielten. Der zuständige Reichskammergerichtsassessor, der das zweitinstanzliche Urteil vorbereitete, überlegte hin und her, ob er das Lübecker Stadtrecht extensiv ausdehnen durfte, ob er es aus seinem eigenen Geist heraus auslegen konnte oder ob er auf die wörtliche Interpretation beschränkt war und bei allen Unklarheiten hilfsweise auf das römische Recht zurückgreifen musste. ${ }^{84} \mathrm{Im}$ Ergebnis entschied sich in beiden Beispielsfällen das Gericht gegen die Anwendung des städtischen Rechts und für die Anlehnung an das römisch-gemeine Recht. Für unsere Fragestellung folgt hieraus eine typisch frühneuzeitliche Form der Rechtsvereinheitlichung: ${ }^{85}$ Je nachdem, wie streng Juristen die fundata-intentio-Lehre ihren Entscheidungen zugrunde legten, konnten sie damit ein materiell weitgehend einheitliches Recht erzeugen. Deswegen findet sich in der Literatur häufig der Satz, die gemeinrechtliche Rechtsanwendungstheorie habe das einheimische Recht benachteiligt und das rezipierte Recht bevorzugt. ${ }^{86}$ Positiv gewendet war genau dies eine Möglichkeit, überregional Recht zu harmonisieren.

Freilich gibt es genügend Gegenbeispiele. Oftmals wandten die Gerichte territoriale Normen, die sie kannten, ohne Bedenken von Amts wegen an. Die Aufwertung des Partikularrechts ${ }^{87}$ ging einher mit der zunehmenden Abrundung der Territorien als eigene Gerichtssprengel. ${ }^{88}$ Unterstützt wurden derartige Öffnungen durch eine allmähliche Überwindung der strikten Interpretation. Einer der ersten Autoren, der einer strikt romanistischen Auslegung des Partikularrechts eine Absage erteilte, war DAvid MEviUs. In seinem 1642/43 erschienenen Kommentar zum Lübeckischen Stadtrecht lehnte er die romanistische Interpretation des Territorialrechts ab und forderte

84 Oestmann, Zivilprozeß (Anm. 75), S. 519-571.

85 Genau andere Wertung bei Ursula Flossmann, Österreichische Privatrechtsgeschichte, 6. Aufl. 2008, S. 10: Rechtszersplitterung nahm zu, lediglich die Dogmatik wurde universell.

86 HeLmut CoIng, Zur romanistischen Auslegung von Rezeptionsgesetzen, ZRG RA 56 (1936), S. 264277 (266-267, 276-277); TruSEN (Anm. 46), S. 111; HERMANN LANGE, Ius commune und Statutarrecht in Christoph Besolds Consilia Tubigensia, in: Dieter Medicus/Hans Hermann Seiler (Hrsg.), Festschrift für Max Kaser zum 70. Geburtstag, 1976, S. 637-655 (654-655); dazu auch OESTMANN, Rechtsvielfalt vor Gericht (Anm. 2), S. 8.

87 So auch Tilman RePGen, Ius Commune, in: Hans-Peter Haferkamp/Tilman Repgen (Hrsg.), Usus modernus pandectarum. Römisches Recht, Deutsches Recht und Naturrecht in der Frühen Neuzeit. Klaus Luig zum 70. Geburtstag (Rechtsgeschichtliche Schriften 24), 2007, S. 157-173 (165): Partikularrecht zunehmend gleichberechtigte Rechtsquelle; klassisch FrANZ WIEACKER, Privatrechtsgeschichte der Neuzeit unter besonderer Berücksichtigung der deutschen Entwicklung, 2. Aufl. 1967, S. 212 (dort bezogen auf die Einpassung deutschrechtlicher Figuren in die gemeinrechtliche Dogmatik).

88 Peter Oestmann, Gerichtsbarkeit als Ausdruck öffentlicher Gewalt - eine Skizze, in: Gerhard Dilcher/Diego Quaglioni (Hrsg.), Gli inizi del diritto pubblico III: Verso la costruzione del diritto pubblico tra medioevo e modernità/Die Anfänge des öffentlichen Rechts III: Auf dem Wege zur Etablierung des öffentlichen Rechts zwischen Mittelalter und Moderne (Fondazione Bruno Kessler. Annali dell'Istituto storico italo-germanico in Trento/Jahrbuch des italienisch-deutschen historischen Instituts in Trient. Contributi/Beiträge 25), 2011, S. 275-309 (297-303). 
stattdessen, die besonderen Stadt- und Landrechte aus ihrem eigenen Geist heraus zu interpretieren. ${ }^{89}$ Damit war ein erster wichtiger Schritt getan. Einige Nachfolger von MEvius, vor allem der Stadtrechtskommentator JoAchim LuCAS STEIN aus der Mitte des 18. Jahrhunderts, gingen diesen eingeschlagenen Weg noch weiter und warfen rückblickend MEviUs vor, er sei auf halbem Wege stehen geblieben und zu mutlos immer noch in den romanistischen Lehren gefangen gewesen. ${ }^{90}$ In prinzipieller Hinsicht handelt es sich hierbei freilich nur um graduelle Abstufungen.

\section{Aktenversendung und Entscheidungsliteratur}

Für die Frage nach frühneuzeitlicher Rechtseinheit sind mehrere andere Perspektiven nützlich, die nicht direkt an die Statutentheorie anknüpfen. Zwei andere Faktoren waren für die Überwindung der Vielfalt im Ergebnis wohl besonders wichtig. Es handelt sich um Aktenversendungen und die sog. Entscheidungsliteratur. Die Aktenversendung, die in ihren letzten Ausläufern bis zum Inkrafttreten der Reichsjustizgesetze gebräuchlich war, ${ }^{91}$ war die typisch frühneuzeitliche Lösung, mit schwierigen Auslegungs- und Rechtsanwendungsfragen umzugehen. Zahlreiche frühneuzeitliche Stadt- und Landgerichte waren nur teilweise professionalisiert und nicht mit studierten Juristen besetzt. Bei allen ernsthaften Rechtsproblemen, auf Antrag der Parteien auch im Rahmen sog. Revisionen oder Läuterungen, schickten die Gerichte ihre vollständigen Akten an den Spruchkörper einer Juristenfakultät und baten dort um ein Urteil. Die Entscheidung konnte in einem bloßen Gutachten oder Vorschlag bestehen. Zumeist aber formulierten die Spruchkollegien den vollständigen Tenor in der Perspektive des anfragenden Gerichts. Das Ausgangsgericht brauchte hinterher dieses Urteil also nur noch zu verlesen. ${ }^{92}$ Zusätzlich arbeitete ein Berichterstatter die

89 Klaus LuIG, Die Anfänge der Wissenschaft vom deutschen Privatrecht, in: ders., Römisches Recht. Naturrecht. Nationales Recht, 1998, S. $222=422^{\star}\left(196-197=396^{\star}-397^{\star}\right)$; DERS., Die Theorie der Gestaltung eines nationalen Privatrechtssystems aus römisch-deutschem Rechtsstoff, in: Helmut Coing/ Walter Wilhelm (Hrsg.), Wissenschaft und Kodifikation des Privatrechts im 19. Jahrhundert (Studien zur Rechtswissenschaft des 19. Jahrhunderts 1), 1974, S. 217-248 (219); STEPHAN BuchHolz, Zum Usus modernus bei David Mevius, in: Nils Jörn (Hrsg.), David Mevius (1609-1670). Leben und Werk eines pommerschen Juristen von europäischem Rang (Schriftenreihe der David-Mevius-Gesellschaft 1), 2007, S. 71-80; zu Mevius’ Methode jetzt auch AsTrid Thomsch, David Mevius und der (Prozess-)Vergleich im Usus modernus pandectarum. Eine Analyse von Gerichtsordnung, Decisionen und Akten (Schriftenreihe der David-Mevius-Gesellschaft 8), 2014.

90 GöTz LANDwEHR, Rechtspraxis und Rechtswissenschaft im Lübischen Recht vom 16. bis zum 19. Jahrhundert, Zeitschrift des Vereins für Lübeckische Geschichte und Altertumskunde 60 (1980), S. 21-65 (38-54).

91 Peter Oestmann, Art. Aktenversendung, in: Albrecht Cordes/Heiner Lück/Dieter Werkmüller (Hrsg.), HRG, Bd. 1, 2. Aufl. 2008, Sp. 128-132.

92 Versuch einer Typologie bei HEINER LücK, Die Spruchtätigkeit der Wittenberger Juristenfakultät. Organisation - Verfahren - Ausstrahlung, 1998, S. 181-192; etwas anders SöNKE LoRENZ, Aktenver- 
Rationes decidendi, die Entscheidungsgründe, aus und legte sie getrennt der Akte bei. Durch solche Aktenversendungen hatten also regelmäßig universitäre Spruchkörper mit der Lösung von Fällen zu tun, die aus ganz verschiedenen Regionen stammten, in denen durchaus abweichendes Partikularrecht einschlägig sein konnte. Es spricht einiges dafür, dass die Fakultäten gleiche Rechtsfragen auch gleich entschieden, unabhängig davon, woher die jeweiligen Anfragen stammten. Auch diese Form der Rechtsbelehrung könnte daher auf Kosten der partikularen Buntheit gegangen sein, wenngleich Zeitgenossen betonten, zumindest die großen Partikularrechtskreise seien an allen Universitäten bekannt. ${ }^{93}$

Deswegen gab es Gegenbewegungen. In einigen Territorien schrieb der Landesherr vor, dass die Aktenversendungen nicht an eine Juristenfakultät, sondern an eine landeseigene Behörde zu erfolgen hatten. In Württemberg etwa sind solche Anfragen an den landesherrlichen Oberrat gut belegt. ${ }^{94}$ In anderen Territorien gründeten die Herrscher eigene Universitäten und verfolgten damit zugleich den Zweck, die Aktenversendungen an ausländische Fakultäten zu verbieten. ${ }^{95}$ Dazu passt es, wenn einige Juristenfakultäten die anfragenden Gerichte geradezu einluden, ihre besonderen Rechte einzusenden, damit man sie bei der Rechtsanwendung künftig besser zu Rate ziehen könne. ${ }^{96}$ In den Einzelheiten sind wiederum ganz verschiedene Ausprägungen dieser Maximen denkbar und in den Quellen zu beobachten. Jedenfalls im Ergebnis dürfte die Aktenversendung aber dazu beigetragen haben, trotz der ganz verschiedenen Rechtsquellen einen weithin einheitlichen Rechtsraum zu schaffen.

Ein weiteres wichtiges Element auf dem Weg zur Eindämmung der Rechtsvielfalt war die praktisch ausgerichtete Entscheidungsliteratur des Usus modernus. ${ }^{97}$ Zahl-

sendung und Hexenprozeß. Dargestellt am Beispiel der Juristenfakultäten Rostock und Greifswald (1570/82-1630) (Studia Philosophica et Historica 1/I), 1982, S. 167-168 (Consilium und Rechtsbelehrung), 175-178 (Rechtsbelehrung in Urteilsform), 180 (Konsilien mit Urteilsformen); zum Problem auch CLAUSDIETER SCHOTT, Rat und Spruch der Juristenfakultät Freiburg i.Br. (Beiträge zur Freiburger Wissenschafts- und Universitätsgeschichte 30), 1965, S. 42-47; speziell zur Läuterung PETER OestmanN, Art. Läuterung, in: Albrecht Cordes/Hans-Peter Haferkamp/Heiner Lück/Dieter Werkmüller (Hrsg.), HRG, 2. Aufl., 19. Lieferung 2014, Sp. 670-673.

$93 \mathrm{Zu}$ diesem Streitpunkt am Beispiel der Juristenfakultät Gießen OestmanN, Rechtsvielfalt vor Gericht (Anm. 2), S. 359, 418-419, 593-594, 597-598.

94 Anita Raith, Hexenprozesse beim württembergischen Oberrat, in: Sönke Lorenz/Dieter R. Bauer (Hrsg.), Hexenverfolgung. Beiträge zur Forschung - unter besonderer Berücksichtigung des südwestdeutschen Raumes (Quellen und Forschungen zur europäischen Ethnologie 15), 1995, S. 101-121.

95 Wilhelm Ebel, Memorabilia Gottingensia. Elf Studien zur Sozialgeschichte der Universität, 1969, S. 53; STEFAn ANDREAS Stodolkowitz, Das Oberappellationsgericht Celle und seine Rechtsprechung im 18. Jahrhundert (Quellen und Forschungen zur höchsten Gerichtsbarkeit im Alten Reich 59), 2011, S. 152-153.

96 FERDINAND FRENSDORFF, Das Wiedererstehen des deutschen Rechts. Zum hundertjährigen Jubiläum von K. F. Eichhorns Rechtsgeschichte, ZRG GA 29 (1908), S. 1-78 (45) mit Hinweis auf Halle 1730; OESTMAnN, Rechtsvielfalt vor Gericht (Anm. 2), S. 596.

97 Sehr guter Überblick bei HEINRICH GeHRKE, Die privatrechtliche Entscheidungsliteratur Deutschlands. Charakteristik und Bibliografie der Rechtsprechungs- und Konsiliensammlungen vom 16. bis 
reiche Professoren, aber auch Richterpersönlichkeiten an Obergerichten bis hin zum Reichskammergericht und dem Reichshofrat, verfassten Werke, die unmittelbar auf ihrer praktischen Tätigkeit beruhten. Teilweise veröffentlichten sie schlechthin ihre Relationen und Voten zu den Fällen, die sie entschieden hatten. Häufig schrieben sie aber auch Nebenstunden oder Observationen und zeigten exemplarisch, wie man Einzelprobleme lösen sollte. Dann verwiesen sie regelmäßig auf spezielle Rechtsfälle, die ihr Gericht in genau derselben Weise entschieden hatte. Manche dieser Autoren zitierten einen Urteilstenor, manche gaben die Namen der Parteien oder das Datum eines Urteils an, andere begnügten sich mit dem Hinweis, dass die von ihnen geschilderte Lösung dem Stilus curiae ihres Gerichts entspreche. Einige Werke dieser Gattung wurden hochberühmt. Eines der bekanntesten Beispiele ist die Observationensammlung von ANDREAS GAIL, die zwischen 1578 und 1771 in etwa dreißig Auflagen in verschiedenen europäischen Staaten wieder und wieder gedruckt wurde. ${ }^{98}$ In seinen kleinen Falllösungen schilderte GAIL immer auch die Rechtsprechung des Reichskammergerichts, dem er für elf Jahre angehört hatte. Je nachdem, welche Autorität diese praktisch ausgerichtete Entscheidungsliteratur des Usus modernus erlangte, beeinflusste und prägte sie die Rechtsauslegung und -anwendung ihrer Zeit in erheblichem Ausmaß. Nach Hermann ConRING sollen die gedruckten Entscheidungen des Reichskammergerichts geradezu gesetzesgleiche Kraft besessen haben. ${ }^{99}$ Die Vermischung ganz verschiedener regionaler Rechtstraditionen mit den Lehren des universalen Rechts wurde nach und nach auf diese Weise zum Vorbild auch für die untere und mittlere Gerichtsbarkeit. In Zweifelsfällen zitierten Anwälte und Gerichtsmitglieder solche hochangesehenen Werke und kamen daher bei streitigen Fragen überregional oftmals zu denselben Ergebnissen. Da diese Entscheidungsliteratur bis ins 18. Jahrhundert weitgehend in lateinischer Sprache geschrieben wurde, war der Rechtsraum, den die Bücher auf diese Weise absteckten, weder durch Sprach- noch Landesgrenzen umzäunt. ${ }^{100}$ Noch der Göttinger Staatsrechtler JoHANN STEPHAN PÜTTER meinte 1776, selbst in seiner Zeit würden kaum praktische juristische Werke von Gewicht erscheinen, die sich nicht auf GAIL und seinen älteren Vorläufer JoACHIM MYNSINGER bezögen. ${ }^{101}$ Freilich hatten alle diese Vereinheitlichungstendenzen ihre Grenzen: Immer dann, wenn die Existenz und der Inhalt des partikularen Rechts

zum Beginn des 19. Jahrhunderts (Ius Commue. Sonderheft 3), 1974.

98 Zu GaIl: KaRL von Kempis, Andreas Gaill (1526-1587). Zum Leben und Werk eines Juristen der frühen Neuzeit (Rechtshistorische Reihe 65), 1988; zusätzlich mehrere Beiträge von KARIN NEHLSENVON STRYK, Rechtsnorm und Rechtspraxis in Mittelalter und früher Neuzeit. Ausgewählte Aufsätze (Schriften zur Rechtsgeschichte 158), 2012, S. 289-328.

99 Hermann ConRING, Der Ursprung des deutschen Rechts, übersetzt von Ilse HofFMANN-MECKENSTOCK, hrsg. von Michael Stolleis (Bibliothek des deutschen Staatsdenkens 3), 1994, S. 229-230. CoNRING bezieht dies auf die Sammlung von ADRIAN GYLMANN.

100 Überblick über die in einem Rechtsstreit des 18. Jahrhunderts zitierte Literatur bei OESTMANN, Zivilprozeß (Anm. 75), S. 585-595.

101 Johann Stephan PÜTter, Litteratur des Teutschen Staatsrechts I, 1776, S. 128. 
unstreitig feststanden, musste jedes Gericht diese Quellen berücksichtigen, dies aber teilweise nur dann, wenn die Parteien sich ausdrücklich darauf berufen hatten. Diese Form von Rechtsvielfalt gab es während der frühen Neuzeit immer. Sie ließ sich schlechthin nicht überwinden. Doch innerhalb des großräumigen europäischen Ius Commune bereitete diese Form von Vielfalt keine Verständigungsprobleme. ${ }^{102}$

\section{Einheit und Vielfalt im Strafrecht}

Sowohl die frühneuzeitliche Rechtsvielfalt als auch die Statutentheorie werden in der rechtshistorischen Literatur immer im Rahmen der Privatrechtsgeschichte diskutiert. Doch darf dies das Bild nicht verzerren. Prinzipiell ähnliche Probleme gab es im frühneuzeitlichen Strafrecht ebenfalls, wenn auch nicht in derselben praktischen Schärfe. ${ }^{103}$ Im Gegensatz zu den weitaus meisten Bereichen des Privatrechts waren das zeitgenössische Strafrecht sowie das Strafprozessrecht von einer einzigen geschriebenen Rechtsquelle beherrscht, nämlich von der Constitutio Criminalis Carolina. Die Carolina, 1532 auf dem Regensburger Reichstag verabschiedet, enthielt in ihrer Vorrede die berühmt gewordene salvatorische Klausel: ${ }^{104}$

daß alle vnd jede vnser vnnd des Reichs vnderthanen sich hinfürter in peinlichen sachen, inn bedenckung der groß und ferligkeyt der selben, jetzt angezeygten begriff, dem gemeynen rechten, billicheyt vnd löblichen herbrachten gebreuchen gemeß halten mögen, wie eyn jeglicher on zweifel für sich selbst zu thun geneygt, vnd deßhalben von dem Almechtigen belonung zu empfahen verhofft. Doch wollen wir durch diese gnedige erinnerung Churfürsten Fürsten und Stenden, an jren alten wohlhergebrachten rechtmessigen vnnd billichen gebreuchen nichts benommen haben. ${ }^{105}$

Bekanntlich war die Carolina keine Kodifikation, ${ }^{106}$ allerdings eines der wichtigsten Reichsgesetze der frühen Neuzeit. ${ }^{107}$ Sie ließ den Rückgriff auf die Lehren des römisch-kanonischen Strafrechts und Prozessrechts ausdrücklich $\mathrm{zu}$ und verwies

102 CoIng (Anm. 1), S. 7; zu den bleibenden Gemeinsamkeiten der Rechtswissenschaft MANLIO BELLOMO, Europäische Rechtseinheit. Grundlagen und System des Ius Commune, übersetzt von ELLEN DiLCHER, 2005, S. 230-231.

103 Guter Hinweis bei Schröder (Anm. 79), S. 22.

104 Wolfgang Sellert, Art. Salvatorische Klausel, in: Adalbert Erler/Ekkehard Kaufmann (Hrsg.), HRG, Bd. 4, 1990, Sp. 1208-1282.

105 Friedrich-Christian Schroeder (Hrsg.), Die Peinliche Gerichtsordnung Kaiser Karls V. und des Heiligen Römischen Reichs von 1532 (Carolina), 2000, Vorrede, S. 10.

106 Grob falsch Friedrich Ebel/Georg Thielmann, Rechtsgeschichte. Von der Römischen Antike bis zur Neuzeit, 3. Aufl. 2003, S. 294, Rn. 436; SuSANnE HÄHNCHEN, Rechtsgeschichte. Von der Römischen Antike bis zur Neuzeit, 4. Aufl. 2012, S. 278, Rn. 596, jeweils mit dem unangebrachten Hinweis auf den angeblichen Grundsatz nulla poena sine lege.

107 Anders Gerhard Schmidt, Sinn und Bedeutung der Constitutio Criminalis Carolina als Ordnung des materiellen und prozessualen Rechts, in: Friedrich-Christian Schroeder (Hrsg.), Die Caroli- 
etwa auf unbenannte Delikte, ${ }^{108}$ die zwar nicht im Gesetz enthalten, aber dennoch strafwürdig seien. Deswegen konnte sie auch keine bedingungslose Normgeltung für sich selbst beanspruchen. In der Vorrede, formuliert aus der Perspektive Kaiser KaRLS V., verwies das Reichsgesetz seinerseits auf das gemeine Recht, die Billigkeit und das Herkommen. Auch sollten die partikularen Gebräuche keine Einschränkung erfahren. Politisch ging dieser letzte Satz aus einem Ringen zwischen Kaiser und Reichsständen hervor. Die Stände bzw. ihre Gesandten waren nur bereit, dem Regensburger Reichsabschied zuzustimmen, wenn das Gesetz ihnen diesen Vorbehalt ausdrücklich einräumte. ${ }^{109}$ Doch inhaltlich bestätigte die salvatorische Klausel lediglich die Rechtsquellenhierarchie des gemeinen Rechts. Selbstverständlich hatten die rechtmäßigen territorialen Gebräuche jederzeit Vorrang vor dem gesetzten Reichsrecht. Genauso sah es die erste Stufe der Statutentheorie vor. Die Inhaltskontrolle des Partikularrechts entsprach zwanglos der sog. Rationabilität von Statutar- und Gewohnheitsrecht, wie sie das zeitgenössische Privatrecht ebenfalls diskutierte. In einem besonderen Artikel zählte die Carolina ausdrücklich mehrere Missbräuche auf und erklärte sie daraufhin für nichtig und abgeschafft. ${ }^{110}$

In der Tat gab es unterschiedliche Strafgesetze im Heiligen Römischen Reich, und in Einzelfragen wichen sie auch durchaus von der Carolina ab. ${ }^{111}$ Gut erforscht ist dies am Beispiel des Hexereidelikts. Die Carolina lehnte sich weithin dem überkommenen römischen Modell des Schadenszaubers an. Die sächsische Tradition unterschied sich seit dem Sachsenspiegel deutlich davon und stellte vielmehr auf den Glaubensabfall ab. Dementsprechend drohten die Kursächsischen Konstitutionen von 1572 die Verbrennungsstrafe für Zauberei bereits zwingend für den bloßen Teufelspakt an und maßen dem Schadenszauber keine entscheidende Bedeutung zu. Das war in den Augen der Carolina keine böse Gewohnheit, sondern einfach ein anderes Deliktsverständnis. Im frühneuzeitlichen Strafrecht bestand über lange Zeit beides nebeneinander her. ${ }^{112}$

na. Die Peinliche Gerichtsordnung Kaiser Karls V. von 1532 (Wege der Forschung 626), 1986, S. 185-204 (199-203), der sich am zu modernen Gesetzesbegriff stört.

108 Wolfgang Sellert/HinRICh RÜPING, Studien- und Quellenbuch zur Geschichte der deutschen Strafrechtspflege, Bd. 1: Von den Anfängen bis zur Aufklärung, von WolfGANG SELLERT, 1989, S. 201 mit Quellen S. 211-212.

109 Klassisch ist die Darstellung bei EBERHARD SCHMidT, Einführung in die Geschichte der deutschen Strafrechtspflege, 3. Aufl. 1965, S. 131-132, § 115.

110 CCC Art. 218, bei SCHroeder (Anm. 105), S. 125-126.

111 Hinweise bei G. Schmidt (Anm. 107), S. 196-199.

112 Zur Spiritualisierung des Hexereidelikts MANFred WiLde, Die Zauberei- und Hexenprozesse in Kursachsen, 2003, S. 28-34; GüNTER Jerouschek, Die Hexen und ihr Prozeß. Die Hexenverfolgung in der Reichsstadt Esslingen (Esslinger Studien. Schriftenreihe 11), 1992, S. 39-40; PETER OestmanN, Hexenprozesse am Reichskammergericht (Quellen und Forschungen zur höchsten Gerichtsbarkeit im Alten Reich 31), 1997, S. 35-36; kurzer Hinweis auf die kursächsischen Konstitutionen auch bei G. Schmidt (Anm. 107), S. 199; HINRICH RÜPING/GüNTER JEROUSCHEK, Grundriss der Strafrechtsgeschichte, 6. Aufl. 2011, S. 48, Rn. 112. 
Auch in Tirol setzte sich die Carolina erst zögernd durch. ${ }^{113}$ Dennoch spielte die Statutentheorie und damit auch die Rechtsvielfalt im Strafrecht eine vergleichsweise geringe Rolle. Die inhaltliche Qualität der Carolina, ihre sprachliche Raffinesse und Genauigkeit, sicherlich auch ihre weitgehende Anlehnung an die Lehren der spätmittelalterlichen italienischen Kriminalwissenschaft verschafften dem Reichsgesetz einen bemerkenswerten Erfolg. Ohne dass sie in allen Territorien förmlich in Kraft gesetzt wurde, orientierten sich sowohl die Gerichte als auch die langsam entstehende deutsche Strafrechtswissenschaft weithin an der Halsgerichtsordnung. ${ }^{114}$ Selbst Territorien, die eigenes strafrechtliches Landesrecht setzten wie etwa Schaumburg-Lippe mit einer Policeyordnung von 1615, lehnten sich hierbei weitgehend an die Vorgaben der Carolina an, wenn auch teilweise auf Anordnung des Reichskammergerichts. ${ }^{115}$

Bezogen auf die Fragestellung nach Rechtsvielfalt und Rechtseinheit hat man es also mit einem frühen und gelungenen Beispiel dafür zu tun, wie qualitativ hochwertige Gesetzgebung rechtsvereinheitlichende Wirkung erzielt, ohne dass dies gesetzlich oder sonstwie erzwungen werden musste, wenn auch mit einer gewissen zeitlichen Verzögerung. Die inhaltliche Geltung der Carolina ging ohnehin schnell über die Grenzen des Heiligen Römischen Reichs hinaus. In Polen erschien eine polnische Übersetzung und erfreute sich dort hohen Ansehens. ${ }^{116}$ Und eine französische Fassung der Halsgerichtsordnung diente noch im 18. Jahrhundert als Militärstrafgesetzbuch für schweizerische Söldner in Frankreich. ${ }^{117}$ Die Autorität der Carolina als

113 Martin P. Schennach, Gesetz und Herrschaft. Die Entstehung des Gesetzgebungsstaates am Beispiel Tirols (Forschungen zur Deutschen Rechtsgeschichte 28), 2010, S. 756-758.

114 Beispiele für die Wirkung der Carolina bei E. Schmidt (Anm. 109), S. 142-143, § 124; S. 150-157, $\S \S 134-142$.

115 GÜNTER JeRouscheK, Der „Nürnberger Hexenhammer“. Der „Malleus Maleficarum“ und seine deutschsprachige Bearbeitung durch den Verfasser Heinrich Kramer O. P. aus dem Jahre 1491, Diss. hist.-phil. Hannover 1988, S. 57, Fn. 90; GERHARD SCHORMAnN, Hexenverfolgung in Schaumburg, Niedersächsisches Jahrbuch für Landesgeschichte 45 (1973), S. 145-169 (146-147); OEstmanN, Hexenprozesse (Anm. 112), S. 197.

116 BartŁomiej Groicki, Ten Postępek wybran iest z Praw Cesarskich, ktory Karolus V. Cesarz kazał wydać po wszystkich swoich Państwiech, 1587 (Übersetzung wohl von 1559); zur europäischen Verbreitung Rolf Lieberwirth, Art. Constitutio Criminalis Carolina, in: Albrecht Cordes/Heiner Lück/ Dieter Werkmüller (Hrsg.), HRG, Bd. 1, 2. Aufl. 2008, Sp. 885-890 (889); JoHN H. LANGBEIN, The Constitutio Criminalis Carolina in Comparative Perspective: An Anglo-American View, in: Peter Landau/ Friedrich-Christian Schroeder (Hsg.), Strafrecht, Strafprozeß und Rezeption. Grundlagen, Entwicklung und Wirkung der Constitutio Criminalis Carolina (Juristische Abhandlungen 19), 1984, S. 215-225 (215); ZBIGNIEW MACIĄK, Probleme bei der Übersetzung von Rechtsakten und rechtswissenschaftlicher Literatur aus der deutschen in die polnische Sprache, in: Armin Paul Frank/Kurt-Jürgen Maaß/ Fritz Paul/Horst Turk (Hrsg.), Übersetzen, verstehen, Brücken bauen. Geisteswissenschaftliches und literarisches Übersetzen im internationalen Kulturaustausch (Göttinger Beiträge zur Internationalen Übersetzungsforschung 8/I), 1993, S. $321-334$ (323); LOTHAR DARGUN, Die Reception der peinlichen Halsgerichtsordnung Kaiser Karls V. in Polen, ZRG GA 10 (1889) S. 168-202.

117 Code Criminel De l'Empereur Charles V. Vulgairement Appellé La Caroline. Contenant Les Loix Qui Sont Suivies Dans Les Jurisdictions Criminelles De l'Empire; Et à l'usage des Conseils de Guerre 
Richtschnur für Strafprozesse haben die zeitgenössischen Gerichte immer wieder hervorgehoben. In der Rechtsprechung des Reichskammergerichts finden sich zahlreiche Hinweise darauf, dass der Inquisitionsprozess genau so stattzufinden hatte, wie die Carolina ihn darstellte. Das betraf die Haftbedingungen, die Verteidigung des Inquisiten und vor allem die gesetzlich geforderten Indizien für die peinliche Befragung, also für die Folter. ${ }^{118}$

\section{Die Policeygesetzgebung}

Schwer zu durchschauen ist ein anderer Bereich, nämlich das frühneuzeitliche Policeyrecht. Hier hat man es mit dem Schwerpunkt der zeitgenössischen Gesetzgebung schlechthin zu tun. Nahezu alle Territorien traten als Policeygesetzgeber hervor, zumeist ergingen im Laufe der Zeit Abertausende einzelner, teilweise kleinteiligster Regelungen. ${ }^{119}$ In den vergangenen Jahren gab es umfassende Forschungen zu zahlreichen Aspekten dieser ungeheuren Normenflut. ${ }^{120}$ Bezogen auf die hier zugrunde gelegte Begrifflichkeit hat man es beim frühneuzeitlichen Policeyrecht allerdings weniger mit Rechtsvielfalt, sondern vielmehr mit Rechtszersplitterung zu tun. Die immer gleichen Regelungsprobleme gaben von Stadt zu Stadt, von Territorium zu Territorium Anlass zu jeweils verschiedenen Arten von Gesetzgebung. Auch wenn einige große Linien immer dieselben waren, etwa das Verbot von übermäßigem Luxus, ${ }^{121}$ gestalteten die einzelnen Gesetzgeber die Feinheiten doch stets verschieden aus. Die territorialen Policeyordnungen überlagerten sich also nicht gegenseitig, sondern standen eher nebeneinander. Oftmals musste der Herrscher sie wiederholen

des Troupes Suisses, 1734 (Nachdruck 1779); stark von der Carolina beeinflusst war auch DANIEL Jousse, Traité de la justice criminelle de France, 4 Bände, 1771.

118 Umfassend OEstmann, Hexenprozesse (Anm. 112), S. 144-323.

119 Sehr guter Überblick über die Quellenlage bei KaRL HÄRTER/MichaEl STOLLEIS (Hrsg.), Repertorium der Policeyordnungen der frühen Neuzeit, seit 1996, zuletzt erschien 2010 der Band zu den Reichsstädten Speyer, Wetzlar und Worms.

120 Maßgeblich sind unter anderem die Arbeiten von KARL HÄRTER, Policey und Strafjustiz in Kurmainz. Gesetzgebung, Normdurchsetzung und Sozialkontrolle im frühneuzeitlichen Territorialstaat (Studien zur europäischen Rechtsgeschichte 190), 2 Halbbände, 2005; außerdem etwa AcHim LANDWEHR, Policey im Alltag. Die Implementation frühneuzeitlicher Policeyordnungen in Leonberg, 2000; ANDRÉ Holenstein, „Gute Policey“ und lokale Gesellschaft im Staat des Ancien Régime. Das Fallbeispiel der Markgrafschaft Baden(-Durlach) (Frühneuzeit-Forschungen 9/I-II), 2 Bände, 2003; WoLFGANG WÜST, Die „gute“ Policey im Reichskreis. Zur frühmodernen Normensetzung in den Kernregionen des Alten Reiches, 2001-2013 (Edition mit vielen Einführungsteilen, inzwischen sechs Bände).

121 Klassisch insoweit Gustav Klemens Schmelzeisen, Polizeiordnungen und Privatrecht (Forschungen zur neueren Privatrechtsgeschichte 3), 1955; außerdem ANKE KeLLER, Von verbotenen Feierfreuden. Hochzeits-, Tauf- und Begräbnisverordnungen im Frankfurt a.M. und Augsburg des 14. bis 16. Jahrhunderts (Heidelberger Veröffentlichungen zur Landesgeschichte und Landeskunde 17), 2012; BENNo KöNIG, Luxusverbote im Fürstbistum Münster, 1999. 
und bei immer höheren Strafdrohungen seinen Untertanen einschärfen. ${ }^{122}$ Doch die bloße Neuverkündung policeyrechtlicher Vorschriften führte keine Rechtsvielfalt im Fahrwasser. Falls die Ordnungen wie nur allzu oft wirkungslos verpufften, ${ }^{123}$ war das kaum etwas anderes als die auf die Spitze getriebene Usualinterpretation. Eine Policeyverordnung, die ihre Regelungsziele von Beginn an klar verfehlte, erlangte nie die von den Zeitgenossen geforderte viridis observantia, die für die Geltung von Rechtsnormen nötig war. ${ }^{124}$ Freilich ergaben sich hier vielfache Abstufungen auf dem Weg zum modernen Gesetzgebungsstaat.

Entschärft war die policeyliche Rechtsvielfalt im Vergleich zu den klassischen Bereichen des Zivilrechts und des Prozessrechts auch aus einem anderen Grund. Nach weithin verbreiteter Auffassung bestand in Policeyangelegenheiten nämlich ein strenges Appellationsverbot. ${ }^{125}$ Teilweise besagten Appellationsprivilegien dies ausdrücklich, doch überwiegend handelte es sich dabei um die Ansicht der zeitgenössischen Rechtsgelehrten. Rein tatsächlich gelangten viele Policeysachen durchaus an die obersten Gerichte des Alten Reiches, etwa im Bereich des Zunftrechts. ${ }^{126}$ Aber bezogen auf die tausendfach erlassenen Vorschriften handelte es sich hierbei nur um ganz schmale Ausschnitte aus einem riesigen Bereich des Rechtslebens.

Das territoriale Nebeneinander policeyrechtlicher Regelungen wurde in einigen Bereichen ergänzt durch die Gesetzgebung auf Reichsebene. ${ }^{127}$ Es gab mehrere

$122 \mathrm{Zu}$ zahlreichen Wiederholungen im Fürstbistum Münster KöNIG (Anm. 121), S. 69-119.

123 Zum Befund Jürgen Schlumвонм, Gesetze, die nicht durchgesetzt werden - ein Strukturmerkmal des frühneuzeitlichen Staates?, Geschichte und Gesellschaft 23 (1997), S. 647-663; neuere Interpretation aus Sicht der sog. Implementationsforschung bei ACHIM LANDWEHR, „Normdurchsetzung“ in der Frühen Neuzeit? Kritik eines Begriffs, Zeitschrift für Geschichtswissenschaft 48 (2000), S. 146162; gegen ihn wiederum SIGRID SCHIEBER, Normdurchsetzung im frühneuzeitlichen Wetzlar, 2008, S. 1-11; grundsätzlich zum Problem auch MichaEL STOLLEIS, Was bedeutet „Normdurchsetzung“ bei Policeyordnungen der Frühen Neuzeit?, in: Richard H. Helmholz/Paul Mikat/Jörg Müller/Michael Stolleis (Hrsg.), Grundlagen des Rechts. Festschrift für Peter Landau zum 65. Geburtstag (Rechts- und Staatswissenschaftliche Veröffentlichungen der Görres-Gesellschaft 91), 2000, S. 739-757.

124 Beispiel bei Schennach (Anm. 113), S. 605.

125 Etwas doppeldeutig blieb § 106 des Jüngsten Reichsabschiedes, bei: BuschmanN (Anm. 67), S. 227; OESTMANN, Rechtsvielfalt vor Gericht (Anm. 2), S. 449-450, 644-646; RITA SAILER, Untertanenprozesse vor dem Reichskammergericht. Rechtsschutz gegen die Obrigkeit in der zweiten Hälfte des 18. Jahrhunderts (Quellen und Forschungen zur höchsten Gerichtsbarkeit im Alten Reich 33), 1999, S. 426-466, 476-478; KARL HÄRTER, Das Reichskammergericht als Reichspoliceygericht, in: Friedrich Battenberg/Filippo Ranieri (Hrsg.), Geschichte der Zentraljustiz in Mitteleuropa. Festschrift für Bernhard Diestelkamp zum 65. Geburtstag, 1994, S. 237-252.

126 BeRnhARD DiestelKamp, Zunftprozesse des 18. Jahrhunderts aus der Reichsstadt Wetzlar vor dem Reichskammergericht, in: ders., Recht und Gericht im Heiligen Römischen Reich (Ius Commune. Sonderheft 122), 1999, S. 349-373; Peter Oestmann, Zunftzwang und Handelsfreiheit im frühen 19. Jahrhundert, ZNR 26 (2004), S. 246-261; PHILIPP NoRDLOH, Kölner Zunftprozesse vor dem Reichskammergericht (Rechtshistorische Reihe 370), 2008.

127 Gerhard Wesenberg, Die Privatrechtsgesetzgebung des Heiligen Römischen Reiches von den Authenticae bis zum Jüngsten Reichsabschied und das Römische Recht, in: L'Europa e il diritto romano. Studi in memoria di Paolo Koschaker, 1954, Bd. 1, S. 187-210; BeRnHARD Diestelkamp, Zur Krise 
Reichspoliceyordnungen, ${ }^{128}$ etwa zum Handwerksrecht oder auch in Vormundschaftssachen. Einige dieser Reichsgesetzgebungen hatten im Gegensatz zu der Vielzahl sonstiger Policeyordnungen durchschlagenden Erfolg. Besondere Beachtung verdienen in diesem Zusammenhang die drei großen Reichspoliceyordnungen von 1530, 1548 und 1577. ${ }^{129}$ Im Vormundschaftsrecht, so verkündet einmütig die rechtshistorische Literatur, spielte das römischrechtliche Vorbild kaum eine Rolle, ja in den Augen der Zeitgenossen seien die römischen Vormundschaftsregeln völlig unanwendbar gewesen. Deshalb müsse den reichsrechtlichen Regelungen, aber auch den territorialen Normen hohe Bedeutung zugekommen sein. ${ }^{130}$ Der Erfolg der Reichspoliceyordnungen jedenfalls im Bereich der normativen Quellen lässt sich in der Tat gut nachzeichnen. Da die Reichsgesetzgebung ohnehin auf einem Kompromiss der Stände beruhte, war der Widerstand, die Ordnungen direkt zu übernehmen oder der Sache nach die eigene Gesetzgebung an ihnen auszurichten, gering. In BrandenburgAnsbach führte Markgraf GEORG FRIEDRICH 1566 eine eigene Policeyordnung ein und berief sich dabei auf die Ermächtigung durch die Reichspoliceyordnung. ${ }^{131}$ Im Fränkischen Reichskreis zeigt sich derselbe Befund, ja selbst einzelne Städte wie Worms lehnten ihre eigene Normsetzung 1582 an die Reichsgesetze an. ${ }^{132}$ Das Vormundschaftsrecht, das die Reichspoliceyordnungen bewusst abweichend vom römischen Recht vergleichsweise engmaschig geregelt hatten, prägte auf diese Weise der Sache nach die territorialen Normen. Etwas ungenau spricht Weber davon, die Reichsgesetze hätten insoweit „rechtsbildend“ gewirkt, seien aber zugleich als subsidiäres Recht auch unmittelbar anwendbar geblieben, und dies weithin bis zum Inkrafttreten des Bürgerlichen Gesetzbuchs im Jahre 1900. ${ }^{133}$

des Reichsrechts im 16. Jahrhundert, in: ders., Recht und Gericht im Heiligen Römischen Reich, 1999, S. 481-502 (494); guter Überblick bei Gerhard WeSEnBERg/GunTER WeSEnER, Neuere deutsche Privatrechtsgeschichte im Rahmen der europäischen Rechtsentwicklung, 4. Aufl. 1985, S. 88-91.

128 Vollständige Übersicht bei HÄRTER/STOLLEIS (Anm. 119), Bd. 1: Deutsches Reich und geistliche Kurfürstentümer (Kurmainz, Kurköln, Kurtrier), hrsg. von Karl Härter, 1996, S. 37-106.

129 Edition und Einführung von Matthias WebER (Hrsg.), Die Reichspolizeiordnungen von 1530, 1548 und 1577. Historische Einführung und Edition (Ius Commune. Sonderheft 146), 2002.

130 Wesenberg/Wesener (Anm. 127), S. 133; FranZ-Josef Pelz, Die Vormundschaft in den Stadtund Landrechtsreformationen des 15. und 16. Jahrhunderts und das zeitgenössische gemeine Recht, Diss. jur. Münster 1966, z.B. S. 44, 127-129; unergiebig in diesem Zusammenhang ist ADALBERT ERLER, Art. Vormundschaft, in: Adalbert Erler/Ekkehard Kaufmann/Dieter Werkmüller (Hrsg.), HRG, Bd. 5, 1998, Sp. 1050-1055; zeitlich zu spät liegt die Untersuchung von MIRJAM HeIDER, Die Geschichte der Vormundschaft seit der Aufklärung (Schriften zum Familien- und Erbrecht 4), 2011, unergiebig vor allem S. 17, wo sich zur älteren Zeit nur zusammengestelltes Lehrbuchwissen findet.

131 Weber (Anm. 129), S. 38; SchenNaCh (Anm. 113), S. 755 (mit Quelle).

132 Weber (Anm. 129), S. 39; bei HÄRTER/StOLleis (Anm. 119), Bd. 10: Reichsstädte 4: Speyer, Wetzlar, Worms (Studien zur europäischen Rechtsgeschichte 251), 2010, S. 570 (bearb. von GUNTER MAHLERWEIN) findet sich für 1582 lediglich eine Apothekerordnung. Allerdings gibt es erhebliche Quellenverluste (ebd., S. 559).

133 Weber (Anm. 129), S. 41. 
Freilich ist hier ein einschränkender Hinweis angebracht. Es handelt sich nämlich lediglich um einen normengeschichtlichen Befund. Die weitgehende Harmonisierung des partikularen Policeyrechts und damit die vereinheitlichende Wirkung der Reichspoliceyordnungen etwa im Handwerks- und Vormundschaftsrecht stand auf dem Papier und lag den verschiedenen Gesetzgebungen zugrunde - immerhin. Wie stark sich die Praxis daran orientierte, steht auf einem anderen Blatt. Zur Vorsicht mahnt ein Beispiel aus dem Intestaterbrecht. Drei Reichsabschiede von 1498, 1500 und 1521 beabsichtigten, einheitlich das römischrechtliche Eintrittsrecht der Abkömmlinge in die Erbfolge nach Stämmen einzuführen. Aber genau dies soll sich in der Praxis nur sehr schleppend durchgesetzt haben. ${ }^{134}$ Soweit es den Unterschied von Norm und Praxis in der Zeit des usualen Rechtsdenkens geben konnte, eröffneten sich den Parteien hier vielfältige Möglichkeiten vor Gericht. In diesem Punkt berührt sich das Problem mit den heutigen Diskussionen um Implementation von Normen, Herrschaftsvermittlung, Aushandlungsprozesse, bezogen auf die Gerichtsbarkeit auch um sog. gerichtlichen Zweikampf und Justiznutzung. ${ }^{135}$ Das frühneuzeitliche Recht war längst nicht so stabil und von oben herab vorgegeben, wie die ältere Forschung glaubte. Aber entsprechend schwierig sind zugleich feste Aussagen über Einheit und Vielfalt.

Die Frage nach dem Verhältnis von Rechtszersplitterung, Rechtsvielfalt und Rechtsvereinheitlichung hat es im Bereich des Policeyrechts also mit einem anderen Ausgangspunkt zu tun als im zeitgenössischen Privatrecht oder Strafrecht. Wenn das römisch-kanonische Recht als Referenzquelle ausfiel, stellte sich die Überlagerung von einheimischem und rezipiertem universalem Recht gar nicht erst. Die ordnenden Maximen der gemeinrechtlichen Statutentheorie verloren hier ihren Anknüpfungspunkt. Mochte das Reichsrecht in solchen Fällen durchaus die territorialen oder sogar lokalen Gewohnheiten überlagern, dann löste es kleinräumige Zersplitterung zugunsten von überregionaler Rechtseinheit auf. Verschiedene, sich teilweise

134 Hierzu Coing (Anm. 1), S. 609; Flossmann (Anm. 85), S. 324-327; Christoph Becker, Art. Eintrittsrecht, in: Albrecht Cordes/Heiner Lück/Dieter Werkmüller (Hrsg.), HRG, Bd. 1, 2. Aufl. 2008, Sp. 1305-1306; MARTIN LiPP, Art. Erbfolgeordnung, ebd., Sp. 1361-1365 (1364).

135 Erster Überblick bei Andreas Blauert/Gerd Schwerhoff (Hrsg.), Kriminalitätsgeschichte. Beiträge zur Sozial- und Kulturgeschichte der Vormoderne (Konflikte und Kultur - Historische Perspektiven 1), 2000 (hier vor allem die Beiträge von GERD ScHwERHOFF, Kriminalitätsgeschichte im deutschen Sprachraum. Zum Profil eines „,verspäteten“ Forschungszweiges, S. 21-67 (34-37); MARTIN DINGES, Justiznutzungen als soziale Kontrolle in der Frühen Neuzeit, S. 503-544); außerdem HARRIET RudolPH, „Eine gelinde Regierungsart“. Peinliche Strafjustiz im geistlichen Territorium. Das Hochstift Osnabrück (1716-1803) (Konflikte und Kultur - Historische Perspektiven 5), 2000, S. $19-20$ (mit Fn. 23); 265-327; Christian Wieland, Verstaatlichung und Homogenisierung, Justiznutzung und Privilegierung: Das frühneuzeitliche Rechtssystem als Motor und Hindernis von Staatlichkeit, in: Peter Eich/Sebastian Schmidt-Hofner/Christian Wieland (Hrsg.), Der wiederkehrende Leviathan. Staatlichkeit und Staatswerdung in Spätantike und Früher Neuzeit (Akademiekonferenzen 4), 2011, S. 181-204; Michael STRÖHMER, Jurisdiktionsökonomie im Fürstbistum Paderborn. Institutionen - Ressourcen - Transaktionen (1650-1800) (Westfalen in der Vormoderne 17), 2013, S. 18. 
widersprechende und überlagernde Rechtsschichten waren damit nicht verbunden. Im Gegensatz zum Strafrecht mit der Carolina war es in solchen policeyrechtlichen Fällen nicht nötig, auf die Fortgeltung und subsidiäre Anwendbarkeit des römischkanonischen Rechts zu verweisen. Die kleinteilige Rechtszersplitterung ließ sich also durchaus im Wege der Gesetzgebung überwinden. Rechtsvielfalt dagegen, also die Überlagerung verschiedener Rechtsmassen innerhalb desselben Gebietes, konnte man nicht so einfach vom Tisch wischen. ${ }^{136}$ Das römische Recht ließ sich nicht kurzerhand per Gesetz abschaffen. Punktuell mochten bewusste Abweichungen als Rechtsneuerungen gelingen. Aber die Rezeption in toto bzw. in complexu, wie man zeitgenössisch sagte, stand dabei nicht zur Diskussion. ${ }^{137}$ In Schweden unternahmen die Könige im 17. Jahrhundert und auch das Sveriges Rikes Lag von 1734 den beherzten Anlauf und schrieben vor, die Richter dürften nur nach einheimischem und nicht nach fremdem Recht richten, vor allem auch keine Quellen in fremden Sprachen zitieren. ${ }^{138}$ Eine solche gesetzliche Abschaffung des römisch-kanonischen Rechts wäre im Alten Reich undenkbar gewesen. Lediglich in Bereichen, die wie das Policeyrecht keine römischrechtliche Grundlage hatten, konnte eine gesetzliche Vorgabe die frühneuzeitliche Zersplitterung und Rechtsvielfalt also beseitigen. Auch in Schweden war übrigens die Praxis erheblich vielschichtiger, als der königliche Befehl es vorgesehen hatte. ${ }^{139}$

136 Zu frühen Kodifikationsplänen KLAus LuIG, Die Rolle des deutschen Rechts in Leibniz' Kodifikationsplänen, Ius Commune 5 (1975), S. 56-70; weitere Nachweise bei BERND MERTENS, Gesetzgebungskunst im Zeitalter der Kodifikation. Theorie und Praxis der Gesetzgebungstechnik aus historisch-vergleichender Sicht (Tübinger rechtswissenschaftliche Abhandlungen 98), 2004, S. 421.

137 Wolter (Anm. 43), 150-153; praktische Diskussion im 18. Jahrhundert: Oestmann, Rechtsvielfalt vor Gericht (Anm. 2), S. 245-246; zum öffentlichen Recht MichaEL STOLLEIS, Geschichte des öffentlichen Rechts in Deutschland. Bd. 1: Reichspublizistik und Policeywissenschaft 1600-1800, 1988, S. 58-59; zur Diskussion des 19. Jahrhunderts SCHÄFER (Anm. 61), S. 524-525.

138 Johan Schmedeman, Koningl. Stadgar/Förordningar Bref och Resolutioner Ifrån Åhr 1528. in til 1701. Angående Justitiae Executions-Ährender Med een Förteckning på Stadgarne fråmst/ och ett fulkommelig Orda-Register efterst wid Wercket öfwer thes innehåld, 1706, S. 856-857 (von 1683), 876-877 (1684), 1324 (1692). Ich danke MIA KoRPIOLA für den Hinweis auf diese Quellen; zum Reichsgesetzbuch LARS BJÖRNE, Das Gesetzbuch von 1734 und die finnische Privatrechtswissenschaft im 19. Jahrhundert, in: Wolfgang Wagner (Hrsg.), Das schwedische Reichsgesetzbuch (Sveriges Rikes Lag) von 1734. Beiträge zur Entstehungs- und Entwicklungsgeschichte einer vollständigen Kodifikation (Ius Commune. Sonderhefte 29), 1986, S. 163-184 (182). Ein älteres Verbot an die Parteien, weitläufige Hinweise auf fremde Rechte zu geben (Rättegångs-Proceß 1615 § 25, bei: ScHMEDEMAN, ebd., S. 159) ähnelt eher den zeitgenössisch üblichen Allegationsverboten und war wohl gegen die Weitschweifigkeit der Anwälte gerichtet.

139 Zur Diskussion: STIG JÄGERSKiöLD, Studier rörande receptionen av främmande rätt i Sverige under den yngre landslagens tid, 1963; Mia Korpiola, On the Reception of the Jus Commune and Foreign Law in Sweden, ca. 1550-1615, Clio@Themis. Revue électronique d'histoire du droit 2 (2009), http://cliothemis.com/On-the-Reception-of-the-Jus (besucht am 01.03.2014); HeIKкI PinLAJAmäKI, "Stick to the Swedish law": The Use of Foreign Law in Early Modern Sweden and Nineteenth-Century Finland, in: Serge Dauchy/W. Hamilton Bryson/Matthew C. Mirow (Hrsg.), Ratio decidendi. Guiding Principles of Judicial Decisions. Volume 2: ‘Foreign’ Law, 2010, S. 169-185. 


\section{Rangordnung von Rechtsquellen und Rechtsanwendung im 19. Jahrhundert}

Das Ende des Alten Reiches beseitigte zwar die beiden obersten Reichsgerichte sowie die förmliche Geltung ehemaliger Reichsgesetze. ${ }^{140}$ Die überkommene Rechtsvielfalt bestand aber fort. Und auch das römisch-kanonische Recht, das man lange Zeit als „des Reichs gemeine Rechte“ bezeichnet hatte, behielt seinen Geltungsrang, obwohl es dieses Reich nun gar nicht mehr gab. ${ }^{141}$ Weiterhin überlappten sich also innerhalb der Gerichtssprengel ganz unterschiedliche Rechtsmassen. Daher sind aus dem 19. Jahrhundert in den Gerichtsordnungen weiterhin Listen anwendbarer Rechtsmassen bekannt, die im Wesentlichen der gemeinrechtlichen Statutenlehre folgten.

\section{Ein Beispiel vom Oberappellationsgericht Lübeck}

Eines der angesehensten deutschen Gerichte im 19. Jahrhundert war das Oberappellationsgericht der vier freien Städte Deutschlands mit Sitz in Lübeck. In seiner Gerichtsordnung von 1831 hieß es:

Das Ober-Appellationsgericht hat bei seinen Erkenntnissen in Civil- und Criminalsachen die in den Freien Städten geltenden Particular-Gesetze und rechtlichen Gewohnheiten, und in deren Entstehung das in den Städten recipirte gemeine Recht, mit Inbegriff der in denselben vor Auflösung der ehemaligen deutschen Reichsverfassung aufgenommenen Reichsgesetze, anzuwenden. Die in jeder Stadt erscheinenden Verordnungen werden dem Gerichte mitgetheilt. ${ }^{142}$

140 Zur Auswirkung des Jahres 1806 auf Reichsrecht und Reichsgerichtsbarkeit BERNHARD DIESTELKAMP (Hrsg.), Das Reichskammergericht am Ende des Alten Reiches und sein Fortwirken im 19. Jahrhundert (Quellen und Forschungen zur höchsten Gerichtsbarkeit im Alten Reich 41), 2002; ERICH-OLIVER MADER, Die letzten „Priester der Gerechtigkeit“. Die Auseinandersetzungen der letzten Generation von Richtern des Reichskammergerichts mit der Auflösung des Heiligen Römischen Reiches Deutscher Nation (Colloquia Augustana 20), 2005; Georg Schmidt-von RHEIn/Albrecht CoRdes (Hrsg.), Altes Reich und neues Recht. Von den Anfängen der bürgerlichen Freiheit, 2006; HANS-PETER HAFERKAMP, Fortwirkungen des Kameralprozesses im gemeinen Zivilprozess des 19. Jahrhunderts, in: Peter Oestmann (Hrsg.), Zwischen Formstrenge und Billigkeit. Forschungen zum vormodernen Zivilprozeß (Quellen und Forschungen zur höchsten Gerichtsbarkeit im Alten Reich 56), 2009, S. 293-310.

141 Überblick bei Klaus LuIG, Art. Gemeines Recht, in: Albrecht Cordes/Heiner Lück/Dieter Werkmüller (Hrsg.), HRG, Bd. 2, 2. Aufl. 2012, Sp. 60-77 (71-76); zu Puchta HANS-PETER HAFERKAMP, Georg Friedrich Puchta und die „Begriffsjurisprudenz“ (Studien zur europäischen Rechtsgeschichte 171), 2004; zur Methode SAVIGnys JoACHim RüCKERT, Savignys Dogmatik im „System“, in: Andreas Heldrich/Jürgen Prölss/Ingo Koller (Hrsg.), Festschrift für Claus-Wilhelm Canaris zum 70. Geburtstag, 2007, Bd. 2, S. 1263-1297.

142 FriEdRICH Bluhme (Hrsg.), Gerichtsordnung für das Oberappellationsgericht der vier Freien Städte Deutschlands, 1843, S. 50; ebenfalls bei KATALIN PoLGAR, Das Oberappellationsgericht der vier freien Städte Deutschlands (1820-1879) und seine Richterpersönlichkeiten (Rechtshistorische Reihe 330), 2007, S. 287. 
Nach dieser Vorschrift galt vor dem Oberappellationsgericht Lübeck in erster Linie das Partikularrecht der vier Städte Frankfurt, Hamburg, Bremen und Lübeck. Bei Lücken sollten die Gerichtsmitglieder auf das gemeine Recht zurückgreifen. Eingeschlossen in den Begriff des gemeinen Rechts waren hier ausdrücklich auch die ehemaligen Reichsgesetze. Von dem früheren Beweis- oder Allegationserfordernis war inzwischen schon längst keine Rede mehr. Die Richter des Oberappellationsgerichts mussten diejenigen städtischen Gesetze anwenden, die einschlägig waren. Die provisorische Gerichtsordnung von 1820, die der endgültigen Fassung vorausgegangen war, hatte ausdrücklich zwischen Gesetzen und Verordnungen unterschieden und vorgeschrieben, dass die Städte dem Gericht ihre gedruckten Gesetzessammlungen zur Verfügung stellten. ${ }^{143}$ Das war inzwischen geschehen, und daher beschränkte sich die endgültige Gerichtsordnung lediglich auf die noch weiterhin verkündeten zukünftigen Verordnungen. Das Stadtrecht jeder der dem Gericht verbundenen Städte unterschied sich also teilweise erheblich voneinander. Das Frankfurter Recht mit seinen stark romanistischen Stadtrechtsreformationen von 1578 und 1611 stand dem Lübecker Recht mit der eher traditionellen Rechtsaufzeichnung von 1586 gegenüber. Insofern gab es Rechtszersplitterung innerhalb des höchstgerichtlichen Jurisdiktionssprengels. Daraus erwuchsen aber keine Probleme, weil die Gerichtsmitglieder die jeweiligen städtischen Rechtsquellen kannten. Das Nebeneinander von städtischem Recht und gemeinem Recht war dagegen die aus der älteren Zeit geerbte Quellenvielfalt selbst innerhalb jeder einzelnen Stadt. ${ }^{144}$

Beim Blick auf die praktische Tätigkeit des Lübecker Oberappellationsgerichts zeigt sich ein erstaunlicher Befund. Die überkommene Mehrschichtigkeit der Rechtsmassen wird in den Entscheidungsgründen des Gerichts sowie in den vorgelagerten Relationen der Gerichtsmitglieder oftmals gar nicht greifbar. Das Gericht grenzte sehr häufig nicht die Geltungsansprüche und Regelungsinhalte von städtischem und gemeinem Recht gegeneinander $\mathrm{ab}$, sondern bemühte sich ganz eigenständig um verallgemeinerbare Lösungen der aufgeworfenen Rechtsprobleme. Auf diese Weise trug die Entscheidungspraxis des Gerichts erheblich zur Rechtsvereinheitlichung bei, auch wenn sich an der materiellen Gesetzeslage nichts änderte und die Gerichtsordnung eine ganz traditionelle Rechtsanwendungsklausel bereithielt. ${ }^{145}$ Ein längeres Zitat aus einem Urteil von 1822 zeigt das anschaulich.

143 Wortlaut der provisorischen Gerichtsordnung bei Bluhme (Anm. 142), S. 50, Fn. c).

144 Umfassend zum Umgang mit der Quellenvielfalt, auch mit Beispielen aus der Praxis, NorA TIRTASANA, Der gelehrte Gerichtshof. Das Oberappellationsgericht Lübeck und die Praxis des Zivilprozesses im 19. Jahrhundert (Forschungen zur Neueren Privatrechtsgeschichte 33), 2012, S. 126-167.

145 Peter Oestmann, Seehandelsrechtliche Streitigkeiten vor dem Oberappellationsgericht der vier freien Städte Deutschlands (1820-1848), in: Albrecht Cordes/Serge Dauchy (Hrsg.), Eine Grenze in Bewegung. Öffentliche und private Justiz im Handels- und Seerecht (Schriften des Historischen Kollegs. Kolloquien 81), 2013, S. 221-264. 
Allein an und für sich hat jeder Staat doch nur für die Aufrechthaltung seiner Gesetze zu sorgen, und wenn er auch auf die benachbarten Staaten Rücksicht nimmt, so beruht das doch blos auf einer völkerrechtlichen Observanz [...]. Jene durch freundschaftliche Verhältniße der Staaten gebildete Observanz besteht aber nur für die Uebertretung solcher Gesetze, welche wider allgemein unerlaubt geachtete Handlungen gerichtet sind (de Vattel le droit des gens Liv.2 Ch. 6 $\S 76)$. Wenn aber ein Staat durch seine Verbote und Strafgesetze gerade darauf ausgeht, die eigenen Unterthanen auf Kosten der Ausländer zu begünstigen und letztere zu beeinträchtigen; so gebietet auch das Völkerrecht nicht, daß der fremde Staat zur Realisirung solcher feindseligen Maaßregeln selbst die Hand biete, und es seinen Unterthanen zum Verbrechen anrechne, wenn sie dieselben zu umgehen suchen. In diese Classe von Verordnungen gehören aber die Einfuhrs- und Ausfuhrs-Verbote und Zollgesetze, wodurch die Staaten den Producten anderer Länder und fremden Kunstfleißes den Zugang verwehren, oder doch wenigstens schwerer machen, die eigenen Producte aber den Auswärtigen nicht zu Gute kommen laßen wollen; und es läßt sich, besonders bey dem neuerdings von manchen Regierungen in der Hinsicht befolgten System nicht erkennen, wie Estrangin in einer Note zu Pothier traité du contrat d'assurance a Paris 1810 pag 91 sehr wahr sagt, ,que ces Systèmes de défenses d'importation ou d'exportation de la part d'un gouvernement, ne faient le plus souvent une espèce de guerre déclaree aux besoins, à l'industrie, aux débouchés des productions d'une autre nation.' Daraus folgt dann aber auch, daß der Staat und dessen Gerichte keine rechtliche Veranlaßung haben, die von ihren Untergebenen vorgenommenen Contraventionen gegen fremde Zollgesetze und Handelsverbote als Illegalitäten zu behandeln. Mit diesen aus der Natur der Sache entspringenden Grundsätzen harmonirt denn auch völlig die jetzige Europäische Völkerpraxis, die es [...] den eigenen Unterthanen nicht verbietet, Unternehmungen gegen fremde Zoll-Gesetze und Handels-Verbote zu machen, oder das Risico solcher Geschäfte zu übernehmen (Emerigon traité des assurances T. 1. Ch. 8. Sect. 5. pag 210 sqq; Estrangin l. c. pag 89-93; Parck on marine assurances Tom. 2 pag. 390; Lacobson im Handbuche über das practische Seerecht der Engländer und Franzosen B. 2. S. 77-79; vergl. die Hamburg. Assec. und Havarey-Ordn. Tit. 4 Art. 10).

Dagegen [...] bleibt ein solcher Handel mit Contrabande stets ein gefährlicher Handel, weil so weit der Contrabandier von den Behörden des fremden Staates, dessen Gesetzen er zuwider handelt, erreicht werden kann, er die von diesen angedrohten Strafen zu fürchten hat. Insofern nun diese Nachtheile auch den bloßen Ueberbringer der unfreien Waare [...] treffen können, nimt die Contrabande auch in Beziehung auf ihn eine gefährliche Eigenschaft an, und da nun bey zweiseitigen Verträgen jeder Contrahent verpflichtet ist, den Mitcontrahenten von den bey dem Vertrage in Betracht kommenden physischen und juristischen Mängeln und von solchen Eigenschaften derselben in Kenntniß zu setzen, welche dem eigenen Vermögen oder gar der eigenen Person des Mitcontrahenten Gefahr dohen; so ist es auch die contractliche Pflicht dessen, der Contrabande nach einem fremden Lande verladet, den Schiffer oder Fuhrmann davon wenigstens dann in Kenntiß zu setzen, wenn im Entdeckungsfall nicht blos die Confiscation der Güter, sondern auch die des Schiffes, des Wagens und der Pferde, und wohl gar noch andere Strafen für den [...] Ueberbringer zu befürchten stehen. Der Ablader, der dieses versäumt, muß daher dem Schiffer für den Schaden aufkommen, den dieser durch die ohne sein Wissen verladenen Contrabande im fremden Lande erleidet. [...]

Allein es widerstreitet aller Rechtsanalogie, daß der Empfänger einer Sache sich nach deren Eigenschaften erkundigen soll; es ist vielmehr an dem, der sie hingiebt und ihre Mängel und Fehler kennt, oder doch kennen sollte, den Empfänger darauf aufmerksam zu machen; und das trifft bey dem Frachtcontracte um so mehr zu, weil der Befrachter nach demselben verpflichtet ist, keine verbotenen Waaren einzuladen, die den unwissenden Schiffer in Gefahr bringen können (s. Abbot law of Merchants Ships p. 280). [...] einestheils ist der Spediteur allerdings verpflichtet, sich um die rechtliche Möglichkeit der Einfuhr, so wie von den Mitteln der Weiterbeförderung [...] 
in Kenntniß zu setzen; und anderntheils kommt es hier gar nicht darauf an, ob die Beklagten im vorliegenden Falle Spediteure waren oder nicht, da sie mit dem Schiffer nicht auf dem Namen ihrer Committenten, sondern auf ihrem eigenen die Fracht-contracte abgeschlossen, sich also - selbst wenn sie ihm im Allgemeinen gesagt haben sollten, daß dieses Speditionsgüter seyen - demselben, der die wahren Eigenthümer nicht kannte, also nur gemeint seyn konnte, sich an die Beklagten zu halten, persönlich als die Befrachter verpflichtet haben (l. 13. C. si certum petatur). ${ }^{146}$

Der längere Quellenauszug stammt aus einem Rechtsstreit, in dem es um Schadensersatzansprüche nach einem gescheiterten Schmuggeleiversuch ging. ${ }^{147} \mathrm{Zu}$ klären war die Frage, ob ein ausländisches Einfuhrverbot inländische Händler binden sollte, und vor allem, wie die Risikoverteilung in gegenseitigen Verträgen beschaffen war. Die aufgeworfenen Fragen löste das Gericht souverän und griff dabei auf zahlreiche internationale Rechtsquellen zurück, aber auch auf andere Maximen. GEORG ARNOLD HEISE, der erste Präsident des Gerichtshofes, stützte seine Erwägungen gern auf die Natur der Sache, ${ }^{148}$ und genau dieses Argument tauchte in den Entscheidungsgründen von 1822 ebenfalls auf. Hinter solchen Überlegungen verblasste der Gegensatz von regionalem und universalem Recht und verlor seine entscheidende Bedeutung für die Falllösung. In den Entscheidungsgründen des Gerichts fallen zahlreiche Hinweise auf Rechtsquellen und Literatur auf, die aus dem vorgegebenen Korsett der traditionellen Rechtsanwendungslehre herausbrachen. So fand das Gericht offenbar nichts dabei, in dem zitierten Fall aus Lübeck auch Hamburger Gesetze heranzuziehen, um allgemeine Prinzipien herausarbeiten zu können. Auch lehnten sich die Gerichtsmitglieder bei ihren Erwägungen oftmals an französische oder englische Literatur an. Der Quellenauszug ist insofern kein Einzelfall. Es mag sich hierbei um Besonderheiten des Handelsrechts gehandelt haben, doch genau für seine Vorreiterrolle im Handels-

146 Archiv der Hansestadt Lübeck OAG L I 22 a, Aktenstück Q 19 (Auszug); zu dem umfangreichen Rechtsstreit, aus dem die Quelle stammt, plane ich die Edition der kompletten Prozessakte.

147 Vorstudien zum Sachverhalt und zu den Entscheidungsgründen: PETER OESTMANN, Ein Schmuggeleiprozeß vor dem Oberappellationsgericht der vier freien Städte Deutschlands, Zeitschrift für Lübeckische Geschichte 91 (2011), S. 199-216; DERS., The unification of law via the institution of jurisdiction in the 19th century: Commercial law before the High Court of Appeal of the four free cities of Germany, Juridica international. Law Review University of Tartu, Estonia 16 (2009), S. 224-230.

148 CHRISTOPH BERGFELD, Handelsrechtliche Entscheidungen des Oberappellationsgerichts der vier freien Städte Deutschlands, in: Karl Otto Scherner (Hrsg.), Modernisierung des Handelsrechts im 19. Jahrhundert (Abhandlungen aus dem gesamten Bürgerlichen Recht, Handelsrecht und Wirtschaftsrecht 66), 1993, S. 81; KirSTen Kraglund, Familien- und Erbrecht. Materielles Recht und Methoden der Rechtsanwendung in der Rechtsprechung des Oberappellationsgerichts der vier Freien Städte Deutschlands zu Lübeck (Rechtshistorische Reihe 93), 1991, S. 136-141; JoHn KARL-HeInz MonTAG, Die Lehrdarstellung des Handelsrechts von Georg Friedrich von Martens bis Meno Pöhls. Die Wissenschaft des Handelsrechts im ersten Drittel des 19. Jahrhunderts (Rechtshistorische Reihe 48), 1986, S. 98-108; Oestmann, Seehandelsrechtliche Streitigkeiten (Anm. 145), S. 248; TiRTASANa (Anm. 144), S. $158-160$. 
recht war das Lübecker Tribunal bereits bei seinen Zeitgenossen hoch angesehen. ${ }^{149}$ Geradezu freischwebend, also nur ganz locker an bindende gesetzliche Vorgaben angelehnt, entwickelte das Oberappellationsgericht seine Rechtsauffassungen und war damit im Ergebnis in hohem Maße rechtsschöpferisch und rechtsfortbildend tätig. Im Ergebnis trug die Rechtsprechung des Lübecker Gerichts erheblich zur Vereinheitlichung, ja überhaupt zur Herausbildung eines übergreifend deutschen Handelsrechts bei. Die formal weiterbestehende und gesetzlich festgeklopfte Rechtsvielfalt war damit in der Praxis weithin beseitigt. Der kurze Hinweis auf das römische Recht am Ende der abgedruckten Quellenstelle erweckt in keiner Weise den Eindruck, als habe das römisch-gemeine Recht für die Urteilsbegründung eine höhere Autorität besessen als die zeitgenössische internationale Literatur oder die Natur der Sache. Dies muss nicht einmal zu Rechtsunsicherheit geführt haben, wenn das Gericht bei seiner Urteilstätigkeit konsequent die eigenen Wege weiterging. In der Tat zitierten die späteren Entscheidungsgründe häufig aus den Erwägungen zu älteren Fällen und trugen auf diese Weise zur Herausbildung einer ständigen Rechtsprechung bei. ${ }^{150}$

Gerade angesichts der Skepsis, mit der die Historische Rechtsschule den Kodifikationsbestrebungen gegenüberstand, kam der Rechtsprechung eine besondere Bedeutung für die Modernisierung und Vereinheitlichung des Rechts zu. In dieselbe Richtung zielten auch zahlreiche rechtswissenschaftliche Werke des 19. Jahrhunderts. In dem Maße, wie die Wissenschaft faktisch zu einer der wichtigsten Rechtsquellen wurde, verloren die Gegensätze zwischen einheimischem, territorialem und überregional-gemeinem Recht ebenfalls ihre trennende Bedeutung. Das gemeine deutsche Recht, das heutige römische Recht, ${ }^{151}$ das deutsche Privatrecht waren allesamt Umschreibungen, die teils als Buchtitel bereits das Programm andeuteten. In historisch-vergleichend-kritischer Durchdringung versuchte auch die Wissenschaft, ein einheitliches Recht herauszubilden, ohne dass es dafür neue gesetzliche Grundlagen geben musste. Vor allem die verbreiteten Pandektenlehrbücher dürften hier eine Vorreiterrolle gespielt haben. ${ }^{152}$ Dennoch darf man dieZersplitterung nicht übersehen,

149 Heinrich Thöl, Das Handelsrecht, Bd. 1, 1. Aufl. 1841, Vorrede; Rudolf von JHering, Agathon Wunderlich. Ein Nachruf, [Jherings] Jahrbücher für die Dogmatik des heutigen römischen und deutschen Privatrechts 17 (1879), S. 145-157.

150 TirTasana (Anm. 144), S. 154-158.

151 Aufstellung zur Berücksichtigung von Partikularrecht im „System“ von Savigny bei STEN GAGNÉR, Die Wissenschaft des gemeinen Rechts und der Codex Maximilianeus Bavaricus Civlis, in: ders., Abhandlungen zur europäischen Rechtsgeschichte (Bibliotheca Eruditorum 29), 2004, S. 213-346 (331).

152 Den Abschluss der Epoche bildete das verbreitete Werk von BERNHARD WINDSCHEID, Lehrbuch des Pandektenrechts, 3 Bände 1862-1870, 9. Aufl. von THEODOR KIPP 1906; zu ihm umfassend UlRICH FALK, Ein Gelehrter wie Windscheid. Erkundungen auf den Feldern der sogenannten Begriffsjurisprudenz (Ius Commune. Schriftenreihe 38), 1989, der aber auf S. 219-220 stark auf die richterliche Freiheit und Einzelfallgerechtigkeit abstellt, die WinDschEID ebenfalls eröffnete. 
die vielfach fortbestand. ${ }^{153}$ Literatur zum Partikularrecht gab es im 19. Jahrhundert weiterhin bis hin zu Kommentaren zu partikularen Gesetzen und zu Universitätsvorlesungen zum Landesrecht. Auch die größeren Handbücher zum Deutschen Privatrecht waren bemüht, die landesrechtlichen oder partikularen Besonderheiten mit ihren Verästelungen quellengenau nachzuweisen. ${ }^{154}$ Die vereinheitlichende Wirkung von Rechtsprechung und Lehre stieß also an ihre Grenzen.

\section{Der Bismarck-Fall des Reichsgerichts}

Einen letzten Blick auf die Buntscheckigkeit des Rechts warf das berühmte Bismarck-Urteil des Reichsgerichts vom Dezember 1899. ${ }^{155}$ Als der ehemalige Reichskanzler ОTTO von BISMARCK gestorben war, drangen zwei Hamburger Fotografen in BISMARCKS Wohnhaus in Friedrichsruh ein und machten mehrere Aufnahmen von der Leiche. Die Familie des Verstorbenen klagte nun gegen die wirtschaftliche Vermarktung dieser unerwünschten Fotoaufnahmen. Das Reichsgericht bejahte im Ergebnis den Anspruch der Hinterbliebenen. Materiellrechtlich ist die Entscheidung in Erinnerung geblieben, weil das Gericht dort wichtige Grundlagen legte für das Recht am eigenen Bild als Ausprägung des allgemeinen Persönlichkeitsrechts. In unserem Zusammenhang ist es aber höchst aufschlussreich, wie das Reichsgericht seine moderne und zukunftsweisende Entscheidung herleitete. Das Urteil, verkündet am 28. Dezember 1899, also vier Tage vor dem Inkrafttreten des Bürgerlichen Gesetzbuchs, beruht vollständig auf der gemeinrechtlichen Rechtsquellenhierarchie, wie sie aus dem Mittelalter bereits bekannt war.

In der Sache selbst konnten, was zunächst die örtliche Bestimmung des maßgebenden Rechtes betrifft, nur das in Hamburg und das in Friedrichsruh geltende Recht in Frage kommen. Da nun weder die Hamburger Statuten, noch der im preußischen Kreise Herzogtum Lauenburg geltende Sachsenspiegel, noch sonst ein hierher gehöriges Partikulargesetz hier einschlagende Normen enthalten, so ist, abgesehen von etwa eingreifenden Reichsgesetzen, jedenfalls nur das gemeine deutsche Recht zur Anwendung zu bringen. (...) Von diesem Standpunkte aus (.... ${ }^{156}$ würde das angefochtene Urteil jedenfalls aus den folgenden Gründen aufrecht zu halten sein.

153 Am Beipsiel des Prozessrechts zeigt sich etwa, welch geringen Einfluss der gemeine Zivilprozess in der Rechtspraxis des 19. Jahrhunderts besaß, dazu HAFERKAMP (Anm. 140).

154 Wichtige Beispiele sind Wilhelm Theodor Kraut/Ferndinand FrensdorfF, Grundriß zu Vorlesungen über das Deutsche Privatrecht mit Einschluß des Lehn- und Handelsrechts nebst beigefügten Quellen, 6. Aufl. 1886; Отто Sтовве, Handbuch des deutschen Privatrechts, 2. Aufl. 1882/85.

155 Dazu ist umfassende Literatur vorhanden, z.B. Rudolf STAMmLER, Deutsches Rechtsleben in alter und neuer Zeit. Lehrreiche Rechtsfälle gesammelt und bearbeitet. Bd. 2: Deutsches Rechtsleben während des 19. Jahrhunderts, 1932, S. 425-438 (dort auch mit den im Urteil nicht genannten Personennamen); OEstManN, Rechtsvielfalt (Anm. 4), S. 122-123; THORSTEN SÜss, Die Bismarck-Entscheidung des Reichsgerichts (aus heutiger Sicht). Oder: Rechtsfindung am Vorabend des BGB, JURA 33 (2011), S. 610-616.

156 Auslassungen auch in der amtlichen Entscheidungssammlung. 
Es ist mit dem natürlichen Rechtsgefühl unvereinbar, daß jemand das unangefochten behalte, was er durch eine widerrechtliche Handlung erlangt und dem durch dieselbe in seinen Rechten Verletzten entzogen hat. Hier nun handelt es sich darum, daß die beiden Beklagten mittels eines Hausfriedensbruches gegen den Willen der Kläger in dasjenige Zimmer eingedrungen sind, in welchem diese die Leiche ihres Vaters, die sie in ihrem Gewahrsam hatten (vgl. §§ 168.367 Nr. 1 St.G.B.), aufbewahrten, und damit das Hausrecht, das den Klägern seit dem Tode ihres Vaters in Ansehung dieses Zimmers zustand, verletzt und diese Gelegenheit benutzt haben, um eine photographische Aufnahme eines Teiles des Innern des Zimmers mit der darin ruhenden Leiche herzustellen. Solche photographische Aufnahme eines umfriedeten Raumes und folgeweise deren Veröffentlichung zu hindern hat der Inhaber des Hausrechtes an sich das Recht und die Macht, und diese Möglichkeit haben hier die Beklagten durch ihr rechtwidriges Thun den Klägern zunächst entzogen, indem sie gleichzeitig für sich die thatsächliche Verfügung über das in Frage stehende photographische Bild erlangt haben. Die Kläger haben den Beklagten gegenüber ein Recht darauf, daß dieses Ergebnis wieder rückgängig gemacht werde. Das römische Recht gewährt in I. 6. Dig. de cond. ob. turp. c. 12, 5 [D. 12,5,6] und I. 6 § 5. I. 25 Dig. de act. rer. am. 25, 2 [D. 25,2,6.5] dem durch eine rechtswidrige Handlung Verletzten eine condictio ob injustam causam auf Wiedererstattung alles desjenigen, was thatsächlich durch jene Handlung aus seinem Machtbereiche in die Gewalt des Thäters gelangt ist. Diese condictio ob injustam causam stellt sich dar als ein ergänzender Rechtsbehelf neben allen Deliktklagen, so weit es sich nicht etwa um Schadensersatz, sondern um Restitution handelt. Dabei ist freilich zunächst nur an körperliche Sachen, die aus dem Vermögen des Beeinträchtigten herrühren, gedacht, sei es, daß das Eigentumsrecht an den Sachen, oder daß wenigstens der Besitz als durch widerrechtliche Entziehung verletzt erscheint (vgl. in der letzteren Beziehung I.2.Dig. de cond. trit. 13.3 [D. 13,3,2]; I.25 § 1 Dig. de furt. 47,2 [D. 47,2,25,1]). Aber dies muß entsprechende Anwendung finden auf die widerrechtliche thatsächliche Entziehung anderer Machtbefugnisse und Aneignung der entsprechenden Vorteile. ${ }^{157}$

Das Reichsgericht ging genau, wie es der überkommenen Lehre entsprach, vom kleinräumigsten Recht aus und prüfte zunächst das Ortsrecht von Friedrichsruh und dann das Hamburger Stadtrecht aus dem frühen 17. Jahrhundert. Da die Richter dort keine Antworten auf die aufgeworfenen Rechtsfragen fanden, zogen sie auf der nächsten Stufe den Sachsenspiegel heran. Auch dort blieb ihre Suche allerdings erfolglos. Deswegen griffen sie auf das gemeine deutsche Recht zurück. Terminologisch zeigt sich abermals, wie flexibel sich das Konzept eines gemeinen Rechts in der Praxis einsetzen ließ. Denn die wesentlichen Argumente, die aus der Gesamtschau des gemeinen deutschen Rechts folgen sollten, beruhten auf dem natürlichen Rechtsgefühl und auf dem römischen Recht. Inhaltlich war das gemeine deutsche Recht damit ganz anders gefüllt als etwa bei den frühen germanistischen Rechtsantiquaren im 18. Jahrhundert. Diese materiellen Verschiebungen innerhalb des gemeinen Rechts ändern aber nichts am prinzipiellen Ergebnis. Das gemeine Recht stand weiterhin als subsidiäres Recht bereit, wenn die vorrangig zu berücksichtigenden lokalen und regi-

157 RGZ 45, S. 170-174; Karl Kroeschell, Deutsche Rechtsgeschichte. Bd. 3: Seit 1650, 5. Aufl. 2008, S. 184-185 (mit Auflösung der Corpus-Iuris-Zitate), S. 175 (dort aber nur als Beispiel für die „pandektistische Begriffssprache"). 
onalen Rechte keine Lösungen für die Rechtsfragen bereithielten. Die Rechtsvielfalt innerhalb kleinräumigster Gebiete war weiterhin eine Selbstverständlichkeit, ein praktisches Problem, das sich jederzeit stellen konnte. ${ }^{158}$ Und der Vorrang des speziellen vor dem allgemeineren Recht blieb bis 1899 ein für die Praxis unerlässliches Ordnungskriterium. Die Verantwortung für die Rechtsermittlung lag inzwischen beim Gericht. \& 293 ZPO, der seit 1879 im Deutschen Reich galt, regelte ausdrücklich die Behandlung von Gewohnheitsrecht und Statuten. Sie durften weiterhin Gegenstand der Beweisführung sein, wenn sie dem Gericht unbekannt waren. ${ }^{159}$ Immer dann, wenn das Gericht solche Rechte kannte, musste es diese Normen von Amts wegen anwenden. Das schloss die Pflicht ein, von Amts wegen den Inhalt solcher Quellen zu ermitteln. Doch wenn die Richter an ihre Grenzen stießen, konnten sie die Parteien zur Mitwirkung heranziehen.

Dieses späte Beispiel vom Dezember 1899 schließt gleichsam die vielhundertjährige Epoche der Rechtsvielfalt im deutschsprachigen Raum ab. Die Überlagerung von Rechtsschichten aus ganz unterschiedlichen Entstehungszusammenhängen gehörte zum Alltag der Rechtsquellenlehre ebenso wie der gerichtlichen Rechtsanwendung. Nicht nur das räumliche Nebeneinander voneinander abweichender Regelungen, hier als Rechtszersplitterung bezeichnet, sondern auch der gleichzeitige Geltungsanspruch mehrerer Rechtsmassen innerhalb desselben Gebietes, hier Rechtsvielfalt genannt, war bis zum Ende des 19. Jahrhunderts die tägliche Erfahrung des Rechtslebens. Vor diesem Hintergrund erscheint die Zäsurwirkung der Kodifikationsbewegung genauso einschneidend, wie sie tatsächlich auch gewesen ist.

\section{Rechtszersplitterung und Rechtsvielfalt im Kodifikationszeitalter}

Die überkommene Vielschichtigkeit des europäischen gemeinen Rechts endete mit dem Kodifikationszeitalter. Die großräumige Rechtsvereinheitlichung auf gesetzlicher Grundlage und damit die Abschaffung von Rechtsvielfalt durch den Staat stellt eines der historisch wichtigsten Ergebnisse der Kodifikationen dar. Unabhängig von der Veränderung des materiellen Rechts bedeutete die Abschaffung der älteren Rechtsquellenlehre durch das verbindliche staatliche Gesetzbuch eine ganz wesent-

$158 \mathrm{Zu}$ diesem Problemkreis MARTin LöHNig, Rechtsvereinheitlichung trotz Rechtsbindung. Zur Rechtsprechung des Reichsgerichts in Zivilsachen 1879-1899, 2012.

159 Zur Situation im 19. Jahrhundert Peter Oestmann, Der Beweis von Rechtsnormen im Zivilprozess - § 293 ZPO im Spiegel der wissenschaftlichen Diskussion des 19. Jahrhunderts, in: Jost Hausmann/Thomas Krause (Hrsg.), „Zur Erhaltung guter Ordnung“. Beiträge zur Geschichte von Recht und Justiz. Festschrift für Wolfgang Sellert zum 65. Geburtstag, 2000, S. 467-512 (508-510). 
liche Veränderung des gesamten Rechtsverständnisses. ${ }^{160}$ Vom Bismarck-Fall von 1899 ist an dieser Stelle ein Rückblick erforderlich. Das BGB, das zum 1. Januar 1900 in Kraft trat, war zwar die erste gesamtdeutsche Kodifikation des Zivilrechts. Aber Kodifikationen sind seit dem 18. Jahrhundert bekannt, und ihre Antworten auf den Umgang mit Rechtsvielfalt waren durchaus verschieden. Terminologisch spricht man von Kodifikationen immer dann, wenn ein staatliches Gesetz ein gesamtes Rechtsgebiet umfassend und abschließend regelt. In der Gegenwart wird diese Begriffsbildung brüchig, weil zunehmend nichtstaatliche und halboffizielle kodifikationsähnliche Rechtssetzungen das staatliche Recht überlagern. ${ }^{161}$ Das ist aber eine Strömung, die erst in den letzten Jahrzehnten einsetzte. Für das klassische Kodifikationszeitalter ist die übliche Definition vollkommen ausreichend.

\section{1 Ältere Kodifikationen}

Gerade im Umgang mit der gewachsenen Rechtsvielfalt zeigen sich deutliche Unterschiede zwischen den älteren und den neueren Kodifikationen. Nach traditioneller Auffassung standen die sog. bayerischen Kodifikationen des Naturrechtszeitalters am Beginn der Kodifikationsbewegung im deutschsprachigen Raum. ${ }^{162}$ In drei großen Gesetzgebungen regelte Bayern unter seinem Kanzler KREITTMAYR das Strafrecht mit dem Strafprozessrecht, das materielle Privatrecht sowie das Zivilprozessrecht. Der Codex Maximilianeus Bavaricus Civilis, das privatrechtliche Gesetzgebungswerk mit einigen öffentlichrechtlichen Inhalten, verstand sich aber keineswegs als exklusiv und ausschließlich geltendes Gesetzbuch. Fortgeltendes Partikularrecht war ausdrücklich anerkannt, und die Subsidiarität des gemeinen Rechts wurde keineswegs abgeschafft. Das Gesetz verwies vielmehr mehrfach auf das römische Recht und zitierte sogar lateinische Versatzstücke aus dem römischen Recht. ${ }^{163}$ Obwohl es

160 Dazu eindringend Pio CARONI, Gesetz und Gesetzbuch. Beiträge zu einer Kodifikationsgeschichte, 2003, S. 50-53 und öfter; sehr ideologisch aufgeladen dagegen PAOLO GROSsI, Das Recht in der europäischen Geschichte, 2010, S. 136: anmaßende Haltung des Gesetzgebers gegenüber der Geschichte; wissenschaftsgeschichtlicher Überblick zur rechtshistorischen Beurteilung von Kodifikationen bei Inge Kroppenberg, Art. Kodifikation, in: Albrecht Cordes/Heiner Lück/Dieter Werkmüller (Hrsg.), HRG, Bd. 2, 2. Aufl. 2012, Sp. 1918-1930 (1920-1926).

161 Nils Jansen/Ralf Michaels (Hrsg.), Beyond the State. Rethinking Private Law, 2008; Jansen (Anm. 37); zur Europäisierung und der damit verbundenen Entstaatlichung FILIPPO RANIERI, Europäisches Obligationenrecht. Ein Handbuch mit Texten und Materialien, 3. Aufl. 2009, S. 100-118.

162 Überblick bei BARbara DölEmeyer, Art. Bayerische Kodifikationen des Naturrechtszeitalters, in: Albrecht Cordes/Heiner Lück/Dieter Werkmüller (Hrsg.), HRG, Bd. 1, 2. Aufl. 2008, Sp. 478-480.

163 Gerhard Immel, Typologie der Gesetzgebung des Privatrechts und Prozessrechts, in: Helmut Coing (Hrsg.), Handbuch der Quellen und Literatur der neueren europäischen Privatrechtsgeschichte. Bd. 2: Neuere Zeit (1500-1800). Das Zeitalter des gemeinen Rechts. Teilbd. 2: Gesetzgebung und Rechtsprechung, 1976, S. 3-96 (64); Peter PöPPERL, Quellen und System des Codex Maximilianeus Bavaricus Civilis, Diss. jur. Würzburg 1967, S. 32, 74-80; allgemeiner mit Blick auf KREITTMAYR: GAG- 
damit umfangreiche landesrechtliche Gesetzgebungen gab, beseitigten sie weder die Rechtszersplitterung noch die Rechtsvielfalt. ${ }^{164}$

Etwas anders stellt sich die Lage beim preußischen Allgemeinen Landrecht von 1794 dar. Die umfassende Gesetzgebung mit mehr als 19.000 Paragraphen versammelte öffentliches Recht, Strafrecht, bürgerliches Recht und zahlreiche andere Rechtsgebiete. ${ }^{165}$ Das römisch-gemeine Recht sollte neben dem Landrecht nicht weiterbestehen und verlor damit nach der Absicht der Gesetzgebung seine Bedeutung als subsidiäre universale Rechtsquelle. Untergesetzliche und regional begrenzte Rechte waren nach dem Allgemeinen Landrecht aber weiterhin anerkannt.

Besondre Provinzialverordnungen, und Statuten einzelner Gemeinheiten und Gesellschaften erhalten nur durch die Landesherrliche Bestätigung die Kraft der Gesetze. Gewohnheitsrechte und Observanzen, welche in den Provinzen und einzelnen Gemeinheiten gesetzliche Kraft haben sollen, müssen den Provinzial-Gesetzbüchern einverleibt seyn. [...] Statuten und Provinzialgesetze werden durch neuere allgemeine Gesetze nicht aufgehoben, wenn nicht in letztern die Aufhebung der erstern deutlich verordnet ist. ${ }^{166}$

Im Gegensatz zum bayerischen Landesrecht zeigt sich eine erheblich stärkere Staatsbezogenheit der gesamten Rechtsquellenlehre. Regionale Vielfalt blieb möglich, war aber von der staatlichen Anerkennung abhängig. Die grundsätzlich vorgesehenen Provinzialgesetzbücher spielten in der preußischen Praxis aber nur eine äußerst untergeordnete Rolle. Es gab Entwürfe und Versuche, das Provinzialrecht in Westpreußen, Ostpreußen und Schlesien auf diese Weise zu sammeln und gesetzlich in Kraft zu setzen. ${ }^{167}$ Doch kamen die meisten derartigen Angänge im Laufe der Zeit

NÉR (Anm. 151), S. 218-222; ebenso auch für das Prozessrecht im Codex Juris Bavarici Judiciarii JoHANN Christoph SchwarTz, Vierhundert Jahre deutscher Zivilprozeß-Gesetzgebung. Darstellungen und Studien zur deutschen Rechtsgeschichte, Nachdruck 1986 der Ausgabe 1898, S. 254, mit Hinweis auf den Publikationserlass; neueste Untersuchung zu den bayerischen Kodifikationen wohl bei KARL Philipp Zimmermann, Die Monita zum Entwurf des Codex Maximilianeus Bavaricus Civilis (Rheinische Schriften zur Rechtsgeschichte 6), 2008, S. 30-32, 85 (Kritik an der lateinischen Sprache).

164 Unter ganz anderen Rahmenbedingungen galt das römische Recht subsidiär auch im Baltikum weiter, nachdem in der Mitte des 19. Jahrhunderts das Privatrecht kodifiziert war, dazu Hesi SiImeTsGross, Das „Liv-, Est- und Curländische Privatrecht“ (1864/65) und das römische Recht im Baltikum (Dissertationes Iuridicae Universitatis Tartuensis 33), 2011; DIES., Legitimation oder Auslegung? Die römischrechtlichen Quellenverweise vom Baltischen Privatrecht in den Riga'schen Stadtgerichtsentscheidungen, Beiträge zur Rechtsgeschichte Österreichs 2/2013, S. 544-551.

165 Leicht zugänglich ist die Edition von HANs HaTtEnHAUER (Hrsg.), Allgemeines Landrecht für die Preußischen Staaten von 1794, 3. Aufl. 1996 (erstmals 1970); Überblick bei JöRN ECKERT, Art. Allgemeines Landrecht (Preußen), in: Albrecht Cordes/Heiner Lück/Dieter Werkmüller (Hrsg.), HRG, Bd. 1, 2. Aufl. 2008, Sp. 155-162.

166 ALR Einleitung §§ 2, 3, 61, bei: HATtenhaueR (Anm. 165), S. 57, 59.

167 Zeitgenössische Dokumentation: Auszug aus dem historischen Theile des von dem vormal. Kammergerichts-Assessor, jetzigen Regierungs-Rath, KRAUSE an das Königl. Ministerium der Gesetzgebung erstatteten Berichts über die Provinzial-Gesetzgebung, Jahrbücher für die Preußische Gesetzgebung, Rechtswissenschaft und Rechtsverwaltung, Bd. 18 (35./36. Heft), 1821, S. 99-210; in Kraft 
über das Planungsstadium nicht hinaus. Aber es blieb genügend partikulares Recht übrig, um eine mehrbändige, dickleibige Sammlung des späteren preußischen Justizministers KARL AlBERT VON KAMPTZ zu füllen. ${ }^{168}$ Lediglich gegenüber dem subsidiären römisch-kanonischen Recht entfaltete das preußische Recht also seine exklusive Funktion. Innerhalb der Monarchie dagegen blieb doch einiges an Kleinteiligkeit bestehen.

\section{Das Bürgerliche Gesetzbuch von 1900}

Blendet man zahlreiche andere Gesetzbücher des 19. Jahrhunderts aus und vergleicht das Allgemeine Landrecht in diesem Punkt mit dem Bürgerlichen Gesetzbuch von 1900, zeigen sich erhebliche Unterschiede. Die gesamten verschiedenen Landesrechte, unabhängig davon, ob es sich um neuere Kodifikationen, um ältere Landund Stadtrechte oder um gemeinrechtliche Gemengelagen handelte, verloren zum 1. Januar 1900 nämlich ihre Geltungskraft. Die Kodifikation des Bürgerlichen Rechts von 1896/1900 zielte damit viel kraftvoller auf Rechtseinheit ab als die älteren einzelstaatlichen Gesetzgebungen. Ausnahmen gab es weiterhin, aber sie waren deutlich anders beschaffen. Zunächst erkannte das BGB von 1900 anders als noch der erste Entwurf von 1887 Gewohnheitsrecht als Rechtsquelle ausdrücklich an. Artikel 2 des Einführungsgesetzes, der jede Rechtsnorm zum Gesetz erhob, sollte nach zeitgenössischer Auffassung genau dies besagen. ${ }^{169}$ Und weiterhin enthielt das Einführungsgesetz zum Bürgerlichen Gesetzbuch eine umfangreiche Liste, welche landesrechtlichen Regelungen auch künftig gültig bleiben sollten. Der Grundsatz aber war klar: „Die privatrechtlichen Vorschriften der Landesgesetze treten außer Kraft, soweit nicht in dem Bürgerlichen Gesetzbuch oder in diesem Gesetz ein anderes bestimmt ist. “170

Eine große Liste von fast 100 Artikeln stellte das fortgeltende Landesrecht zusammen, freilich nicht nach Rechtsquellen geordnet, sondern nach Regelungsgegenständen. Bestimmte Sachbereiche gehörten nach diesem Verständnis also gar nicht zum Bereich des gesamtdeutschen bürgerlichen Rechts. Vielmehr handelte es sich hierbei

traten nur Provinzialgesetzbücher für Ostpreußen und Westpreußen, kurz erwähnt auch bei HaNS SCHLOSSER, Neuere Europäische Rechtsgeschichte. Privatrecht und Strafrecht vom Mittelalter bis zur Moderne, 2012, Kap. 10, Rn. 64.

168 Karl Christoph Albert Heinrich von Kamptz, Die Provinzial- und statutarischen Rechte in der Preußischen Monarchie, 3 Teile, 1826-1828.

169 JOACHIM RÜCKERT, vor $\S 1$. Das BGB und seine Prinzipien: Aufgabe, Lösung, Erfolg, in: Mathias Schmoeckel/Joachim Rückert/Reinhard Zimmermann (Hrsg.), Historisch-kritischer Kommentar zum BGB, Bd. 1: Allgemeiner Teil §§ 1-240, 2003, S. 34-122 (Rn. 26-27).

170 Art. 55 EGBGB, dazu aus der zeitgenössischen Literatur MARTIN GEORG ViKTOR SCHERER, Einführungsgesetz zum Bürgerlichen Gesetzbuche für das Deutsche Reich, 1899, S. 86-87. 
um die sprichwörtliche „Verlustliste der Rechtseinheit“171. Dabei war die Anschaulichkeit der Vorgaben teilweise kurios. So blieben etwa landesrechtliche Vorschriften über die Aneignung freifliegender Tauben in Kraft (Art. 130 EGBGB), ebenso das Deich- und Sielrecht sowie das Bergrecht (Art. 66-67 EGBGB). Soweit es solche Normen freilich nicht gab, griffen die allgemeinen Regeln des BGB ein. In diesen Bereichen konnte es also weiterhin Rechtsvielfalt geben, nämlich die Überlappung spezieller landesrechtlicher Vorschriften und allgemeiner reichsrechtlicher Vorgaben. Im Vergleich zur frühneuzeitlichen Rechtsvielfalt, aber auch zum bayerischen und preußischen Landesrecht, war der Bereich der fortgeltenden Mehrschichtigkeit jedoch ganz erheblich eingeschränkt.

Vielleicht zeigt dieses Beispiel, dass sich vollständige Rechtseinheit auf der Grundlage lediglich einer einzigen Rechtsquelle überhaupt nicht erreichen lässt. Die Ausschließlichkeit einer Kodifikation war historisch immer nur eine Annäherung und bezog sich auf den jeweiligen Kernbereich des Regelungsgebiets. An den Rändern blieben Grauzonen bestehen, die zu keiner Zeit gänzlich verschwanden. ${ }^{172}$ Die völlige Abschaffung sämtlicher besonderer und kleinräumigerer Rechte war nie beabsichtigt und erfolgte zu keinem Zeitpunkt. Zudem ist auch das kirchliche Recht keineswegs verschwunden, selbst wenn man in der Moderne das Nebeneinander weltlichen und kirchlichen Rechts nur selten betont. Doch sind hier die Gerichtszuständigkeiten vergleichsweise deutlich voneinander geschieden.

\section{Ergebnis}

Der Gang durch die Rechtsgeschichte zeigt ganz unterschiedliche Problemstellungen und Lösungen im Umgang mit nebeneinander und übereinander stehenden Rechtsmassen. Der älteste mitteleuropäische Ansatz war vermutlich das Personalitätsprinzip, also die rechtliche Zuordnung der Menschen zu ihrem jeweiligen Stamm. Es ging nicht um geographische Grenzen oder um Siedlungsgebiete, sondern um die Zugehörigkeit zu einer Stammesgemeinschaft. Stammesfremde unterlagen ihrem je eigenen Recht, waren außerhalb des Siedlungsgebietes ihres Verbandes aber sehr häufig

171 Als Buchtitel: Wolfgang E. KrüGER, Die Verlustliste der deutschen Rechtseinheit. Ein Beitrag zur Geschichte der deutschen Einheitsbewegung, 1935. THILo RAMM, Zwischen Verfassungspositivismus und Kadijustiz - was nun?, in: Rolf Gröschner/Martin Morlok (Hrsg.), Rechtsphilosophie und Rechtsdogmatik in Zeiten des Umbruchs (Archiv für Rechts- und Sozialphilosophie. Beiheft 71), 1997, S. 21-41 (24) weist darauf hin, dass das Bonmot offenbar von Justus Wilhelm HedEMANN stammt und von seinem Schüler KRÜGER 1935 lediglich übernommen wurde; DERS., Kodifikation des Arbeitsrechts?, in: ders., Zum freiheitlichen sozialen Rechtsstaat. Ausgewählte Schriften (Ius Commune. Sonderheft 112), hrsg. von Rainer Schröder, 1999, S. 447-472 (463).

172 Paralleler Befund mit Beispielen aus dem Nebenstrafrecht im späten 19. Jahrhundert bei THoмAS VormBAUM, Einführung in die moderne Strafrechtsgeschichte, 2009, S. 143-146. 
rechtlich benachteiligt. Daneben gab es seit der Christianisierung immer und überall die Normen des entstehenden Kirchenrechts.

Seit dem hohen Mittelalter, vor allem in der entfalteten Blüte des Spätmittelalters, stellte sich das Recht überwiegend in Form von Rechtskreisen oder Rechtsfamilien dar. Dieses Nebeneinander kleinräumiger, teils auch in größeren Gebieten verbreiteter Rechte erscheint in der vorliegenden Studie als Rechtszersplitterung. Doch die daraus möglicherweise folgenden Probleme spielten für die Praxis der spätmittelalterlichen ungelehrten Gerichtsbarkeit kaum eine Rolle. Jedes Urteilerkollegium fand das Recht in Kenntnis der eigenen Rechtsgewohnheiten und entschied damit auf der Grundlage seines eigenen ius fori. Fremde Rechte konnten daneben keine Bedeutung haben, denn das Erfahrungswissen der Rechtshonoratioren bezog sich nur auf diejenigen Gewohnheiten, die sie in ihrem eigenen Lebensumfeld kennenlernen konnten und kennengelernt hatten. Falls innerhalb eines Oberhofzuges eine anfragende Stadt oder Partei das Sonderrecht ihres engeren Umkreises anführte, lehnten es die Schöffen regelmäßig ab, auf dieser Grundlage ein Urteil zu finden.

Das führt zu einem kuriosen Befund: Immer dann, wenn Gerichte bereit waren, sich mit fremden Rechten näher auseinanderzusetzen und sie zu berücksichtigen, ist dies ein wichtiges Indiz für die zunehmende Kenntnis der gelehrten Rechtsquellenund -anwendungsregeln. Das mittelalterliche gelehrte Recht entwickelte ausgefeilte Lehren, wie man in der Theorie die nebeneinander stehenden Rechte und die sich überlagernden Rechtsschichten ordnen sollte. Für die praktische Rechtsanwendung setzten sich Auslegungs-, Allegations- und Beweisregeln durch. Das materielle Recht blieb auf diese Weise weiterhin verschieden. Aber das Prozessrecht, also die Methode, wie man mit der Rechtsvielfalt umgehen sollte, folgte weitgehend einheitlichen Lehrsätzen und beruhte auf einer einheitlichen Grundlage. Durch die strikte Interpretation von Statutarrecht und Gewohnheiten gab es eine deutlich spürbare Sogwirkung, auch die Inhalte des Rechts aneinander anzugleichen. Das europäische Ius Commune war damit nie eine feststehende, einheitliche und großräumige Rechtsmasse. Aber es verfügte über einen Kern von Regeln und Inhalten, die nicht nur akademisch die europäische Rechtswissenschaft prägten, sondern auch praktische Bedeutung erlangten. Die komplizierten Einzelheiten der Statutentheorie mitsamt der fundataintentio-Lehre beseitigten keineswegs die horizontale Rechtszersplitterung noch die vertikale ${ }^{173}$ Rechtsvielfalt. Doch sie schufen weithin akzeptierte Vorgaben, die es der Praxis ermöglichten, mit den ganz verschiedenen Quellen zu arbeiten. In den Feinheiten gab es zahlreiche Abweichungen. Das einheimische Partikularrecht wurde als ius commune in loco oftmals anders behandelt als das auswärtige Recht. Die fundata intentio schloss aus der Sicht des Normanwenders also ganz verschiedene Rechtsquellen ein oder aus. Die Amtsermittlung des einschlägigen Rechts konnte die Beweislast für die Parteien mindern oder sogar aufheben. Mit den Aktenversendungen und der praktisch ausgerichteten Entscheidungsliteratur standen zwei wesentliche Faktoren

173 Diese Terminologie auch bei Schennach (Anm. 113), S. 752. 
bereit, die im Ergebnis die kleinteilige und vielschichtige Buntheit durch einheitliche große Linien überwölbten. Doch die auf diese Weise beförderte Rechtsharmonisierung stieß schnell an ihre Grenzen, nämlich immer dann, wenn Partikularrecht zweifelsfrei einschlägig und inhaltlich unstreitig war. Auch im 19. Jahrhundert konnten Obergerichte auf wissenschaftlich hohem Niveau die Quellenvielfalt durchbrechen und einheitliche Rechtsgrundsätze formulieren. Doch die Prozessordnungen bewahrten die materiellrechtliche Gemengelage. Insbesondere eine gesetzgeberische Beseitigung der überkommenen Rechtsvielfalt stand vor den großen Kodifikationen nie zur Debatte. Selbst diejenigen Germanisten, die eine fundata intentio für das einheimische Recht forderten, drehten den Spieß der Rechtsanwendungslehre zwar um, schafften die dahinter stehenden Regeln aber gerade nicht ab.

Erst das Kodifikationszeitalter beseitigte die im Ius Commune gewachsenen Überlappungen. Die Kodifikationen ersetzten nicht nur die kleinteilige Zersplitterung durch ein gesamtstaatliches Gesetzbuch. Vielmehr beendeten sie zugleich den Pluralismus mehrerer gleichzeitig einschlägiger Rechtsquellen aus ganz verschiedenen Entstehungs- und Geltungszusammenhängen. Doch bei genauem Blick waren klare Schwarz-Weiß-Lösungen in der Praxis nicht möglich. Fortgeltendes Landesrecht gab es weiterhin, wenn auch teilweise nur in Randbereichen. Ein einheitliches Recht aus ausnahmslos nur einer Quelle ist damit ein kodifikatorisches Ideal, das in der historischen Wirklichkeit aber kaum anzutreffen ist. 



\title{
Diskussion zum Vortrag von Peter Oestmann
}

\author{
Leitung: WolfGANG SELLERT
}

\section{SELLERT:}

Herr Oestmann, ganz herzlichen Dank für diesen fulminanten Vortrag, in dem es um die bunte Vielfalt der rechtshistorischen Quellen und das zwischen ihnen bestehende Rangverhältnis sowie um Versuche zur Harmonisierung ging. Eine wichtige Rolle spielten dabei das Personalitätsprinzip, das Territorialitätsprinzip, die Statutenlehre und die Entwicklung des gemeinen Rechts. Zur Bestimmung des Rangverhältnisses waren im Wechsel allgemeine und spezielle Prinzipien maßgebend, die Sie im Einzelnen durchleuchtet haben. Offen blieb für mich, welches die Gründe für den jeweiligen Wechsel waren. Damit eröffne ich die Diskussion und gebe Herrn Zimmermann das Wort.

\section{ZIMMERMANN:}

Ich darf mich zunächst einmal der Würdigung „fulminant“ anschließen; der Vortrag war zudem von besonderer Klarheit geprägt. Ich habe eine Frage und eine Bemerkung. Die Frage ist: Man spricht vom „römisch-kanonischen“ Recht, und Sie haben sich ja eingehend mit der Rechtsquellenlehre befasst. Aber ein Punkt blieb doch offen: Wie war eigentlich das Verhältnis zwischen römischem und kanonischem Recht? In der Quelle aus Lüneburg steht: „Erst einmal Kaiserrecht und dann - wenn im Kaiserrecht nichts steht - das kanonische Recht.“ War das charakteristisch für die zeitgenössische Rechtsquellenlehre? Man hätte es sich ja eigentlich auch genau umgekehrt vorstellen können. Das kanonische Recht war gegenüber dem römischen Recht das jüngere Recht. Das ist meine Frage und nun eine Anmerkung zu dem, was Sie zum Usus modernus gesagt haben: Für mich war auf den ersten Blick überraschend, dass Sie sagten, dies sei die Zeit, in der Rechtseinheit erzielt und die Rechtsvielfalt überwunden worden sei; und ich kann das auch gut nachvollziehen, weil Sie die Verschmelzung des partikularen Gewohnheitsrechts und des gemeinen Rechts betrachten. Damit hört die Rechtsvielfalt an diesem bestimmten Ort auf. Aus anderer Sicht betrachtet kann man aber auch genau das Gegenteil sagen. Denn wenn man es unter dem Blickwinkel des gemeinen Rechts betrachtet, dann hat der Usus modernus geradezu das Ende einer Rechtseinheit herbeigeführt, weil der Gerichtsgebrauch in Holland anders war als derjenige in Spanien, in Sachsen oder in Bayern. Dadurch wurde eine Rechtsvielfalt auf europäischer Ebene insofern erzeugt, als es nunmehr nicht mehr ein gemeines Recht gab, sondern ein römisch-holländisches Recht, ein römisch-sächsisches Recht, ein römisch-hispanisches Recht und so weiter.

\section{OESTMANN:}

Zum ersten Punkt: Das Verhältnis von römischem und kanonischem Recht, das ist tatsächlich vergleichsweise unklar, denn die meisten Rechtsanwendungsklauseln, die 
ich kenne, sprechen von gemeinen Rechten im Plural. Und die gemeinen Rechte, sagt man ja üblicherweise, sind das römische und kanonische Recht. Das muss aber nicht einmal alles sein, denn wenn man das ius commune in loco dazu zählt, dann können zu den gemeinen Rechten auch Gesetze, Stadtbücher und so weiter dazukommen. Also: Das ist ziemlich unklar. Dass das römische und kanonische Recht ausdrücklich voneinander geschieden werden, ist vergleichsweise selten. Da ist dieses Beispiel aus Lüneburg eines der ganz, ganz wenigen, die ich kenne. Die rechtshistorische Literatur sagt, dass das kanonische Recht das jüngere Recht ist und deswegen bei einer Abweichung des kanonischen Rechts vom römischen Recht das kanonische Recht vorgeht. In den prozessualen Fragen ist das sowieso ganz häufig der Fall, weil das kanonische Recht viel mehr Prozessrecht enthält. Da müsste ich mich jetzt tatsächlich viel besser auskennen, wissen, wo es zum Beispiel materielle Überschneidungen zwischen dem kanonischen und dem römischen Recht gibt. Jedenfalls war es so, dass man in den protestantischen Territorien nach der Reformation das kanonische Recht immer noch als subsidiäre Rechtsquelle in Fragen des Ehe- und Familienrechts vor den Konsistorien anerkannt hat. Man hat zwar versucht, es abzuschaffen, es hat aber nicht funktioniert. Das setzte sich ab den 1530er Jahren schon wieder durch. UDo WoLTER hat ja auch dazu geschrieben, dass man innerhalb der Rechtsanwendungslehre auf das kanonische Recht so zugreifen sollte. ${ }^{1}$ Insofern ist das ein berechtigter Punkt, den Sie angesprochen haben. Aber es ist mir nicht vollkommen klar; ob das überhaupt irgendjemandem klar ist, weiß ich auch nicht so genau.

Der zweite Bereich mit dem Usus modernus ist auch schwierig. Ich würde sagen: Beide Ansatzpunkte, Ihrer und meiner, sind irgendwie richtig, bezogen auf einen anderen Bezugsrahmen. Sie argumentieren aus der Perspektive einer europäischen Rechtskultur, die eine Art Diskussionseinheit ist auf der Grundlage dieser corpora, und die Einheitlichkeit wird natürlich dadurch geschwächt, dass auch die wissenschaftliche Literatur anfängt, sich um etwas anderes zu kümmern, das ist vollkommen klar. Was ich stärker dachte - deswegen habe ich versucht, zwischen Rechtszersplitterung und Rechtsvielfalt zu unterscheiden -: In den einzelnen Rechtssprengeln oder Rechtskreisen empfand man diesen Gegensatz nicht mehr so stark, weil man, glaube ich, versucht hat, ihn aufzulösen. Eines der wichtigsten Werke in dem Zusammenhang ist der Kommentar von DAvid Mevius zum Lübecker Stadtrecht von 1642. ${ }^{2}$ Das kann man bei der Gelegenheit einmal sagen, das ist ein Jahr erschienen vor dem Buch von Hermann Conring, ${ }^{3}$ es ist also keine ConRING-Rezeption. Und Mevius hat im Einleitungsteil seines Kommentars gesagt: „Man muss die Partikularrechte aus ihrem eigenen Geist heraus auslegen.“ Und: „Wir brauchen das römische Recht für alles Mögliche, aber jedenfalls dürfen wir keine strikte Interpretation mehr betreiben.“ Hinterher wurde ihm dann vorgeworfen, er habe doch strikt interpretiert, weil

1 Udo Wolter, Ius canonicum in iure civili, 1975.

2 David Mevius, Commentarii in ius Lubecense, erstmals 1642/43.

3 HeRmann ConRIng, De origine iuris germanici, erstmals 1643. 
hundert Jahre später die Leute noch eigenständiger gewesen sind, aber auf die Weise näherten sich die beiden Schichten aneinander an.

Deswegen würde ich sagen: Von Ihrer Warte aus stimmt es; die Rechtsordnungen haben sich flächenmäßig stärker voneinander unterschieden, aber innerhalb der Territorien war die Rechtsanwendung wesentlich einfacher, wenn man sich über die Observanz und den Usus im Klaren war. Man sagt übrigens, das sei das Besondere an den Rechtsordnungen gewesen, die wissenschaftlicher Bearbeitung unterlagen Sachsen und Lübeck werden hier angeführt. Deren Eigenständigkeit beruhte gerade darauf, dass sie diese Literatur geschaffen haben, und diese Rechte haben sich bis ins 19. Jahrhundert gehalten, viele andere hingegen nicht.

\section{SELLERT:}

Vielen Dank. Frau Wendehorst.

\section{WENDEHORST:}

Herzlichen Dank. Ich möchte bei Ihren Schlussbemerkungen anfangen, und zwar habe ich dort mitgeschrieben: „Vielfalt endete mit dem Kodifikationszeitalter.“ Sie haben das dann ein bisschen eingeschränkt, allerdings nur im Hinblick auf die fortgeltenden Artikel des Landesrechts, die es auch trotz des BGB noch gab.

Ich möchte die provokative Frage stellen, ob die recht verbreitete Auffassung, dass das Kodifikationszeitalter der Vielfalt ein Ende gesetzt hat, eine spezifisch deutsche Wahrnehmung ist. Ich selbst arbeite nun seit fünf Jahren in Österreich und habe es täglich mit einer für deutsche Kollegen schwer nachvollziehbaren Gemengelage der unterschiedlichsten Rechtsquellen zu tun. Und ich spreche jetzt nicht vom EU-Recht, sondern ich spreche vom ABGB und von pandektistischer bzw. deutscher Dogmatik, die teilweise in Reinform, teilweise verfälscht durch führende Textbücher und durch die Generationen immer wieder weiterentwickelt die Kodifikation überlagert. Ich spreche über ein Richterrecht, das teilweise der Kodifikation offen widerspricht. Man muss über Jahre hinweg ein Gefühl entwickeln, wie sich diese verschiedenen Rechtsquellen zueinander verhalten. Und ich glaube zumindest $\mathrm{zu}$ ahnen, dass Österreich nicht das einzige Land in Europa ist, in dem es sich so verhält. Das Problem ist nur: Es fehlt daran, dass dies einmal offen ausgesprochen und analysiert wird, denn die Regeln, nach denen diese verschiedenen Rechtsschichten gegeneinander abgewogen werden, die stehen nirgends. Offiziell gilt auch für Österreich die BYDLINSKI'sche oder die LARENZ/CANARIs'sche Methodenlehre, und danach ist all dies, wovon ich gerade gesprochen habe, nicht existent. De facto, so wage ich aber zu behaupten, haben wir stellenweise eine fast frühneuzeitliche Situation.

\section{OESTMANN:}

Ich kann mich natürlich nicht kompetent zu solchen gegenwärtigen Fragen äußern. Der Ansatzpunkt war: Ist das etwas typisch Deutsches? Und da bin ich mir nicht so ganz sicher. Denn wenn Sie sich einmal Frankreich anschauen, da hat man traditionell immer gesagt: Das französische Recht ist im Wesentlichen zweigeteilt, in ein 
coutumier-Recht, das stark gewohnheitlich geprägt war mit großen Ähnlichkeiten zu deutschen Rechtsgewohnheiten, und in das in Südfrankreich geltende droit écrit, was ziemlich stark an römisches Recht angenähert war. Und eine Absicht der französischen Kodifikationsbewegung bestand gerade darin, diese Zweiteilung des französischen Rechts zu überwinden. Sie sagen jetzt: „Daneben gibt es die Lehren der Rechtslehrer und so weiter." Da würde ich aus meiner Perspektive sagen: Wahrscheinlich müsste man versuchen, zwischen der Intention des Kodifikators und der späteren Praxis zu unterscheiden. In Preußen kann man das ganz gut sehen; da war tatsächlich beabsichtigt, das römische Recht abzuschaffen. Das war eine ganz deutliche rechtspolitische Stoßrichtung des ALR und es war übrigens auch beabsichtigt, die Rechtsprechung als Quelle abzuschaffen, denn es ist eine Gesetzeskommission gegründet worden und man hat gesagt: „Wenn der Richter nicht weiß, was im Gesetz steht, muss er die Regierung fragen, und die Regierung muss das entscheiden. “ Der Richter durfte das Gesetz nicht auslegen. Das gab es in Frankreich auch einmal, unter LuDWIG XIV., den référé legislatif. In der Praxis hat das nicht funktioniert; diese Gesetzeskommission ist nach zwanzig oder dreißig Jahren abgeschafft worden. Offensichtlich kann man die Justiz nicht einfach nur zum bouche de la loi erklären. Deswegen würde ich sagen, dass es in der Praxis neben der Kodifikation immer auch andere Möglichkeiten der Rechtsfortbildung gibt. Aber das kodifikatorische Ideal hat sich im Laufe der Zeit doch dahin verschoben, dass der Exklusivitätsanspruch von Kodifikationen gestiegen ist.

SELLERT:

Vielen Dank. Frau Kieninger.

\section{KIENINGER:}

Ganz besonders interessant fand ich an Ihrem Vortrag die verschiedenen Stufen der Statutentheorie und besonders die dritte Stufe. Sie haben ja ausgeführt, dass es eine Beibringungsobliegenheit für das Partikularrecht gegeben hat und dass das gelehrte Recht galt, wenn die Parteien dem nicht genügen konnten. Genau derselbe Grundsatz existiert heutzutage immer noch im Verhältnis des englischen Rechts zu anderen nationalen Rechten. Im englischen Prozess ist es immer noch so, dass, wenn die Parteien sich nicht aktiv auf eine fremde Rechtsordnung berufen und diese durch Gutachten belegen - da tauchen dann manchmal auch deutsche Juraprofessoren in mündlichen Verhandlungen vor dem High Court, dem Court of Appeal oder dem Supreme Court auf -, dann englisches Recht, also das Common Law, angewendet wird. Mich würde besonders interessieren: Gibt es eigentlich Forschungen dazu? Dieser Grundsatz des Common Law ist sehr alt - wahrscheinlich ebenso alt wie das, was Sie uns aus dem 13./14. Jahrhundert geschildert haben - und er gilt unangefochten bis heute und macht uns größte Schwierigkeiten bei der europäischen Kollisionsrechtsvereinheitlichung. Denn es ergibt keinen großen Sinn, in x Verordnungen die Kollisionsnormen gleichförmig auszugestalten, wenn es auf der einen Seite Länder gibt, in denen sie strikt beachtet werden müssen und das fremde Recht dann auch anzuwenden ist, und es andere Länder gibt, in denen sie nur fakultativ gelten. Dann kann man im 
Grunde fragen: „Was soll das?“ Dann können wir eigentlich alles lassen. Gleichzeitig ist aber dieser Grundsatz im englischen Recht so stark verwurzelt und so sehr Teil des Selbstverständnisses der englischen Juristen, dass es dort nicht vorstellbar ist, dass man ihn über Bord werfen könnte. Aber offensichtlich ist es bei uns gelungen, ihn über Bord zu werfen. Mich würde interessieren: Gibt es Forschungen dazu, die diese beiden Entwicklungen miteinander vergleichen und ihren wechselseitigen Einfluss unter die Lupe nehmen oder untersuchen, warum es in der geschichtlichen Entwicklung in Deutschland gelungen ist, diesen Grundsatz zu überwinden? Ich glaube, das würde uns helfen, in diesem ganz realen Konflikt, der sich gegenwärtig in der europäischen Kollisionsrechtsvereinheitlichung stellt, weiterzukommen.

\section{OESTMANN:}

Ich kann nur eine einzige dieser Fragen kompetent beantworten, nämlich die, warum es bei uns gelungen ist, das zu überwinden. Zu England selbst: Das ist ein Problem, weil die Engländer aus der nationalen Perspektive immer behaupten, sie hätten das römische Recht nicht rezipiert. Ob das stimmt oder nicht, ist unklar; es gibt aber aktuelle Forschungen, etwa von RANIERI ziemlich intensive Forschungen zur Rezeption des römischen Rechts bei BlackstonE. ${ }^{4}$ Das ist natürlich dann ein bisschen später. Aber mein Kollege LoHSSE hat diese Frage anhand des englischen Grundstücksrechts im hohen Mittelalter untersucht ${ }^{5}$ und da sieht man durchaus auch Einflüsse des römischen Rechts. Also ich kann das nicht hundertprozentig sagen, aber die Parallelerscheinung spricht dafür, dass da in irgendeiner Weise auch ein Transfer ist.

Was ich dazu noch sagen möchte: Reste davon gibt es heute bei uns übrigens auch noch in § 293 ZPO. Da steht irgendetwas über Statuten und Gewohnheiten. Keiner weiß, was Statuten sind, aber das Wort taucht da noch auf. Warum man das nicht abgeschafft hat, hat mehrere Gründe, aber auch einen ganz formalen Grund. Denn die Beibringungs- und Beweisobliegenheit für Recht setzt voraus, dass es sich um Tatsachen handelt. Für den Rest ist das Gericht zuständig. Und da hat man immer gesagt: Ob es eine Rechtsquelle gibt oder nicht, ist eine Tatsachenfrage. Das kann man mit ja oder nein beantworten. Dazu hat sehr stark das Buch von Puchta zum Gewohnheitsrecht (Band 1 von 1828) beigetragen, wo es heißt: „Jeder Richter muss jede Quelle, die er kennt, von Amts wegen anwenden.“ Und das ist im Prinzip auch auf ungeschriebene Rechtsquellen zu beziehen. In der älteren Zeit hatte man immer gesagt: „statuta sunt facti“ - also Statuten sind des Faktischen. Ob es das gibt, ist eine Beweisfrage. Und in dem Maße, wie man das Beweisproblem überwindet, ist

\footnotetext{
4 FILIPPO RANIERI, Eine frühe deutsche Übersetzung der „Commentaries on the Laws of England“ von William Blackstone. Zugleich ein Beitrag zur Instrumentalisierung des Common Law in der deutschen Germanistik des 19. Jahrhunderts, in: Tiziana J. Chiusi/Thomas Gergen/Heike Jung (Hrsg.), Das Recht und seine historischen Grundlagen. Festschrift für Elmar Wadle zum 70. Geburtstag, 2008, S. 875-899. 5 Sebastian Lohsse, Die Rezeption des Grundsatzes superficies solo cedit auf dem europäischen Kontinent und in England, in: Yu-Cheol Shin (Hrsg.), Rezeption europäischer Rechte in Ostasien, 2013, S. 19-40.
} 
man die Parteien natürlich los, weil das dann die Amtspflicht des Richters ist. Das hat ganz verschiedene Schichten. Erst einmal müssen die Territorien dem Gericht ihr Gesetz einschicken. Das war nicht nur am Reichskammergericht so. Auch bei vielen Juristenfakultäten mussten die Territorien ihr Landesrecht einschicken - und wenn die Juristen das kannten, mussten sie es anwenden. Es gibt auch Rechtsanwendungsklauseln, die ich hier nicht genannt habe, da heißt es dann: „Die Richter sind verpflichtet, diese Quellen auch zu berücksichtigen.“ Die englische Situation kenne ich nicht gut genug, aber dieser Übergang, dass man Rechtsquellen nicht mehr als Fakten ansieht, sondern auch als Normen, das ist ein ganz wichtiger Punkt in dem Zusammenhang. Und dann ist es auch klar, dass das die Aufgabe des Richters ist. Die Grenzbereiche haben wir natürlich auch - mit dem ausländischen Recht, darüber kann man heute auch noch Gutachten anfordern. Die wichtigsten Entscheidungen heute stammen vom Bundesfinanzhof und da geht es immer darum, ob irgendwelche ausländischen Kindergeldansprüche berücksichtigt werden können. Wie soll das ein Amtsrichter wissen?

KIENINGER:

Wenn ich ganz kurz dazu ergänzen darf: Natürlich muss der inländische Richter kein ausländisches Recht können, darüber kann er ein Gutachten anfordern. Aber er muss das Kollisionsrecht von Amts wegen anwenden.

OESTMANN:

Ja, klar.

KIENINGER:

Und das muss der englische Richter nicht.

SELLERT:

Herr Ruffert und dann Herr Heun.

RUFFERT:

Ich möchte aus öffentlich-rechtlicher Sicht Ihre Ausführungen, auch vielleicht Ihr letztes Element „Auftragsforschung“, in Bezug zu dem Begriff der Integration setzen, den die Veranstalter in das Oberthema der Tagung genommen haben. Wenn die Lübecker oder Magdeburger Schöffen ein Partikularrecht nicht anwenden wollten, sondern nur das eigene Recht, dann hatte das ja wahrscheinlich überwiegend auch praktische Gründe: Sie wollten sich einfach nicht mit diesen Partikularismen, die von weit herkommen, befassen. Wenn aber auf Reichsebene Polizeiordnungen oder auch Gesetze wie die Carolina eine solche Anordnung trafen, sollte das dann integrierenden Charakter haben? Also, wenn die Lübecker oder Magdeburger Schöffen nach ihrem eigenen Recht urteilten, dann haben sie damit ja nicht beabsichtigt, andere Kleinterritorien gewissermaßen aufzusaugen oder in ihren Rechtsraum einzubinden - der Recht setzende Kaiser oder König, der das territorienweit macht, vielleicht aber schon. Dort haben wir also auch irgendwie einen Wandel von Recht als Konfliktlö- 
sungsmechanismus hin zum Recht als Steuerungsinstrument - mit der Funktion, Territorien, die nicht zusammengehören, irgendwie zu integrieren.

\section{OESTMANN:}

Das ist eine gute Frage. Ich würde beim ersten Teil übrigens sogar ein bisschen widersprechen. Sie haben gesagt: „Den Magdeburger Schöffen ging es nicht darum, irgendwelche Städte aufzusaugen und in ihren Rechtsraum einzubinden.“ Denen ging es wirklich nicht darum, Städte aufzusaugen, aber sie in ihren Rechtsraum einzubinden, darum ging es denen schon. Es gibt ganz klare Aussagen zum Beispiel der Ingelheimer Schöffen. Da fragt irgendjemand an: „Wie sollen wir den Fall lösen?“ Und die sagen: „Wir beantworten das nur, wenn ihr euch verpflichtet, in Zukunft immer bei uns anzufragen.“ Man kann zwar im Einzelfall nicht immer feststellen, ob die das dann auch gemacht haben, aber es gibt Gerichte, die über 200 Jahre ganz treu bei einem Schöffenstuhl anfragen. Es gab offensichtlich schon ziemlich feste Beziehungen. Es gibt jetzt eine aktuelle Untersuchung von ALEXANDER KREY, ${ }^{6}$ die zeigt, dass es im Rhein-Main-Gebiet Orte gab, die an vier Oberhöfen angefragt und zu allen gesagt haben: „Selbstverständlich fragen wir immer euch“, und sich dann das aussuchten, was ihnen am besten passte. Aber aus der Perspektive des Oberhofes ging es um Rechtsvereinheitlichung. Das kann man ganz deutlich sagen und die Städte selbst wussten auch, zu welchem Rechtskreis sie gehörten.

Bei der Frage, ob es aus der Perspektive des Normsetzers darum ging, die Herrschaft durch den Geltungsbereich von Recht abzusichern, wäre ich zurückhaltend. Denn nach meinem Eindruck ist es so: Das Herrschaftsrecht, das in irgendeiner Weise Landesherrschaft gekennzeichnet hat, war bis weit ins 17. Jahrhundert hinein jurisdictio. Die jurisdictio ist das oberste Recht des Herrschers gewesen. Das heißt, das Gebiet, über das er geherrscht hat, hat man daran erkannt, aus welchen Gegenden Anfragen an sein Gericht gelangt sind, und nicht daran, in welchen Gegenden er selbst Recht gesetzt hat. Im Bereich der Carolina war der Anspruch allerdings schon, dass das Recht im Heiligen Römischen Reich nach Möglichkeit umgesetzt werden sollte; bei den Reichspolizeiordnungen war das auch so, aber es gab Umsetzungsdefizite und die waren den Zeitgenossen auch ganz klar bekannt. Ich glaube, den Befehl zu erteilen, irgendeine Norm müsse strikt befolgt werden, hätte sich wahrscheinlich der Normsetzer nicht getraut, weil das Risiko, Misserfolg zu erleiden, viel zu groß gewesen wäre. MASSIMo MECCARELLI hat nachgezeichnet, dass die Gesetzgebung erst ab Mitte des 17. Jahrhunderts planmäßig versucht hat, die Landesgrenzen zu erzeugen. ${ }^{7}$ Vorher spielt die Gerichtsbarkeit eine viel stärkere Rolle; die integrative Wirkung haben die höchsten Gerichte.

6 AleXANder Krey, Die Praxis der spätmittelalterlichen Laiengerichtsbarkeit. Gerichts- und Rechtslandschaften des Rhein-Main-Gebietes im 15. Jahrhundert im Vergleich, 2015.

7 Massimo Meccarelli, Das Problem der Rechtsmodernisierung durch die Theologen der Spätscholastik, in: Nils Jansen/Peter Oestmann (Hrsg.), Rechtsgeschichte heute. Religion und Politik in der Geschichte des Rechts - Schlaglichter einer Ringvorlesung, 2014, S. 119-130. 


\section{SELLERT:}

Wir haben noch eine ganze Reihe von Meldungen und die Zeit läuft uns davon. Ich bitte daher die Diskutanten, sich kurz zu fassen. Auf meiner Liste stehen jetzt noch Herr Heun, Herr Eichenhofer, Herr Behrends und Frau Schumann. Zunächst bitte Herr Heun.

HEUN:

Wie sieht eigentlich das Verhältnis von Theorie und Praxis bzw. institutioneller Entscheidung aus? Also die Theorie, insbesondere die Statutentheorie, und auch die folgenden abstrakten Überlegungen geben ja so viel Flexibilität, dass der Richter eigentlich machen kann, was er will. Wenn er will, kann er sich für das eine oder für das andere entscheiden. Das heißt, die Frage der Vereinheitlichung hängt doch auch an den Institutionen, die entscheiden. Und ist das dann nicht auch der entscheidende Unterschied zu den anderen europäischen Ländern, in denen eine viel stärkere Vereinheitlichung der Institutionen, also der Gerichtsbarkeit, gelingt, und sich deswegen auch viel stärker ein einheitliches Common Law ausbilden kann als in der Vielfalt des Heiligen Römischen Reiches? Also kommt es nicht sehr viel mehr darauf an, dass die Theorie eigentlich alles erlaubt und alles nur an den Institutionen hängt, und dann sich daraus auch die entscheidenden Unterschiede $\mathrm{zu}$ anderen europäischen Ländern ergeben?

OESTMANN:

Also zunächst einmal zur Theorie selbst: Die Statutentheorie war in vielen europäischen Ländern bekannt und war als solche in der Gelehrtenliteratur stark verbreitet. Die praktische Umsetzung ist sicherlich unterschiedlich gewesen, allerdings würde ich so etwas wie Justizaufsicht oder Instanzenzüge nicht unterbewerten. Selbstverständlich war das Heilige Römische Reich territorial zersplittert, aber die Wirkung, die von den Obergerichten ausging, würde ich nicht unterschätzen. Das müssen im Heiligen Römischen Reich nicht unbedingt die Reichsgerichte gewesen sein, aber Gerichte wie das Oberappellationsgericht Celle oder das Wismarer Tribunal von 1653 hatten ganz starke rechtsvereinheitlichende Kraft. Und wenn ein Richter aus dem, was andere Juristen für üblich gehalten haben, ausbrach, gab es immer Rechtsmittel. Im Strafrecht und im Polizeirecht nicht, da sah die Situation anders aus, aber im Zivilrecht konnte man gegen falsche Entscheidungen Rechtsmittel einlegen. Und der wesentliche Bereich, um den es gerade in dieser Lehre geht, ist ja das Zivilrecht. Im Einzelfall mag ein Gericht abgewichen sein, aber dass ein Gericht konsequent diese Lehre nicht anwandte, das ist, wenn dieses Gericht gleichzeitig in einen größeren Gerichtssprengel eingebunden war, ziemlich unwahrscheinlich. Also sicherlich gibt es Theorie- und Praxisunterschiede, aber dass die von Gericht zu Gericht mit dieser Lehre unterschiedlich umgesprungen wären, das würde ich sehr erstaunlich finden. Materiell war das Ergebnis natürlich immer anders, je nachdem was es für Statuten gab, aber die Art und Weise der Rechtsanwendung, die ist vergleichsweise ähnlich gewesen. 


\section{SELLERT:}

Man könnte noch ergänzen, dass hier auch die ständige Rechtsprechung der Gerichte, von der sie aus naheliegenden Gründen nur ungern abwichen, eine Rolle spielte. Das gilt nach meinem Eindruck auch für die beiden höchsten Reichsgerichte, das Reichskammergericht und den Reichshofrat.

\section{OESTMANN:}

Vielleicht sage ich noch ganz kurz zu Herrn Heun: Es gab eine sehr starke europaweite Ausstrahlung der Rota Romana, das war eines der professionalisiertesten Gerichte überhaupt, das Gericht der katholischen Kirche. Und das ist das Vorbild gewesen für das Prozessrecht des Reichskammergerichts; das haben die sich nicht ausgedacht, sondern das ist übernommen worden.

\section{SELLERT:}

Herr Eichenhofer.

\section{EICHENHOFER:}

Kann man nicht auch sagen - und das ist das Moderne Ihres Themas und auch der Lösung, die Sie angeboten haben -, dass der Konkretisierungsgrad von Recht unterschiedlich war, je nach der Rangstufe? Das heißt, das Stadtrecht war sehr konkret, sehr detailliert, auch technisch, und das gemeine Recht und auch das kaiserliche Recht waren prinzipiell, abstrakt, prinzipienorientiert und auch innovativ. Also, wenn man etwa die Reichspolizeiordnungen zur Einführung der Armenfürsorge aus dem 16. Jahrhundert nimmt, dann wurde damit einfach eine neue Struktur von Programmverwaltung geschaffen. Und ist das die Differenz, die wir heute auch haben? Auf der einen Seite ein sehr stark an allgemeinen Prinzipien orientiertes, universales Recht verbunden mit innovatorischen Ansprüchen und auf der anderen Seite ein sehr detailliertes, ins Detail gehendes, konkret werdendes Recht, das auf der lokalen Ebene $\mathrm{zu}$ finden ist.

\section{OESTMANN:}

Das würde ich eigentlich nicht sagen. Also in der Zeit des ungelehrten Rechts, da kann man den Gegensatz zwischen abstrakt und konkret machen. Das ungelehrte Recht konnte praktisch nicht abstrakt denken, denn im Einzelfall musste Konsens über das Ergebnis erzielt werden und das nennt man Rechtsfindung, das hat jedenfalls MARTIN Pilch gesagt ${ }^{8}$ und das glaube ich ihm übrigens auch. Aber in der Zeit einer gelehrten Rechtswissenschaft gab es verschiedene Stufen von Normen, die im Prinzip gleich konkret sein konnten. Ein schönes Beispiel dafür ist die erbrechtliche Diskriminierung von Frauen. In vielen Stadt- und Landrechten war das Intestaterbrecht von Frauen schlechter als das von Männern, während es im römischen Recht prinzipiell gleich war. Das kann man nicht nur an den jeweiligen Rechtsquellen, sondern auch

8 MARTIN Pilch, Der Rahmen der Rechtsgewohnheiten. Kritik des Normensystemdenkens entwickelt am Rechtsbegriff der mittelalterlichen Rechtsgeschichte, 2009. 
an den jeweiligen Ergebnissen von Erbrechtsprozessen sehen. Das ist keine Frage, was allgemeiner ist, das ist einfach die Frage von sich widersprechenden Quellen: Welchen räumlichen Ausdehnungsbereich haben diese? Das heißt, das allgemeine Recht ist das, was überall gilt, und nicht das, was allgemeine Rechtsgrundsätze hat. In einem Punkt haben Sie natürlich trotzdem Recht: Die ganz kleinen Rechte haben allein deswegen keine Rechtsgrundsätze, weil sie niemanden haben, der als Rechtsgelehrter diese Grundsätze erfindet. Das ist eben gerade der Vorteil von Lübeck oder der Vorteil von Sachsen. Da gab es jemanden wie DAvid Mevius oder wie CARPzov, die haben diese Grundsätze formuliert und dann hat das Recht auch eine größere Stabilität, aber eigentlich geht es um den Ausdehnungsgrad von Normen und nicht um den Konkretisierungsgrad von Normen.

SELLERT:

Herr Behrends.

BEHRENDS:

Meine Frage knüpft an Ihre Bemerkung an, dass Sie ein Gericht, das Lübische Oberappellationsgericht, auf der Suche nach Grundsätzen gesehen haben. Sie zielt daher darauf ab, ob nicht allgemeine Grundsätze und die Suche danach ein typisches Element des Richterrechts bilden, weil Grundsätze über dem positiven Recht stehen und so dem Gericht eine Handhabung der Vielfalt und der Abfolge der Rechtsquellen erlauben. Es war beeindruckend, zu hören, wie der Satz statuta sunt stricte interpretanda durch eine Interpretation nach den Grundsätzen des gemeinen Rechts beiseite geschoben wird, so dass man fast überlegen kann, ob es dadurch ein lokal wirksames ius commune gibt, das das Lokalrecht durch Auslegung in seine Grundsätze integriert. Solche Grundsätze erscheinen damit als etwas, was der Gerichtsbarkeit eine originär wirkende Selbständigkeit verleiht und sie in gewisser Weise über die Rechtsquellenvielfalt stellt. Angesichts dieses Phänomens ist ein Rechtsquellenpurismus, wie ihn die Kodifikationen und vorher die Historische Rechtsschule erstrebt haben, eine Illusion. Mir ist insofern immer ein Beispiel aus dem Usus modernus aufschlussreich gewesen, der entgegen dem römischen Recht den Grundsatz der Klagbarkeit des Tausches vertrat, und zwar mit der die Rechtsquellenvielfalt relativierenden Erklärung, dass es gleichgültig sei, ob diese Verallgemeinerung des Vertragsrechts aus den Stammesrechten, dem Sachsenspiegel oder dem kanonischen Recht abgeleitet werde. Es gibt für die Selbständigkeit richterrechtlicher Grundsätze noch ein anderes Beispiel. Im BGB gibt es nicht die exceptio doli generalis, den Einwand des Rechtsmissbrauchs. Dieses Kontrollmittel war aber ein fester Bestandteil der Judikatur des Reichsgerichts. Als das BGB kam, hat das Reichsgericht mit Selbstverständlichkeit an der Geltung des Grundsatzes festgehalten und sich am Ende gegenüber dem Gesetz damit beruhigt, er stände im § 242, obwohl sich in ihm kein Wort davon findet. All das zeigt, dass Grundsätze etwas sind, was sowohl intertemporale Differenzen ausgleichen als auch Rechtsquellenvielfalt zusammenführen kann. Der Usus modernus, der 
so dachte, war denn auch entgegen dem eher verächtlichen Urteil der Historischen Rechtsschule eine sehr achtbare und für die Gegenwart lehrreiche Epoche.

\section{OESTMANN:}

Also, die Anlehnung an Rechtsgrundsätze, das habe ich aber auch gesagt, das finde ich persönlich ganz wichtig und ich glaube, das kann man in der Praxis auch gut sehen. Ich würde jetzt hier ganz konventionell sagen: Die Rezeption hat praktisch zwei Elemente und in beiden dieser Elemente muss man sich auf die Suche nach den Rechtsgrundsätzen machen. Einmal sozusagen, was das materielle Recht betrifft, nämlich den Inhalt; und das andere sind die Methoden- und Auslegungsfragen - und das, was Sie am Anfang angesprochen haben, sind ja gerade die Methoden- und Auslegungsfragen. Das wäre vielleicht auch noch einmal eine Antwort auf die Frage von Herrn Zimmermann: Wenn das Recht anfängt, sich materiell zu unterscheiden, kann es trotzdem sein, dass methodisch und technisch die Juristen das gleiche machen. Denn die sortieren das nach ganz bestimmten Grundsätzen und wenden einfach nur andere Inhalte an und kommen zu anderen Ergebnissen. Bei dieser Quelle aus Lübeck kann man das sehr schön sehen. Da geht es um die Frage, ob man sich an ein Gesetz eines fremden Landes halten muss, wenn man Schmuggelei betreibt. Und darüber gibt es wahrscheinlich keine inländischen Normen. Dann zitieren sie französische Literatur, amerikanische Literatur, englische Literatur; obwohl der Fall aus Lübeck ist, zitieren sie eine Quelle aus Hamburg und kommen dann zu allgemeinen Rechtsgrundsätzen, die als solche formuliert sind. Das ist aus meiner Sicht das, was man unter „heutigem römischem Recht“ im 19. Jahrhundert verstanden hat.

$\mathrm{Zu}$ Ihrem zweiten Punkt, wo die Klagbarkeit von Verträgen allgemein - pacta nuda - herkommt: Das kommt aus dem kanonischen Recht von JoHANnEs TEUTONICUS und aus dem mittelalterlichen römischen Recht von BARTOLUS (aus dem Handelsrecht), ist dann übernommen worden im Stadtrecht von Freiburg von 1520, also Statutarrecht, und ist dann irgendwann als Rechtsgrundsatz ins allgemeine Privatrecht abgewandert.

\section{SELLERT:}

Frau Schumann.

\section{ScHumanN:}

Ich habe noch eine kleine Anmerkung zu Ihrer Frage, Herr Ruffert. Sie haben gefragt: „Welche Interessen hatte das Reich an einer Integration der Territorien durch Gesetzgebung?“. Jedenfalls hatte ich Ihre Frage so verstanden. Bei den Reichspolizeiordnungen oder besser den Polizeimaterien - denn die Polizeimaterien sind nicht nur in den Reichspolizeiordnungen geregelt, sondern auch in vielen Reichsabschieden - kann man sehr deutlich sehen, dass es Interessen gab, die tatsächlich die gesamte „Nation“ betrafen. Diese werden dann auch genauso eingeleitet, nämlich dass die Regelung im Interesse der „deutschen Nation“ ergehe. So soll man beispielsweise nicht in Frankreich Luxusartikel kaufen, sondern einfache, deutsche Tücher, um 
das Geld in Deutschland zu halten. Ein anderes Beispiel sind grenzüberschreitende Fragen zwischen den Territorien des Reiches, etwa zu Bettlern, die durchs Land ziehen. $\mathrm{Zu}$ nennen sind auch gemeinsame außenpolitische Interessen wie etwa die Türkengefahr. Bei diesen Materien kann man sehen, dass der Kaiser bemüht war, alle mitzunehmen, und auch ein Interesse der Reichsstände bestand, diese gemeinsamen Interessen mitzutragen.

Und dann habe ich noch eine Frage an Herrn Oestmann, die vielleicht den Bogen zu den Themen, die wir im Anschluss hören, schlägt: Sie haben sehr schön herausgearbeitet, dass ein Motor der Rechtsvereinheitlichung die Gerichte waren, also zunächst die Oberhöfe und dann auch das Reichskammergericht. Erst im Kodifikationszeitalter kommt ein neuer Motor der Rechtsvereinheitlichung, nämlich der Gesetzgeber hinzu. Nun kann man feststellen, dass vor den Kodifikationen im 17./18. Jahrhundert eine sehr starke Kritik am Recht bestand. Ist das auch eine Kritik an der Rechtsprechung oder richtet sich diese Kritik gegen etwas anderes? Heute haben wir ja auch eine starke Kritik an der Rechtsprechung im europäischen Raum und vielleicht ist es eine typisch deutsche Vorstellung, dass die Kodifikation Probleme besser lösen kann. Daher meine Frage: Die Kritik, die im 17./18. Jahrhundert aufkommt und dann zu den Kodifikationen führt, richtet sich diese auch gegen die Gerichte als Motor einer Rechtsvereinheitlichung im Reich?

OESTMANN:

Also, mit dieser Kritik am Recht, da wäre ich persönlich viel zurückhaltender. Da würde ich jetzt einmal fragen, was das für Kritik ist. Es gibt aus ganz unterschiedlichen Perspektiven Kritik am Recht. Es gibt in der Rezeptionszeit eine ziemlich radikale Kritik daran, dass Recht sich verwissenschaftlicht. FRIEDRICH III. soll angeblich einmal gesagt haben: „Das Recht ist den Juristen härter verschlossen als den Laien.“ Das gibt es im 16. Jahrhundert. Bei der Kritik im 18. Jahrhundert, da weiß ich nicht ganz genau, was Sie meinen. Also ich glaube, es ist sehr viel rechtspolitische Kritik von Seiten dieser germanistischen Rechtsantiquare.

\section{SCHUMANN:}

Ich meinte zum Beispiel die Kritik von Thomasıus um 1700.

OESTMANN:

Ja, Thomasius hatte ich gestrichen, weil ich $\mathrm{zu}$ viel hatte. THomasius sagt: „Wir müssen die fundata intentio des römischen Rechts abschaffen und sie ersetzen durch die fundata intentio des deutschen Rechts." Und das deutsche Recht ist die Quersumme von Sachsenspiegel, Schwabenspiegel, oberbayerischem Landrecht und kleinem Kaiserrecht. Und der hat einen Schüler gehabt, GEORG BEYER, der hat das auch gemacht, und die haben das alle geschrieben. Da würde ich sagen: Das ist prinzipiell das gleiche, nur mit anderen Quellen. Es geht nicht darum, dass man Recht 
kodifizieren soll. Soweit ich weiß, hat sich KLAUS LUIG damit beschäftigt ${ }^{9}$ und gesagt: „Es gibt frühe Vorläufer der Kodifikationsbewegung“, und das sind Leute wie LEIBNIZ - das sind nicht die großen Rechtspolitiker, das sind nicht die Lauten; das sind die Leisen, die gesagt haben: „Es geht um Qualität, es geht um Technik und so weiter.“ Also deswegen würde ich die rechtspolitische Kritik gar nicht so hochheben. Und ich glaube übrigens auch, dass es die fundata intentio des Sachsenspiegels nie gegeben hat.

\section{SELLERT:}

Meine Damen und Herren, damit sind wir am Ende unserer Diskussion. Einige Fragen sind sicherlich offen geblieben. So hätte ich zum Beispiel gerne noch darüber diskutiert, ob und gegebenenfalls welchen Einfluss der bekannte Satz „Altes Recht, gutes Recht“ auf das Rangverhältnis hatte. $\mathrm{Zu}$ überlegen wäre meines Erachtens auch gewesen, ob im Alten Reich für die Wertigkeit und den Rang eines Rechts das politische Gewicht und das Ansehen seines jeweiligen Herkunftsterritoriums von Bedeutung waren. Auch die Frage, welche Rolle die Rechtsprechung des Reichskammergerichts und der Kaiserliche Reichshofrat insbesondere in seiner Eigenschaft als oberste Justizaufsichtsbehörde für die Rechtsvereinheitlichung spielten, hätte noch vertieft werden können. Zunächst einmal danke ich aber allen Diskutanten für ihre weiterführenden Beiträge und Anregungen sowie nochmals ganz besonders Herrn Oestmann für seinen eindrucksvollen Vortrag.

9 KLAUS LUIG, Römisches Recht - Naturrecht - Nationales Recht, 1998 (dort über das Sachregister gut greifbar); DERS., Die Rolle des deutschen Rechts in Leibniz‘ Kodifikationsplänen, Ius Commune 5 (1975), S. 56-70. 
